CLAUDIA FABIANA JOCA DE ARRUDA

Avaliação da ação do EGFR na regulação da expressão das proteínas claudinas e do microRNA-18a no carcinoma mucoepidermoide das glândulas salivares 

CLAUDIA FABIANA JOCA DE ARRUDA

\section{Avaliação da ação do EGFR na regulação da expressão das proteínas claudinas e do microRNA-18a no carcinoma mucoepidermoide das glândulas salivares}

\section{Versão Original}

Tese apresentada à Faculdade de Odontologia da Universidade de São Paulo, pelo Programa de Pós-Graduação em Diagnóstico Bucal, Radiologia e Imaginologia,. para obter o título de Doutora em Ciências.

Orientadora: Profa. Dra. Silvia Vanessa Lourenço 
Autorizo a reprodução e divulgação total ou parcial deste trabalho, por qualquer meio convencional ou eletrônico, para fins de estudo e pesquisa, desde que citada a fonte.

Catalogação-na-Publicação

Serviço de Documentação Odontológica

Faculdade de Odontologia da Universidade de São Paulo

Arruda, Claudia Fabiana Joca de.

Avaliação da ação do EGFR na regulação da expressão das proteínas claudinas e do microRNA-18 ${ }^{a}$ no carcinoma mucoepidermoide das glândulas salivares / Claudia Fabiana Joca de Arruda; orientadora Silvia Vanessa Lourenço -- São Paulo, 2020.

114 p. : tab., fig. ; $30 \mathrm{~cm}$.

Tese (Doutorado) - Programa de Pós-Graduação em Diagnóstico Bucal, Radiologia Odontológica e Imaginologia. - Faculdade de Odontologia da Universidade de São Paulo.

Versão original

1. Carcinoma mucoepidermoide. 2. Junção compacta. 3. Proteínas claudinas. 4. Carcinogênese. I. Lourenço, Silvia Vanessa. II. Título. 
Arruda CFJ. Avaliação da ação do EGFR na regulação da expressão das proteínas claudinas e do microRNA-18a no carcinoma mucoepidermoide das glândulas salivares. Tese apresentada à Faculdade de Odontologia da Universidade de São Paulo para obtenção do título de Doutora em Ciências.

Aprovado em: 22 /07 /2020

\section{Banca Examinadora}

Profa. Dra. Camila de Barros Gallo

Instituição: FOUSP Julgamento: Aprovada

Profa. Dra. Milena Monteiro de Souza Antunes

Instituição: Externa Julgamento: Aprovada

Prof. Dr. Ivan Onone Gialain Instituição: UNIB Julgamento: Aprovada 

Dedico este trabalho a minha amada família como forma de agradecer por todo o suporte e dedicação durante todos esses anos!

Eu tenho certeza que sem a ajuda de vocês eu não chegaria nem até a metade do caminho!

Obrigada pai, obrigada mãe, obrigada irmãos, obrigada marido! Todo o meu amor para sempre! 



\section{AGRADECIMENTOS}

Ao meu Senhor e Deus porque sem a sua ajuda e proteção eu não seria capaz de realizar nada! Obrigada Pai por me dar a força e a coragem necessárias para concluir esse trabalho, obrigada Senhor por me ajudar a fazer a minha parte na sua obra!

À Faculdade de Odontologia da Universidade de São Paulo pela infraestrutura disponibilizada e por ser a minha secunda casa desde 2004, ano em que iniciei a minha graduação em odontologia.

À Profa. Dra. Silvia Vanessa Lourenço por ter aceitado me orientar, obrigada pela paciência em me ensinar algo novo a cada dia, sempre com muita dedicação e profissionalismo, obrigada pelo carinho e amizade desenvolvidos ao longo desse projeto, obrigada por me ajudar a desenvolver este trabalho!

À Profa. Dra. Cláudia Malheiros Coutinho-Camillo por ter aceitado ser minha coorientadora, obrigada por ser calmaria em meio a tempestade! Obrigada pela paciência em ensinar uma dentista a realizar técnicas de biologia molecular, obrigada pelos almoços e pelas conversas tranquilas e descontraídas, obrigada por toda a ajuda com o desenvolvimento deste trabalho!

À Profa. Dra. Marcia Martins Marques, pelos conhecimentos transmitidos e por me receber tão bem no seu laboratório!

A todos os professores das disciplinas de Estomatologia Clínica, Patologia Geral, Radiologia e Clínica Integrada da FOUSP, por todos os ensinamentos compartilhados.

À amiga Cibele P Nagano pela importante ajuda com a graduação histológica dos casos de carcinoma mucoepidermoide estudados na minha tese!

À amiga Sheyla Bologna Batista pela ajuda com o desenvolvimento do meu projeto de qualificação e consequentemente, do meu primeiro artigo referente a este projeto! 
As amigas Ana Clara Pedroni e Giovana Sarra, pelo treinamento e ajuda com a cultura de células!

À amiga Kátia Klug, técnica da patologia do AC Camargo, pela grande ajuda com o desenvolvimento da parte envolvendo biologia molecular da minha pesquisa, obrigada também pela amizade, pelas conversas e pelos almoços divertidos!

A todos os meus colegas de pós-graduação, especialmente Fernanda, Milena, Giovanna, Ana Maria, Tathyane e Jaqueline!

Às funcionárias do Departamento de Estomatologia Nynna, Cecilia, Marilia, Ivone e, especialmente à Cidinha! Obrigada Cidinha pela boa vontade em sempre ajudar e por ser um anjo na vida dos pós-graduandos.

Ao Capes pela concessão da bolsa de estudos de doutorado.

Ao Laboratório de Pesquisa Básica do Departamento de Dentística pela infraestrutura disponibilizada.

Ao AC Camargo Cancer Center pela infraestrutura disponibilizada.

A meu pai Pedro, minha mãe Terezinha, minha irmã Kátia e meu irmão Darwin pelo incentivo, suporte, amizade e amor.

Ao meu marido Alexandre pela paciência, amizade e amor. 
"Dê-me, Senhor, agudeza para entender, capacidade para reter, método e faculdade para aprender, sutileza para interpretar, graça e abundância para falar, acerto ao começar, direção ao progredir e perfeição ao concluir."

São Tomás de Aquino 



\section{RESUMO}

Arruda CFJ. Avaliação da ação do EGFR na regulação da expressão das proteínas claudinas e do microRNA-18a no carcinoma mucoepidermoide das glândulas salivares [tese]. São Paulo: Universidade de São Paulo, Faculdade de Odontologia; 2020. Versão Original.

O carcinoma mucoepidermoide é uma neoplasia maligna derivada do ducto excretor das glândulas salivares. Histologicamente é composta por células epiteliais com fenótipo mucoso, intermediário e epidermoide. As células epiteliais possuem especializações que as ajudam a manter a união entre elas, uma dessas especializações é a junção compacta. A junção compacta é o componente de adesão celular que está localizado mais apicalmente na membrana celular. Do complexo panorama das junções compactas, participam várias famílias de proteínas, sendo a mais importante e numerosa a família das claudinas. Alterações na adesividade celular são investigadas em diversas neoplasias malignas e sabe-se que mecanismos como fatores de crescimento epidérmico e regulação gênica mediada por microRNAs podem estar relacionados a regulação da expressão dessas proteínas. Para testar a hipótese de influência das claudinas no comportamento do carcinoma mucoepidemoide das glândulas salivares, essa pesquisa pretendeu responder se a junção compacta está relacionada ao processo de desenvolvimento do carcinoma mucoepidermoide e se fatores de crescimento podem interferir na expressão das proteínas da junção compacta e do microRNA18a nesta neoplasia. $O$ desenho do estudo incluiu 2 etapas: 1) Etapa clínico patológica que incluiu o levantamento de casos de carcinoma mucoepidermoide (totalizando 36 casos), estudo dos prontuários dos pacientes, análise histopatológica dos casos e análise imunoistoquímicas das claudinas $-1,-3,-4,-5$ e -7 nos espécimes incluídos no estudo; 2) etapa experimental: cultivo de células provenientes de carcinoma mucoepidermoide, com estimulação pelo fator de crescimento EGF e análise do microRNA-18a. Os resultados mostraram que todas as claudinas estudadas se encontram expressas, mas não foi possível relacionar a expressão delas com o grau histológico, apenas com a etnia branca $(p=0,024)$ e com idade superior a 40 anos $(p=0,050)$. Também não foram encontradas 
alterações de expressão genica delas relacionadas ao EGF. O microRNA-18a se encontra expresso nas células do tumor e apresenta aumento significante em sua expressão nas culturas celulares que receberam tratamento com EGF nas concentrações de $25 \mathrm{ng} / \mathrm{ml}$ ( $p=0.015$ ) e $100 \mathrm{ng} / \mathrm{ml}$ ( $p=0.024)$. Conclui-se que por apresentar grande expressão em todos os graus histológicos do tumor e estar expressa principalmente em células epidermoides e intermediárias que são as que mais apresentam alterações, as claudinas devem ter um papel importante no processo de carcinogênese desse tumor e, aparentemente, a sua expressão não é influenciada pelo EGF, enquanto que para a expressão do microRNA-18a ocorre influência do EGF, entretanto, ainda não sabemos qual a importância da expressão desse microRNA para 0 processo de carcinogênese no carcinoma mucoepidermoide. Mais estudos são necessários para determinar com clareza os papéis específicos das claudinas e do microRNA-18a no carcinoma mucoepidermoide.

Palavras-chave: Carcinoma mucoepidermoide, junção compacta, proteínas claudinas, carcinogênese 


\begin{abstract}
Arruda CFJ. Evaluation of EGFR action in the expression of claudins proteins and microRNA-18a in salivary gland mucoepidermoid carcinoma [thesis]. São Paulo: Universidade de São Paulo, Faculdade de Odontologia; 2020. Versão Original.
\end{abstract}

Mucoepidermoid carcinoma is a malignant neoplasm derived from excretory duct of the salivary glands, histologically it is composed of epithelial cells with mucous, intermediate and epidermoid phenotype. The epithelial cells have specializations that help them maintain the union between them, one of these specializations is the tight junction. The tight junction is the cell adhesion component that is most apically located on the cell membrane. In the complex panorama of the tight junctions, several families of proteins participate, being the most important and numerous the family of claudins. Changes in cell adhesiveness are investigated in several malignant neoplasms and it is known that mechanisms such as epidermal growth factors and microRNA-mediated gene regulation may be related to the regulation of the expression of these proteins. To test the hypothesis of the influence of claudins on the behavior of mucoepidermoid carcinoma of the salivary glands, this research aimed to answer if the tight junction is related to the process of development of the mucoepidermoid carcinoma and if growth factors may interfere with the expression of the tight junction proteins and the microRNA-18a in this neoplasm. The study design included 2 stages: 1) Pathological clinical stage that included the survey of cases of mucoepidermoid carcinoma (totaling 36 cases), study of the patients medical records, histopathological analysis of the cases and immunohistochemical analysis of claudins $-1,-3,-4,-5$ and -7 in the specimens included in the study; 2) Experimental stage: Cultivation of cells from mucoepidermoid carcinoma, stimulated by EGF growth factor and microRNA-18a analysis. The results showed that all studied claudins are expressed, but it was not possible to relate their expression to histological grade, only to white ethnicity $(p=0.024)$ and over 40 years of age $(p=$ 0.050). Neither EGF-related gene expression changes were found. MicroRNA-18a is expressed in tumor cells and shows significant increase in its expression in cell cultures that received EGF treatment at concentrations of $25 \mathrm{ng} / \mathrm{ml}(p=0.015)$ and $100 \mathrm{ng} / \mathrm{ml}(\mathrm{p}=0.024)$. It is concluded that due to its high expression in all histological 
grades of the tumor and mainly expressed in epidermoid and intermediate cells that are the ones that present the most alterations, the claudins should have an important role in the carcinogenesis process of this tumor and, apparently, Its expression is not influenced by EGF, whereas for the expression of microRNA-18a there is influence of EGF, however, we still do not know how important is the expression of this microRNA for the carcinogenesis process in mucoepidermoid carcinoma. Further studies are needed to clearly determine the specific roles of claudins and microRNA-18a in mucoepidermoid carcinoma.

Keywords: Mucoepidermoid carcinoma, Tight junction, Claudine proteins, Carcinogenesis 


\section{LISTA DE ILUSTRAÇÕES}

Figura 2.1 - Glândula salivar evidenciando o ducto excretor, local de origem do CM.29

Figura 2.2 - Tipos celulares mais frequentemente encontrados no CME: A - grande quantidade de células mucosas apresentando citoplasma claro e abundante (Magnificação original 400x); B - grande quantidade de células intermediárias com núcleos evidentes e citoplasma escasso (Magnificação original 400x); C - grande quantidade de células epidermoides com formato poliédrico e citoplasma abundante (Magnificação original 200x) 32

Figura 2.3 - Padrões histológicos de apresentação das células do CME: A - CME apresentando padrão cístico com abertura de inúmeros espaços císticos (Magnificação original 40x); B - CME apresentando padrão sólido com a formação de ilhas de células epidermoides $e$ intermediárias (Magnificação original 40x)

Figura 2.4 - Representação do complexo juncional destacando seus componentes, entre eles, a junção compacta

Figura 2.5 - Representação esquemática da interação célula-célula promovida pelas fitas selantes que compõem a junção compacta

Figura 2.6 - Representação esquemática da estrutura geral das proteínas claudina.41

Figura 2.7 - Biogênese do miRNA

Gráfico 5.1 - Graduação histológica da amostra segundo o sistema da OMS (ElNaggar et al., 2017) 63 
Figura 5.1 - Marcação imunoistoquímica: A - CLDN1 em CME de grau intermediário: distribuição ampla em torno da membrana celular de células epidermoides e intermediárias (Magnificação original 200x); B CLDN1 em glândula salivar: ampla distribuição na membrana celular das células ductais (Magnificação original 400x); C - CLDN3 em CME de alto grau: marcação na membrana celular das células epidermoides e intermediárias das ilhas tumorais (Magnificação 400x); D - CLDN3 em glândula salivar: células ductais marcadas (Magnificação original 400x); E1 - CLDN4 em CME de alto grau: ampla distribuição em citoplasma e membrana celular das células epidermoides e intermediárias (Magnificação original 400x); E2 - CLDN4 em CME de baixo grau: ampla distribuição em citoplasma e membrana celular das células epidermoides e intermediárias (magnificação original 400x); F _ CLDN4 em glândulas salivares: células ductais apresentando marcação em membrana (Magnificação original 400x); G1 - CLDN5 no CME de alto grau: ampla distribuição no citoplasma e membrana celular das células epidermoides das ilhas tumorais (Magnificação original 400x); G2 - CLDN5 em CME de baixo grau: ampla distribuição nas células intermediárias (Magnificação original 400x); H - CLDN5 em glândula salivar: marcação no citoplasma e membrana celular das células ductais (Magnificação original 400x); I1 - CLDN7 em CME: marcação positiva em membrana celular das células tumorais, incluindo células mucosas (Magnificação 400x); I2 - CLDN7 em CME: marcação em membrana celular das células intermediárias (Magnificação original 400x); J - CLDN7 na glândula salivar: áreas focais de marcação fraca nas células ductais (Magnificação original 400x).

Figura 5.2 - Marcação imunoistoquímica para o anticorpo anti-EGFR em CME: A marcação positiva da membrana das células epidermoides (Magnificação original 100x); B - marcação positiva das células intermediárias e negativa das células mucosas (Magnificação 400x) 68

Figura 5.3 - Expressão dos mRNAs das CLDNs estudadas na linhagem celular HMUMC-3A de CME, a expressão foi medida nas células tratadas e nas células não tratadas pelo EGF $(100 \mathrm{ng} / \mathrm{ml})$. A expressão relativa foi medida por qPCR considerando um pool de mucosa oral não neoplásica como calibrador e os resultados foram normalizados pela expressão do gene $A C T B$. Legenda: cld 1 - claudina 1; cld 3 - claudina 3 ; cld 4 - claudina 4 ; cld 5 - claudina 5 ; cld 7 - claudina 7 75

Figura 5.4 - Expressão do mRNAs do miRNA-18a estudado na linhagem celular HM-UMC-3A de CME, a expressão foi medida nas células tratadas e nas células não tratadas pelo EGF nas três diferentes concentrações $(25 \mathrm{ng} / \mathrm{ml}, 50 \mathrm{ng} / \mathrm{ml}$ e $100 \mathrm{ng} / \mathrm{ml})$. A expressão relativa foi medida por qPCR considerando um pool de mucosa oral não neoplásica como calibrador e os resultados foram normalizados pela expressão do micro-RNA endógeno RNU48. 


\section{LISTA DE TABELAS}

Tabela 2.1 - Pontuação atribuída as características histológicas usadas para a graduação do CME, segundo a OMS (El-Naggar et al., 2017)

Tabela 4.1 - Caracterização dos anticorpos utilizados para esse estudo contendo o soro primário utilizado, o tipo de clone, a diluição, a marca comercial e o tipo de tratamento para recuperação antigênica do anticorpo utilizado 56

Tabela 5.1- Caracterização da amostra de cortes histológicos contendo CME .64

Tabela 5.2- Analise semiquantitativa da expressão das CLDNs no CME das glândulas salivares 69

Tabela 5.3- Associação entre a expressão das CLDNs e as características demográficas, clinicas e patológicas dos pacientes com CME das glândulas salivares .71

Tabela 5.4- Comparação da expressão das proteínas CLDNs entre si 73 



\section{LISTA DE ABREVIATURAS E SIGLAS}

$\begin{array}{ll}\text { ACTB } & \text { beta-actina } \\ \text { CAR } & \text { receptor coxsackie/adenovírus } \\ \text { CK } & \text { citoqueratina } \\ \text { COOH } & \text { grupo carboxila } \\ \text { CRTC1 } & \text { CREB regulated transcription coactivator 1 } \\ \text { EGFR } & \text { epidermal growth factor receptor } \\ \text { EGF } & \text { epidermal growth factor } \\ \text { JAM } & \text { molécula de adesão juncional } \\ \text { MAML2 } & \text { mastermind like transcriptional coactivator } 2 \\ \text { MAPK } & \text { proteína-quinase ativada por mitógeno } \\ \text { min } & \text { minuto } \\ \text { miRNA } & \text { microRNA } \\ \text { mRNA } & \text { RNA mensageiro } \\ \text { NaCL } & \text { cloreto de sódio } \\ \text { NH2 } & \text { grupo amino } \\ \text { OMS } & \text { organização mundial da saúde } \\ \text { PAS } & \text { ácido periódico de Schiff } \\ \text { RNA } & \text { ácido ribonucleico } \\ \text { rpm } & \text { rotação por minuto } \\ \text { TEM } & \text { transição epitélio-mesênquima } \\ \text { TRIS } & \text { hidroximetil aminometano } \\ \text { ZO } & \text { zona ocludente } \\ \end{array}$





\section{LISTA DE SÍMBOLOS}

$\begin{array}{ll}\text { kDalton } & \text { quilodalton } \\ \mu \mathrm{m} & \text { micrometro } \\ { }^{\circ} \mathrm{C} & \text { graus Celsius } \\ \mu \mathrm{l} & \text { microlitro } \\ \mathrm{g} & \text { gravidade } \\ \mathrm{U} & \text { unidade } \\ \mathrm{mM} & \text { micromolar } \\ \mathrm{ng} & \text { nanograma } \\ \mathrm{ml} & \text { mililitro }\end{array}$





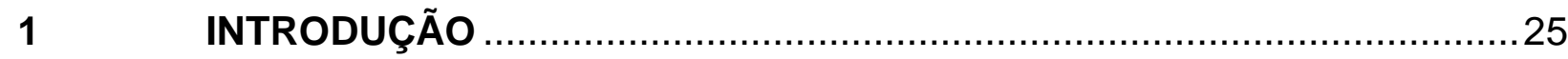

2 REVISÃO DA LITERATURA

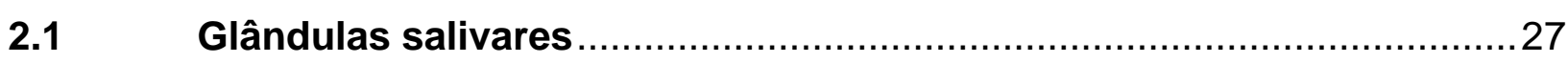

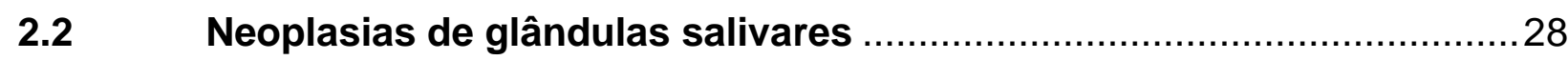

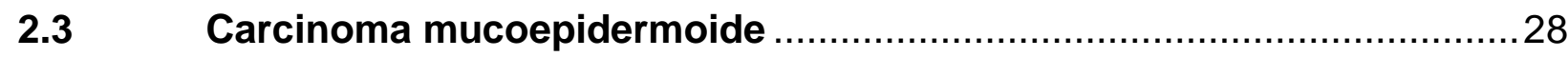

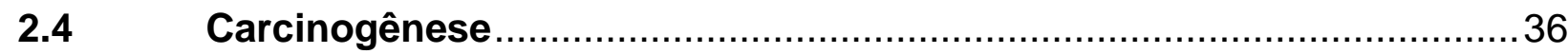

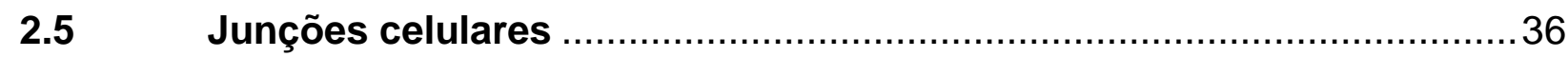

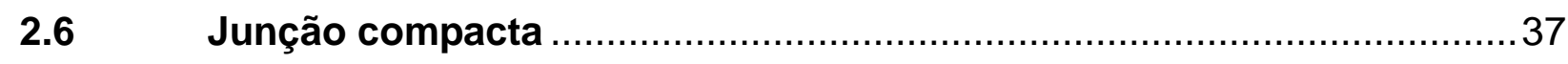

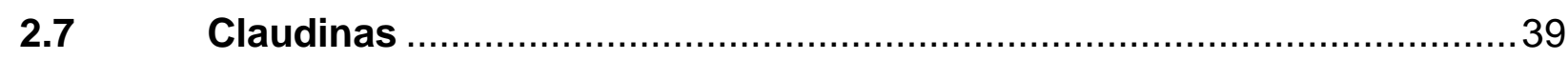

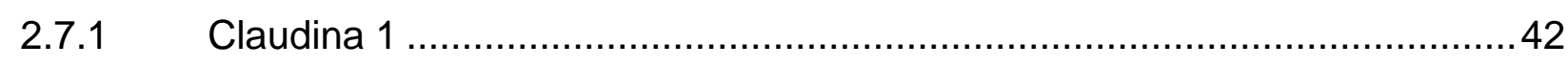

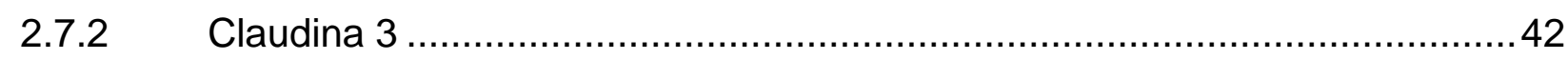

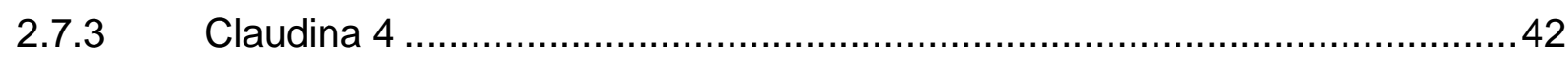

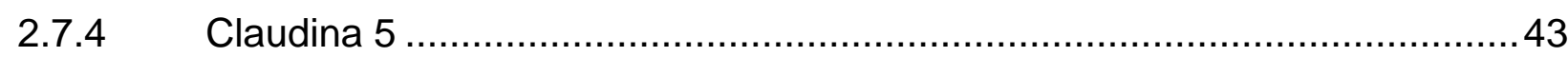

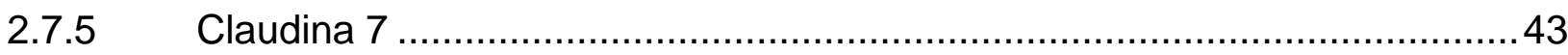

2.7.6 Expressão das claudinas em neoplasias............................................. 44

2.8 Receptor de Fator de Crescimento Epidérmico - EGFR ........................44

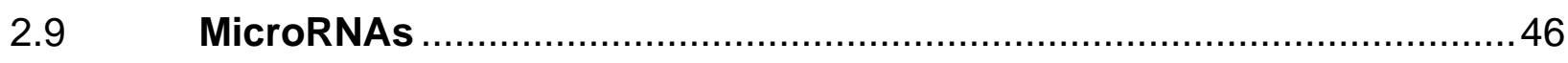

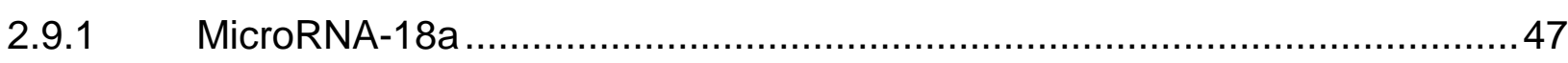

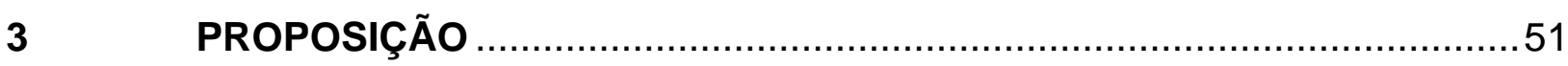

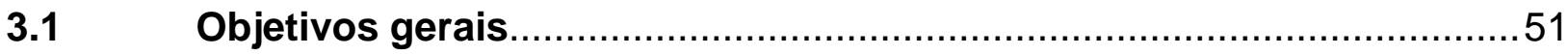

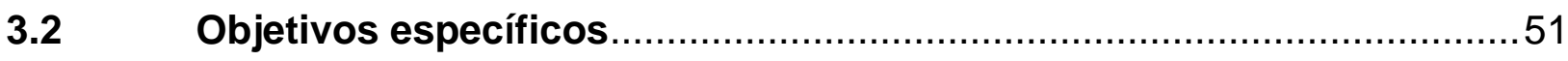

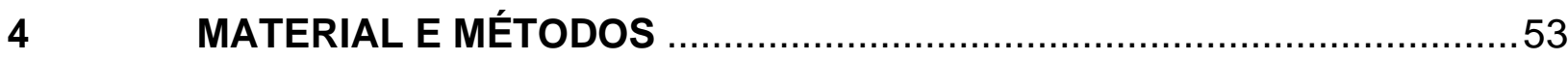

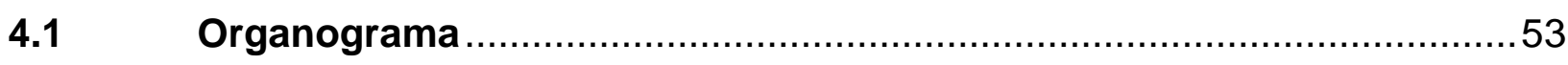

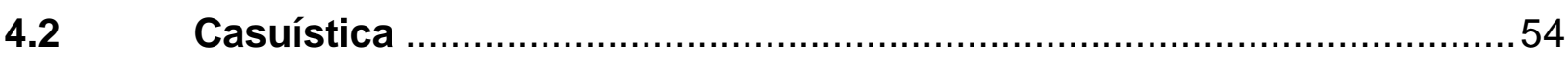

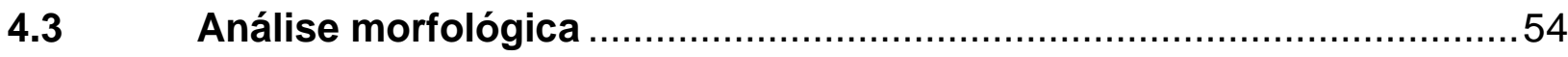

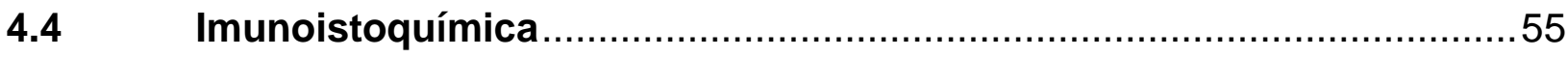

4.5 Análise estatística da imunoistoquímica .........................................57 


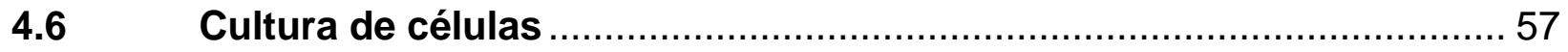

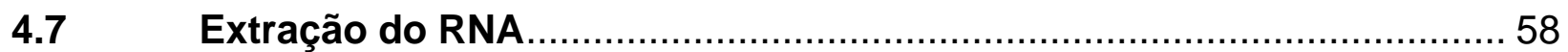

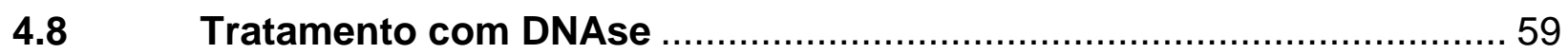

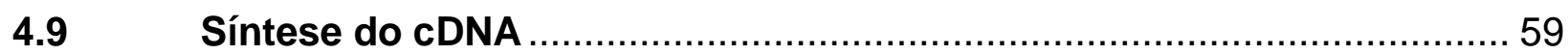

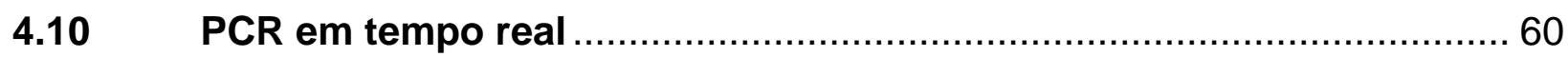

4.11 Análise estatística do PCR em tempo real......................................... 61

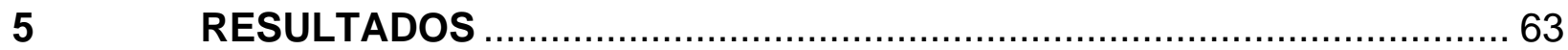

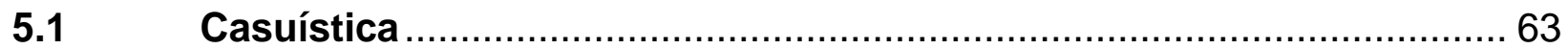

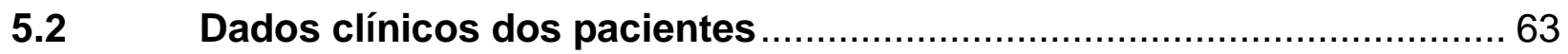

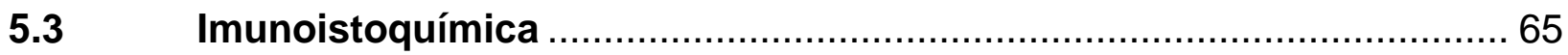

5.4 Relação entre a expressão das claudinas e os dados clínicos e

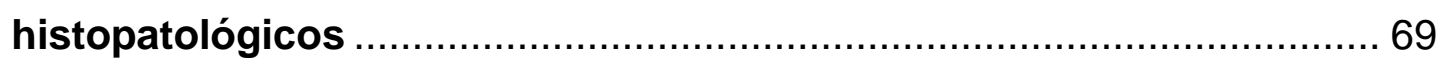

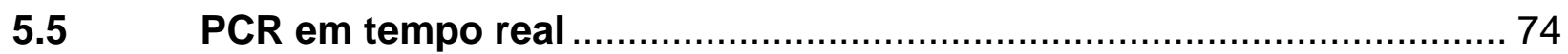

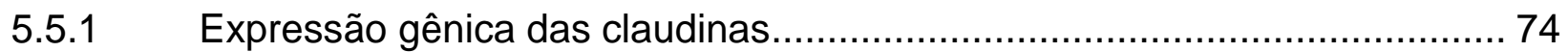

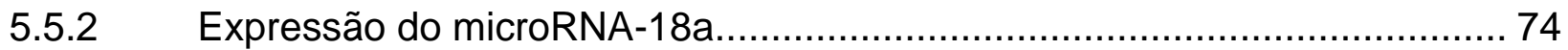

$6 \quad$ DISCUSSÃO

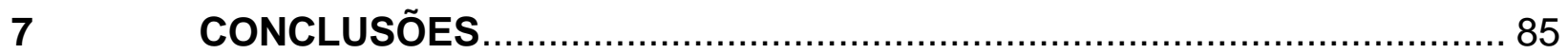

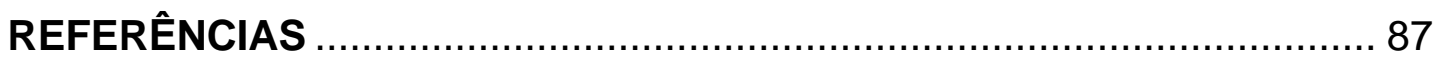

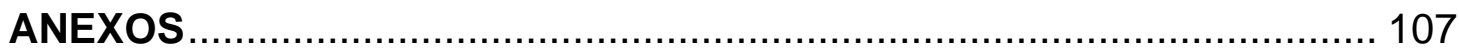




\section{INTRODUÇÃO}

As neoplasias malignas das glândulas salivares compreendem cerca de 3 a $5 \%$ dos tumores malignos que acometem a região de cabeça e pescoço; elas somam, aproximadamente, $0,3 \%$ de todas as neoplasias malignas que podem atingir o corpo humano (Dardick, 1996; Pinkston; Cole, 1999).

Dentre as neoplasias malignas que ocorrem na glândula salivar, o carcinoma mucoepidermoide é o tipo histológico mais comum; trata-se de uma neoplasia maligna epitelial que é derivada das células epiteliais do ducto excretor das glândulas salivares (Coca-Pelaz et al., 2015; Neville et al., 2008).

As células epiteliais dependem da adesão célula-célula e da adesão célulamatriz para a manutenção de suas funções como, por exemplo, a estruturação do epitélio de maneira polarizada (Alberts et al., 2010; Frixen et al., 1991).

A adesão entre as células é mantida por meio de estruturas celulares especializadas que atuam mantendo-as unidas entre si ou à lâmina basal; dentre estas estruturas destacam-se as junções compactas (Stelwagen; Singh, 2014; Singh; Dhawan, 2015).

Em neoplasias malignas há evidências de profundas alterações nessas estruturas, com impacto nos mecanismos de adesão celular (Kimura et al., 1997; Turksen; Troy, 2004). Nosso trabalho pretendeu responder se a junção compacta está relacionada ao processo de desenvolvimento do carcinoma mucoepidermoide e se fatores de crescimento podem interferir na expressão das proteínas da junção compacta e do microRNA-18a nesta neoplasia. 



\section{REVISÃO DA LITERATURA}

\subsection{Glândulas salivares}

As glândulas salivares são glândulas exócrinas localizadas na cavidade oral responsáveis pela produção e excreção da saliva (Katchburian; Arana, 2004). Existem três pares principais de glândulas salivares, conhecidas como glândulas salivares maiores - a glândula parótida, a glândula submandibular e a glândula sublingual. Essas glândulas são responsáveis pela produção de $90 \%$ de toda a saliva excretada. Além das glândulas salivares maiores também são encontradas na cavidade bucal as glândulas salivares menores que são constituídas por numerosos agregados de tecido glandular distribuídos por toda a cavidade oral (Humphrey et al, 2001; Delporte; Steinfeld, 2006; Amano et al, 2012; Holmberg; Hoffman, 2014; Patel et al, 2014).

O parênquima das glândulas salivares é constituído por ácinos que são compostos por células serosas, células mucosas ou pelos dois tipos celulares e ductos que podem ser ductos intercalados, ductos estriados e ductos excretores; além disso também são encontradas células mioepiteliais, importantes no auxílio da secreção salivar (Humphrey et al, 2001; Katchburian; Arana, 2004; Patel et al, 2014; Patel et al, 2014).

Hitologicamente, a glândula parótida é constituída por três grandes lóbulos que são constituídos por ácinos serosos em sua grande maioria, a glândula submandibular é composta por ácinos mistos e a glândula sublingual apresenta maioria de ácinos mucosos. As glândulas salivares menores são constituídas por ácinos mucosos (Katchburian; Arana, 2004). 


\subsection{Neoplasias de glândulas salivares}

A Organização Mundial da Saúde (OMS) classifica, ao todo, 23 diferentes neoplasias malignas que podem acometer as glândulas salivares; estas neoplasias malignas compreendem cerca de 3 a $5 \%$ de todos os tumores malignos que podem acometer a região de cabeça e pescoço (Dardick, 1996; Pinkston; Cole, 1999; Ellis; Auclair, 2008). Essas, por sua vez, totalizam cerca de 20 a $26 \%$ de todas as neoplasias que podem acometer as glândulas salivares (Ellis; Auclair, 2008). Nesse universo, o carcinoma mucoepidermoide é apontado por alguns autores como sendo o tipo histológico mais comum (Vargas et al., 2002; Neville et al., 2008; Adams et al., 2013; Coca-Pelaz et al., 2015).

\subsection{Carcinoma mucoepidermoide}

Descrito pela primeira vez por Stewart e colaboradores em 1945, o carcinoma mucoepidermoide (CME) é uma neoplasia maligna epitelial que se origina de células epiteliais do ducto excretor das glândulas salivares, como graficamente representado na Figura 2.1, sendo considerada por muitos pesquisadores como o tipo histológico mais comum que acomete estas glândulas. Sua ocorrência é maior na glândula parótida, entretanto, também pode acometer a submandibular, sublingual e glândulas salivares menores (Galdirs et al., 2019; Reinheimer et al., 2019; Adams et al., 2013; Stewart et al., 1945, Guntinas-Lichius et al., 2004; Neville et al., 2008; Coca-Pelaz et al., 2015).

Em 1972, o CME foi classificado pela Organização Mundial da Saúde (OMS) como "tumor mucoepidermoide", já que à época, suas características de malignidade ainda não estavam bem determinadas. Em 1991, a OMS reconhece o perfil maligno da lesão, classificando-o como "carcinoma mucoepidermoide" (Barnes et al., 2005; Seifert et al., 1990). A OMS define o CME como uma neoplasia maligna epitelial de glândula salivar caracterizada por apresentar células mucosas, células intermediárias e células epidermoides, além de células claras e colunares (Barnes et al., 2005). 
Figura 2.1 - Glândula salivar evidenciando o ducto excretor, local de origem do CME

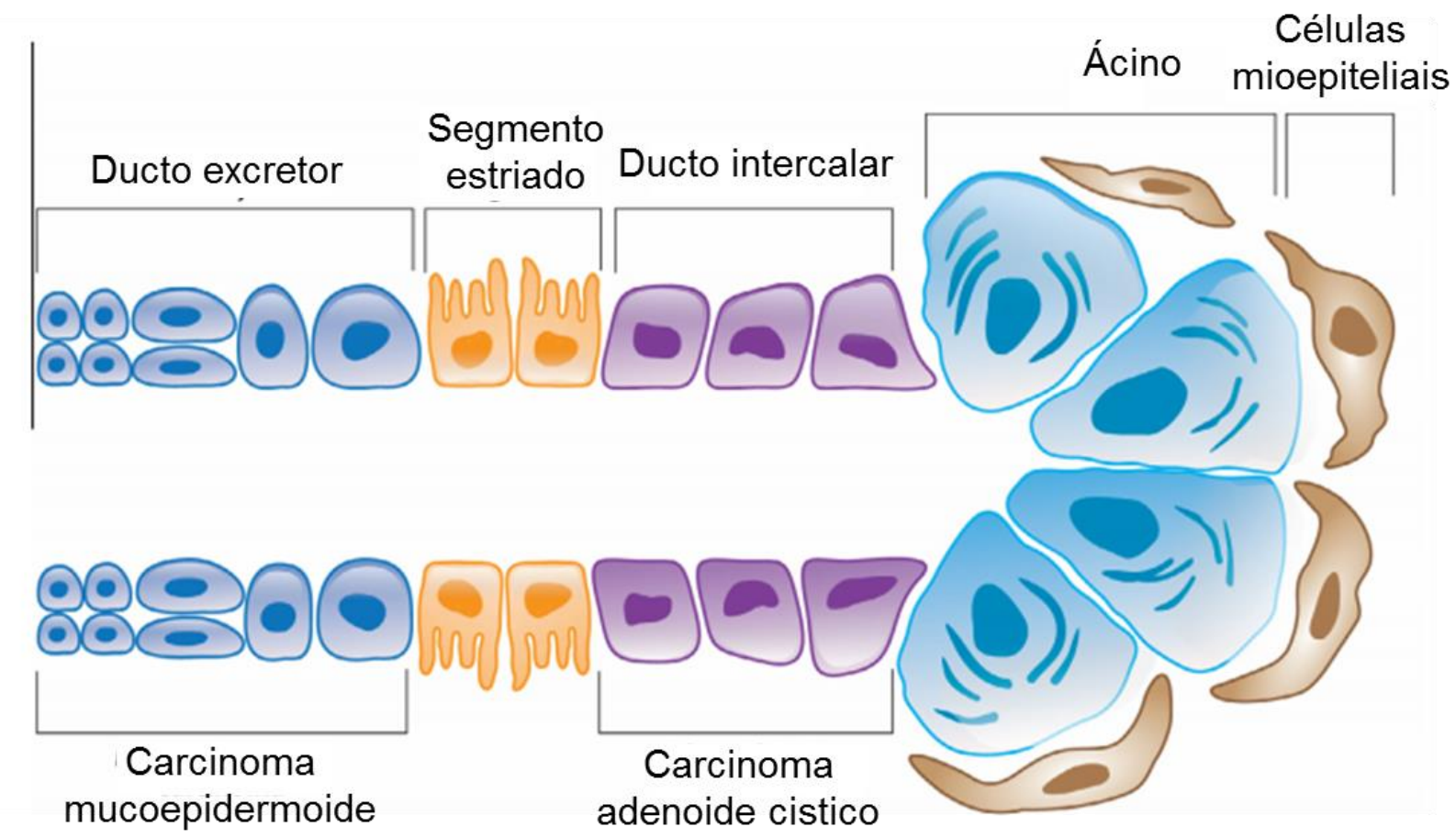

Fonte: Adams et al., Oral Oncol. 2013

O CME apresenta uma ligeira predileção pelo sexo feminino, que pode, contudo, variar de acordo com o sítio anatômico da lesão. Ele ocorre em todas as faixas etárias embora a idade média ao diagnóstico seja 45 anos. Uma diminuição da sua ocorrência é observada em ambos os extremos do espectro etário (Galdirs et al., 2019; Coca-Pelaz et al., 2015; Hellquist; Skalova, 2014). Apesar disso, é o tipo mais comum de neoplasia maligna que acomete as glândulas salivares em crianças (Morse et al., 2018; Kupferman et al., 2010)

Clinicamente, a lesão se apresenta como uma massa de crescimento tumoral, assintomática, com desenvolvimento lento, consistência firme, podendo ser fixa ou móvel; em muitos casos, o CME pode apresentar invasão neural, e nesses casos, tanto a paralisia facial quanto a dor são sintomas relatados como indicativos iniciais da doença (Neville et al., 2008; Hellquist; Skalova, 2014). Nas glândulas salivares menores a localização mais comum é o palato e a lesão pode apresentar coloração avermelhada ou azulada e ser flutuante. Além disso, devido a essas características, 
quando localizado nos lábios, o CME é facilmente confundido com uma mucocele (Hellquist; Skalova, 2014).

O CME intraósseo é raro e a maioria ocorre na mandíbula. Radiograficamente, ele se apresenta como um abaulamento cortical que revela áreas radiolúcidas uni ou multiloculares de bordas bem definidas (Chiu et al., 2012; Cohen-Kerem et al., 2004).

Além das glândulas salivares, o CME também pode acometer outros órgãos, como mama, esôfago, pâncreas, pulmão, pele, timo e tireoide (Hellquist; Skalova, 2014).

Algumas alterações em genes específicos podem ser observadas no CME; acredita-se que o surgimento do CME esteja associado com a translocação dos cromossomos 11 e 19, t(11;19)(q14-21; p12-13) (Nordkvist et al., 1994); uma fusão especifica que combina o exon 1 de um gene no cromossomo 19 CRTC1, com os exons 2-5 de um gene no cromossomo 11 MAML2 (Tonon et al., 2003). Alguns estudos mostram a presença dessa translocação em grande parte dos casos de CME (Pérez-de-Oliveira et al., 2019; Martins et al., 2004; Tirado et al., 2007).

A translocação dos genes CRTC1-MAML2 vem sendo apontada como a chave para o processo de tumorigênese no $C M E$, e já se sabe que tumores que apresentam essa translocação apresentam prognóstico mais favorável, entretanto, ela não pode ser relacionada com a sua recorrência (Pérez-de-Oliveira et al., 2019; Cipriani et al., 2019; Komiya et al., 2006).

Histologicamente, o CME é um tumor de constituição heterogênea, composto por 3 tipos celulares principais que se apresentam em proporções variadas: células mucosas, células intermediárias e células epidermoides. Além disso, também podem ser encontradas células claras, assim como, células colunares e outros tipos celulares, podendo mostrar ou não um arranjo luminal (Luna, 2006; Barnes et al., 2005).

As células mucosas apresentam-se, em geral, com formato colunar ou poligonal, citoplasma abundante, espumoso e basófilo que contem mucina, o que as confere uma aparência clara; o núcleo é pequeno e geralmente não apresenta atipia ou atividade mitótica. Elas se assemelham às células acinares normais, produzindo mucina, que se acumula no citoplasma ou é secretada, e podem apresentar-se tanto isoladamente como em aglomerados. Quando as células mucosas são escassas, ou 
não bem definidas, utilizam-se colorações histoquímicas para a demonstração da mucina como o PAS ou o Alcian Blue (Luna, 2006; Hellquist; Skalova, 2014).

As células intermediárias apresentam um aspecto basaloide, sendo menores, menos coesas e com citoplasma escasso. São células com núcleos evidentes que, muitas vezes, apresentam um halo claro perinuclear que corresponde ao escasso citoplasma. Podem estar presentes no revestimento de cistos, situadas abaixo das células mucosas. A célula intermediária apresenta atipia e mitoses frequentes. É o tipo celular de reconhecimento mais difícil no CME, entretanto, sua demonstração é importante para o diagnóstico da lesão (Luna, 2006; Hellquist; Skalova, 2014).

As células epidermoides (escamosas) possuem o aspecto de uma célula epidermoide madura, com formato poliédrico e citoplasma eosinofílico abundante. Podem ainda apresentar atipia, bem como mitoses (Luna, 2006; Hellquist; Skalova, 2014).

As células claras também são bastante comuns, especialmente quando a neoplasia tem origem nas glândulas salivares mucosas. Apresentam formato poligonal, com limites bem definidos e núcleos pequenos, muitas vezes picnóticos e arranjados centralmente. Estas células são oriundas da degeneração hidrópica que leva a formação de áreas claras, que pode ser uma característica dominante, determinando a variante de células claras deste tumor. (Yang; Chen, 2010). Os tipos celulares mais presentes no CME estão ilustrados na Figura 2.2.

Em menor frequência, células colunares e células oncocíticas podem estar presentes. As células colunares apresentam aspecto poligonal e núcleo deslocado para a basal e costumam revestir estruturas ductais e císticas (Luna, 2006; Hellquist; Skalova, 2014). As células oncocíticas são derivadas da proliferação e acúmulo de mitocôndrias no interior de células tumorais; CMEs que apresentam grande quantidade deste tipo celular são referidos como CMEs oncocíticos (Weinreb et al., 2009).

O infiltrado inflamatório é comum no CME; ele é, em geral, difuso, e visto com maior intensidade ao redor de áreas císticas e em torno de ninhos celulares sólidos que normalmente são compostos por células intermediárias (Hellquist; Skalova, 2014). 
Figura 2.2 - Tipos celulares mais frequentemente encontrados no CME: A - grande quantidade de células mucosas apresentando citoplasma claro e abundante (Magnificação original 400x); B - grande quantidade de células intermediárias com núcleos evidentes e citoplasma escasso (Magnificação original 400x); C - grande quantidade de células epidermoides com formato poliédrico e citoplasma abundante (Magnificação original 200x)
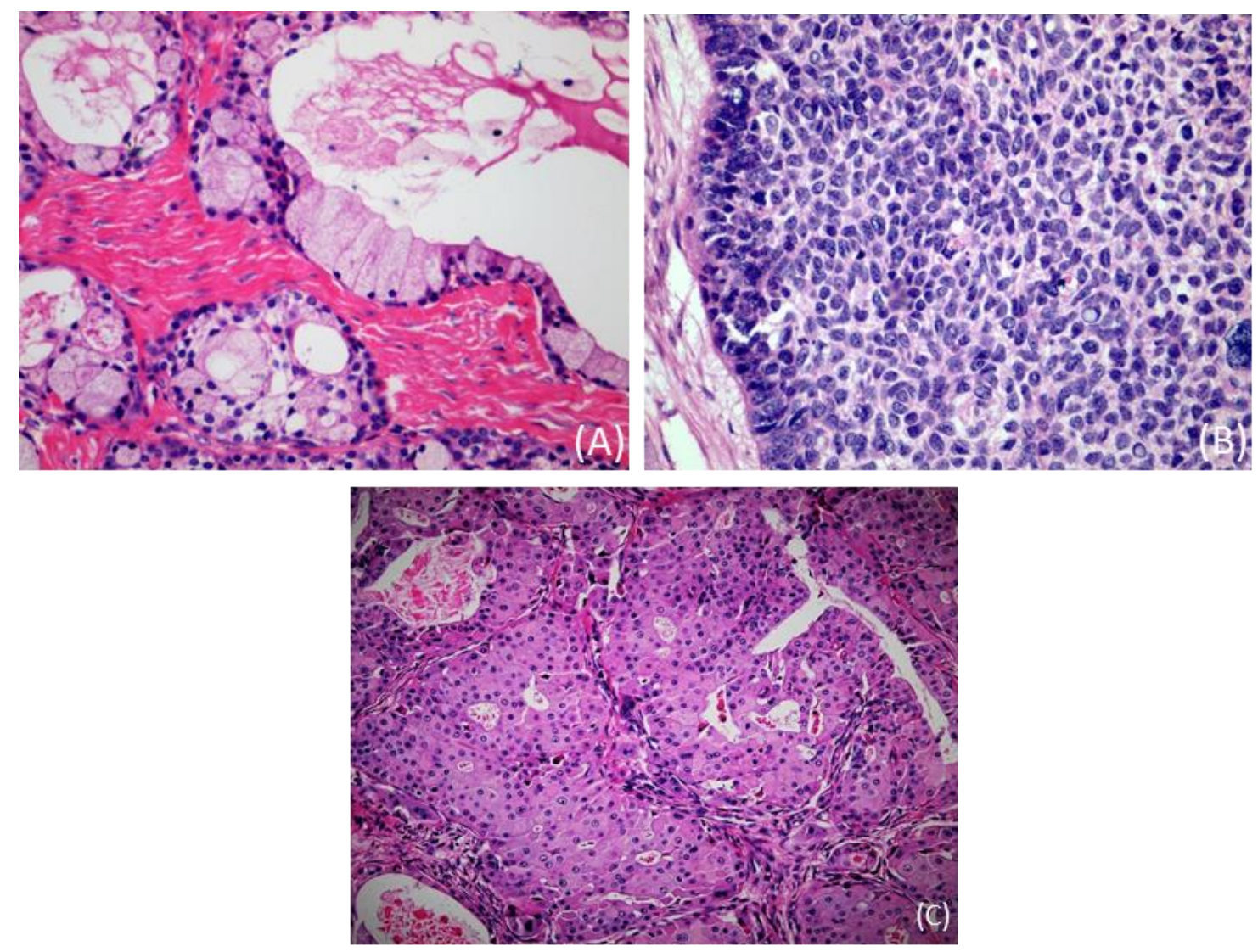

Fonte: O autor

As células do CME podem estar organizadas em padrão cístico, quando apresentam a formação de estruturas císticas e de estruturas glandulares ductais, ou em padrão sólido, quando apresentam a formação de ilhas de células tumorais cercadas por um estroma colagenizado (Luna, 2006). Na Figura 2.3 podemos observar os dois padrões.

Vários sistemas de graduação histológica têm sido propostos para tentar classificar esta neoplasia; estes métodos variam em complexidade devido ao número de parâmetros morfológicos avaliados (Jakobsson, et al., 1968; Healey, et al., 1970; Batsakis; Luna, 1990; Auclair et al., 1992) porém, todos apresentam um caráter subjetivo, visto que dependem da avaliação de seus critérios pelo patologista e de sua experiência (Coca-Pelaz et al., 2015). 
Segundo a OMS (2005), os CMEs podem ser histologicamente classificados como sendo de baixo grau, de grau intermediário e de alto grau. Esta graduação histológica é obtida por meio de um sistema de pontuação que leva em conta os vários aspectos morfológicos presentes no espécime, como a presença de necrose, a alta frequência de mitoses, o componente cístico do tumor, entre outros. (Barnes et al., 2005). A classificação da OMS foi revisada recentemente, entretanto, para o CME não houve alterações (El-Naggar et al., 2017). A Tabela 2.1 apresenta o sistema de pontuação utilizado pela OMS para a classificação da graduação histológica do CME.

Tabela 2.1 - Pontuação atribuída as características histológicas usadas para a graduação do CME, segundo a OMS (El-Naggar et al., 2017)

\begin{tabular}{cc|cc} 
Característica & $\begin{array}{c}\text { Valor do } \\
\text { ponto }\end{array}$ & Graduação histológica & Pontuação \\
\hline Componente cístico $<20 \%$ & 2 & Baixo grau & $0-4$ \\
Invasão neural & 2 & Grau intermediário & $5-6$ \\
Mitose $\geq 4 / 10$ CAP $^{*}$ & 2 & Alto grau & $\geq 7$ \\
Necrose & 3 & & \\
Anaplasia & 4 & & \\
\hline
\end{tabular}

${ }^{*} \mathrm{CAP}$, campos de alta potencia

Os CMEs de baixo grau apresentam grande quantidade de células mucosas e ninhos de tumor bem circunscritos são frequentemente encontrados, assim como grande quantidade de espaços císticos que, muitas vezes, são revestidos por células colunares além de apresentarem baixa frequência de atipia celular e de mitoses; os tumores classificados como grau intermediário apresentam menor quantidade de áreas císticas e menor quantidade de células mucosas, a população de células intermediarias é maior, os ninhos celulares irregulares e a atipia celular é mais pronunciada; já os CMEs de alto grau costumam ser sólidos contendo mais células epidermoides que apresentam anaplasia celular, alta contagem mitótica, invasão perineural e, em alguns casos, necrose (Hellquist; Skalova, 2014).

A graduação histológica é importante para a avaliação do comportamento clínico e prognóstico da lesão, pois, sabe-se que o CME de baixo grau costuma apresentar prognóstico mais favorável, enquanto o CME de alto grau apresenta 
comportamento agressivo tendo o desenvolvimento de metástases distantes mais relacionado a ele. Nos casos de CME de grau intermediário, existe uma dificuldade maior para a predição do seu comportamento; acredita-se que o comportamento da lesão de grau intermediário seja semelhante ao do tumor de baixo grau. Entretanto, sabe-se que mesmo em CME de baixo grau, as recorrências são possíveis e todos eles apresentam potencial metastático, sendo pulmões, ossos e cérebro os sítios mais comuns para a ocorrência de metástase (Israel et al., 2019a; Israel et al., 2019b; Liu et al., 2014; Hicks et al., 1995; Nance et al., 2008; Nagano et al., 2016).

As metástases regionais acometem cerca de 3\% a 15\% dos pacientes diagnosticados com CME e as metástases distantes afetam cerca de $6 \%$ a $15 \%$ desses pacientes (Bradley, 2001). A sobrevida de 5 a 10 anos, no caso de metástase regional é de $60 \%$ dos casos e de $40 \%$ nos casos de metástases distantes (Okabe et al., 2001).

O diagnóstico diferencial inclui o carcinoma epidermoide pois, embora seja relativamente simples distinguir um CME de baixo grau ou de grau intermediário de um carcinoma epidermoide, quando se trata de um tumor de alto grau que apresenta padrão sólido, esse diagnóstico se torna mais complexo (Woolgar; Triantafyllou, 2009). Ainda, no âmbito dos diagnósticos diferenciais, o carcinoma metastático de células renais também pode gerar dúvida quando se trata de um CME variante de células claras (Pires et al., 2010) e também pode ser confundido com variantes celulares do sialadenoma papilífero (Woolgar et al., 2014), além de carcinoma adenoide cístico, tumores de células claras, entre outros (Hellquist; Skalova, 2014).

Quando ocorrem dificuldades no diagnóstico da lesão, como nos casos em que as células mucosas podem ser escassas ou não estarem muito bem definidas, pode-se aplicar técnicas de coloração histoquímica para a evidenciação da mucina, como o PAS ou o Alcian Blue. Estas colorações também evidenciam a mucina contida no interior de cistos e estruturas ductais. Além dessas colorações, uma outra aliada aos diagnósticos mais difíceis é a imunoistoquímica. As células colunares e mucosas expressam a citoqueratina (CK) 7 , já as células intermediárias e epidermoides expressam mais frequentemente a CK14 (Loyola et al., 1998; Azevedo et al., 2008). Os CMEs são geralmente negativos para actina de músculo liso e demais anticorpos indicativos da diferenciação das células mioepiteliais (Hellquist; Skalova, 2014). 
Figura 2.3 - Padrões histológicos de apresentação das células no CME: A - CME apresentando padrão cístico com abertura de inúmeros espaços císticos (Magnificação original 40x); B - CME apresentando padrão sólido com a formação de ilhas de células epidermoides e intermediárias (Magnificação original $40 x$ )
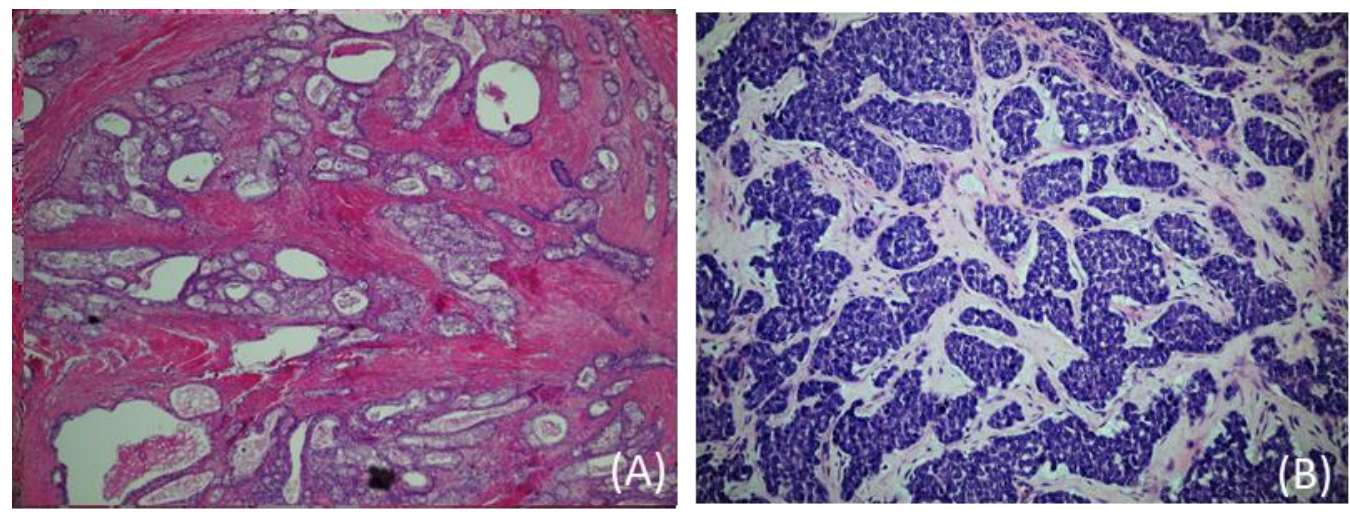

Fonte: $\mathrm{O}$ autor

O tratamento do CME é feito a partir da remoção cirúrgica da lesão. A localização, o grau histopatológico e o estágio clínico do tumor determinam a extensão da margem de segurança. Nos tumores acessíveis em pacientes que estão livres de metástase, o tratamento de escolha é a ressecção cirúrgica completa com margem de segurança (Vander Poorten et al., 2014); no caso de tumores de alto grau, tumores avançados ou inacessíveis, que apresentam invasão neural ou óssea e metástase, o planejamento cirúrgico é mais complexo podendo envolver ressecção de pele, ossos da face, músculos e nervos. Tumores muito extensos podem requerer mandibulectomia, maxilectomia, mastoidectomia ou ressecção craniofacial anterior (Byrd et al., 2013; Garden et al., 1997; Neville et al., 2008).

A utilização de radioterapia é aconselhada em casos de CME de alto grau e em casos onde a excisão cirúrgica não foi completa (Hosokawa et al., 1999). Casos que apresentam risco aumentado de recorrência, como aqueles que apresentam invasão perineural, também são indicados para o tratamento radioterápico assim como pacientes com maior risco de metástases em linfonodos (Chen et al., 2007a; Chen et al., 2007b).

O desenvolvimento de neoplasias costuma estar relacionado com a ocorrência de alterações genéticas que, frequentemente, causam danos ao sistema de diferenciação celular ou ao sistema de apoptose (Alberts et al., 2010). 


\subsection{Carcinogênese}

Eventos como o surgimento de sinais proliferativos autossuficientes, redução da expressão de moléculas de adesão superficial da célula, o fenômeno de transição epitélio-mesênquima (TEM), entre outros fatores, se relacionam diretamente com o surgimento de neoplasias (Thompson et al., 2005).

Durante os estágios iniciais da carcinogênese, ocorrem alterações na expressão de moléculas de adesão (Singh et al., 2010), alterações em proteínas ligadas a adesão celular, como claudinas e E-caderinas, resultando na perda de adesão o que pode induzir a invasão tecidual ou vascular (Frixen et al., 1991). Uma importante estrutura de adesão celular, constituída por proteínas claudinas, que atua na manutenção da polaridade celular é a junção compacta. Essa estrutura de adesão se apresenta como a mais apicalmente localizada na membrana plasmática das células (Lal-Nag; Morin, 2009).

\subsection{Junções celulares}

As junções celulares estão presentes no epitélio dos vertebrados; são estruturas que facilitam a estabilidade e a comunicação entre células (Stelwagen; Singh, 2014), auxiliam na adesão celular e atuam como vedantes impedindo o fluxo de moléculas, íons e solutos pelo espaço intercelular (Junqueira; Carneiro, 2008). Além disso, as junções celulares também apresentam um papel crucial na manutenção da estrutura tridimensional do epitélio (Stelwagen; Singh, 2014).

Existem três grupos de junções celulares, sendo estes: o grupo das junções aderentes e desmossomos, o grupo das junções comunicantes e o grupo das junções compactas (JCs) (Alberts et al., 2010).

As junções aderentes e desmossomos formam o "cinturão de adesão contínuo", que é responsável pela adesão mecânica que mantem as células adjacentes unidas através de proteínas denominadas caderinas (Denker; Nigam, 1998). 
As junções comunicantes atuam na comunicação celular que se dá através da passagem de íons e pequenas moléculas conferindo às células um acoplamento metabólico e elétrico entre si.

A JC possui um importante papel na fisiologia celular atuando como uma barreira seletiva que separa a membrana plasmática em dois domínios distintos, um apical e outro basolateral. Essa estrutura é importante auxiliar na manutenção da polaridade celular, impedindo que moléculas localizadas na parte apical se misturem com moléculas da parte lateral (Martin; Jiang, 2009; Denker; Nigam, 1998).

A JC forma, juntamente com o desmossomo e com a junção aderente, 0 complexo juncional (CJ), sendo que a JC é a estrutura mais apical desse complexo, como ilustrado na Figura 2.4. O CJ tem importante papel na interação celular em todos os vertebrados (Alberts et al., 2010; Tsukita et al., 2001), com a função de conectar as células de forma polarizada e manter sua homeostase (Förster, 2008). Neste aspecto, a junção compacta é fundamental componente do CJ, pois está diretamente relacionada com a manutenção da estrutura polarizada do epitélio (Mitic et al., 2000).

\subsection{Junção compacta}

A JC é formada por um complexo multiproteico especializado localizado na porção mais apical da membrana lateral de células epiteliais polarizadas (Mitic et al., 2000). A JC controla a passagem de solutos entre as células; é impermeável a macromoléculas, entretanto, permite a passagem de pequenas moléculas, sendo esta permeabilidade distinta em cada tipo de epitélio. A especificidade dessa função é determinada pelas proteínas que compõem a JC (Van Itallie; Anderson, 2006; Alberts et al., 2010). A estrutura é dinâmica e tem como característica um processo contínuo de remodelação molecular, podendo ser alterada pelas células epiteliais de forma temporária e com isso, aumentar o fluxo de soluto e água através dela (Niessen; Gottardi, 2008). 
Figura 2.4 - Representação do complexo juncional destacando seus componentes, entre eles, a junção compacta

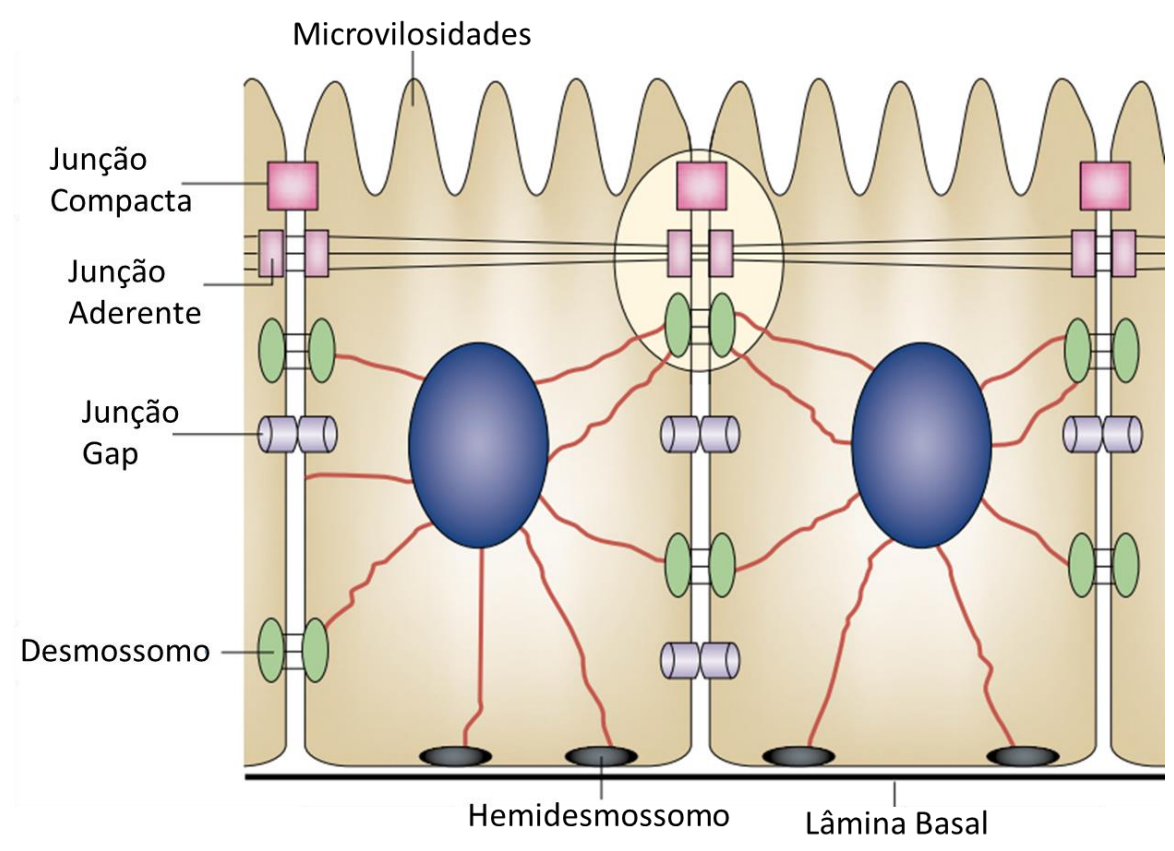

Fonte: Tsukita et al., Nat Rev Mol Cell Biol. 2001

A ultraestrutura da JC compreende uma região de fusão da membrana plasmática próxima à região apical de células epiteliais adjacentes (Farquhar; Palade, 1963). Estruturalmente, ela está organizada como uma cinta de fitas selantes anastomosadas que circundam a parte apical de células epiteliais, como representado na Figura 2.5. Estas fitas selantes são formadas por proteínas de adesão transmembrânicas que estão aderidas à membrana plasmática das células que interagem entre si. Os domínios extracelulares destas proteínas se conectam para bloquear o espaço intercelular (Van Itallie; Anderson, 2006; Stevenson; Keon, 1998; Matter et al., 2005).

As propriedades de selagem da JC dependem de vários fatores como 0 número de fitas selantes, a quantidade de agressão sofrida pelo selo de vedação e a composição proteica das fitas selantes que as formam (Claude; Goodenough, 1973; Ivanov, 2008). A proximidade da JC também é determinada pelas proteínas que compõem as fitas selantes (Shen et al., 2008; Ivanov, 2008), que são: as claudinas, as ocludinas, as tricelulinas, as moléculas de adesão juncional (JAM), o receptor associado à coxsackie/adenovírus (CAR), as proteínas "scaffold" que ligam proteínas de membrana ao citoesqueleto de actina, como a zona ocludente 1, 2 e 3 
(ZO-1, ZO-2 e ZO-3), e outras proteínas com funções de sinalização como fatores de transcrição, quinases e fosfatases (Angelow et al., 2008). Essas proteínas atuam como moléculas de adesão célula-célula e impedem a migração celular (Shen et al., 2008).

As proteínas claudinas formam a família mais numerosa de proteínas que compõem a JC e encontram-se ligadas intracelularmente ao citoesqueleto de actina através das proteínas "scaffold" ZO-1, ZO-2 e ZO-3 (Furuse et al., 1993; Furuse et al., 1998; Fanning et al., 1998).

\subsection{Claudinas}

As claudinas (CLDNs) são proteínas da família das tetraspaninas transmembrânicas que foram primeiramente descritas em 1998 por Furuse e colaboradores; elas formam uma grande família que, até o momento, conta com 27 membros (Mineta et al., 2011), tendo seu nome derivado da palavra em latim "claudere" que significa fechar. Muitas destas proteínas apresentam peso molecular entre 20 e 34 kDalton (Lal-Nag; Morin, 2009) e os genes que as codificam encontram-se em sua maioria nos cromossomos 3 e 7 (Mitic et al., 2000; Chiba et al., 2008).

As CLDNs apresentam como características a formação de barreira e a formação de poros. Os poros são mecanismos de permeabilidade paracelular, atuando como canais seletivos que permitem que íons específicos cruzem a barreira da JC de um espaço extracelular para outro (Lingaraju et al., 2015). A capacidade de passagem dos poros está relacionada com a quantidade de CLDNs formadoras de poro que são expressas na JC e, sabe-se que as CLDNs -2, -10, -15 e -17 estão relacionadas com a formação de poros (Van Itallie et al., 2008; Krug et al., 2014).

As CLDNs podem ser divididas em: clássicas e não clássicas, sendo consideradas clássicas as CLDNs de 1 até 10 e as CLDNs -14, -15, -17 e -19. Nesta classificação são levados em conta os aspectos funcionais (Krause et al., 2008). Ademais, são expressas nos diferentes tecidos em combinações específicas, o que Ihes confere características próprias de barreira em cada tecido (Capaldo et al., 2014; Capaldo; Nusrat, 2009). 
Estruturalmente, as CLDNs apresentam 4 domínios transmembrânicos (LalNag; Morin, 2009), sendo que sua estrutura geral consiste em duas alças extracelulares que medeiam a interação entre as células formando uma selagem entre elas (Mineta et al., 2011; Capaldo; Nusrat, 2015). Essas proteínas também apresentam uma alça curta intracelular com um terminal $\mathrm{NH}_{2}$ intracelular muito curto e um terminal $\mathrm{COOH}$ intracelular mais comprido (Mineta et al., 2011; Lal-Nag; Morin, 2009).

Figura 2.5 - Representação esquemática da interação célula-célula promovida pelas fitas selantes que compõem a junção compacta

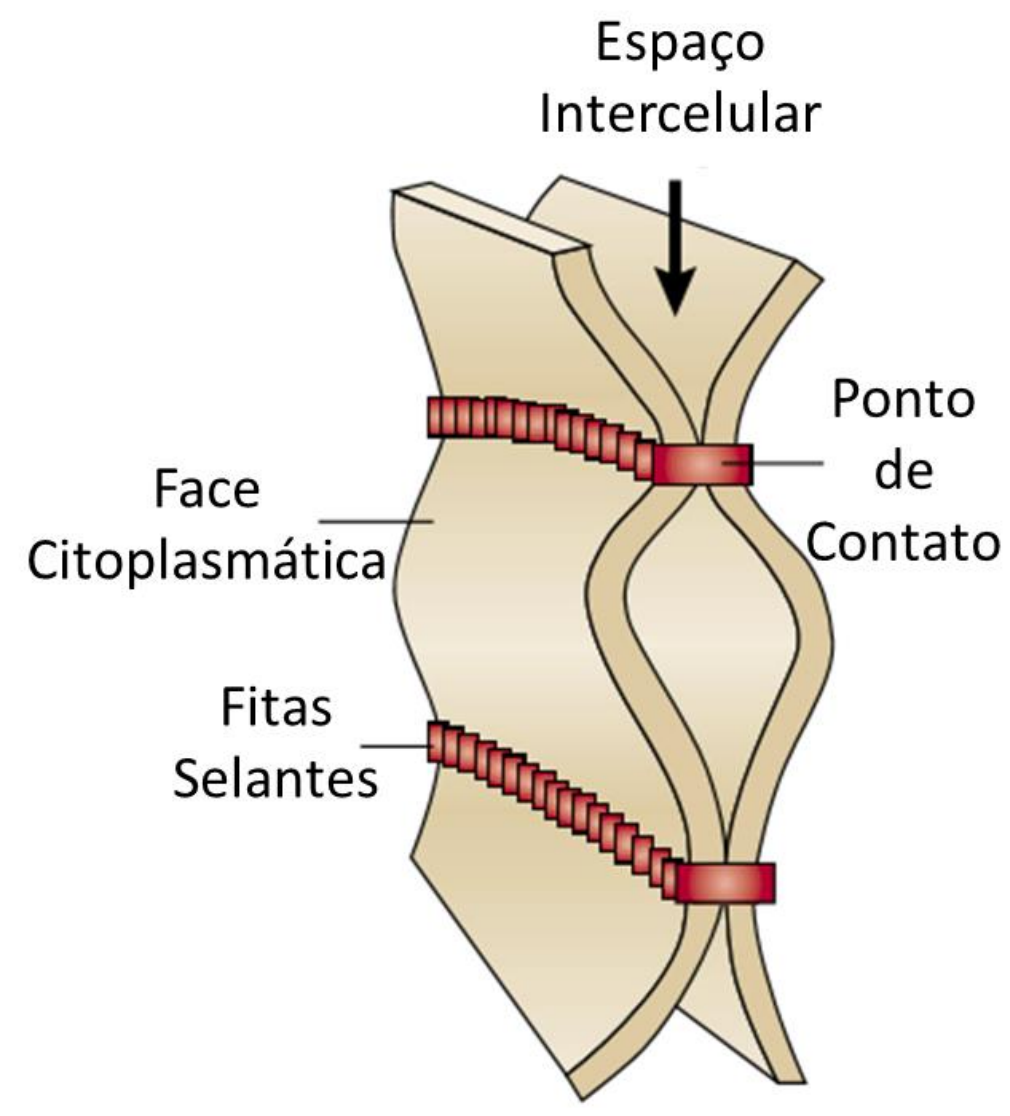

Fonte: Tsukita et al., Nat Rev Mol Cell Biol. 2001

A primeira alça extracelular da proteína CLDN contém aminoácidos (aproximadamente 52) que apresentam uma variação em sua sequência. Eles estão 
carregados e regulam a seletividade paracelular de cátions e aníons (Tsukita; Furuse, 2000; Chiba et al., 2008). A outra alça extracelular contém entre 16 e 33 aminoácidos e atua na oligomerização das CLDNs que participam na formação dos cordões da JC da célula, além de também atuar na interação celular entre CLDNs e células adjacentes (Daugherty et al. 2007; Chiba et al., 2008).

A cauda citoplasmática que contém o terminal carboxila $(\mathrm{COOH})$ é a que mais difere em tamanho e sequência entre as várias isomorfas de CLDNs, esta cauda citoplasmática atua na adesão da junção com a CLDN e contém resíduos que regulam sua estabilidade (Van Itallie et al., 2004; Chiba et al., 2008) e permitem que a proteína interaja com as proteínas de ancoragem, como as proteínas "scaffold" (D'Souza et al., 2005). A Figura 2.6 mostra uma representação esquemática da estrutura geral das CLDNs.

Figura 2.6 - Representação esquemática da estrutura geral das proteínas claudinas

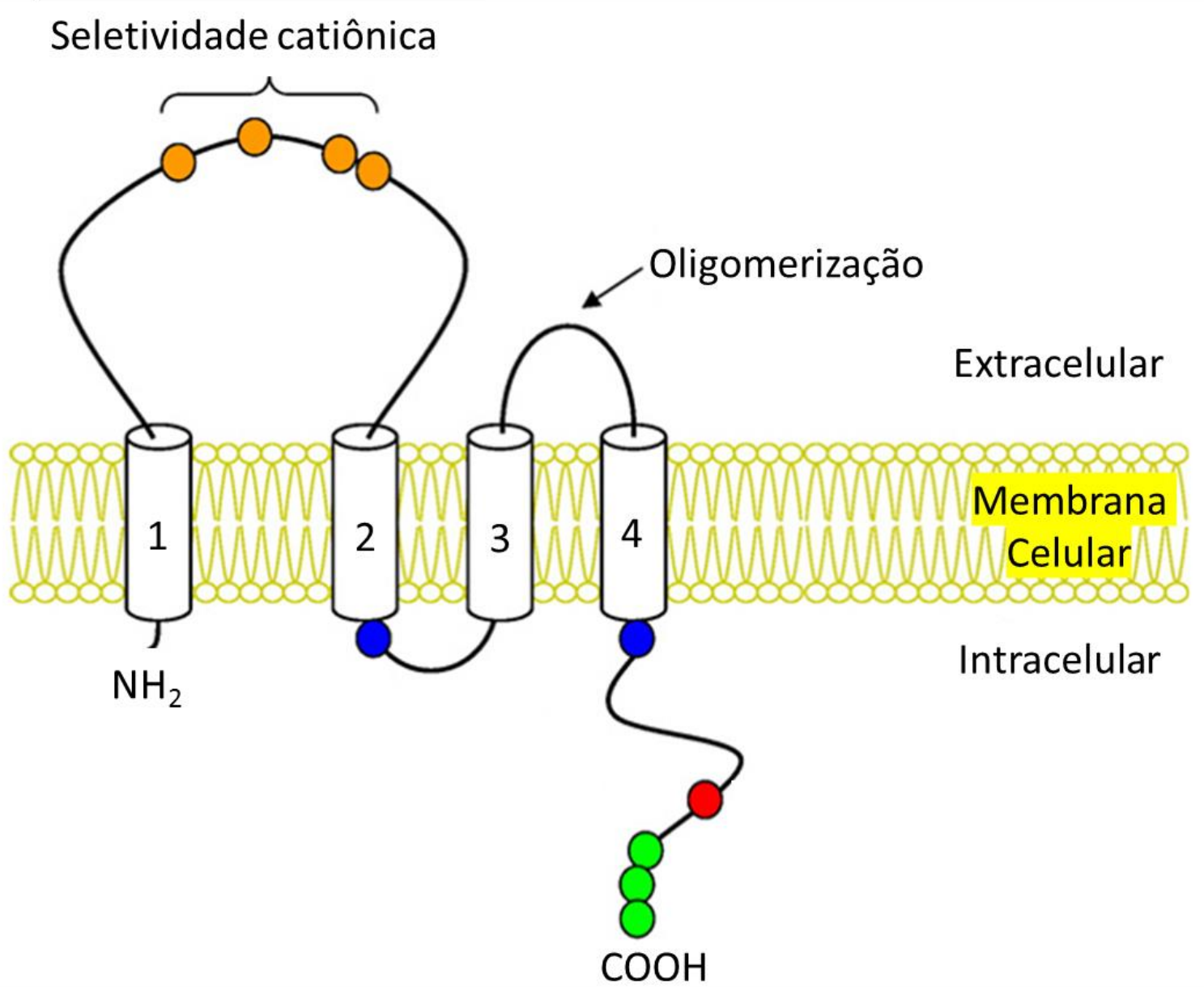

Fonte: Chiba et al., Biochim Biophys Acta. 2008 


\subsubsection{Claudina 1}

A proteína CLDN-1 foi a primeira proteína dessa família a ser identificada (Furuse et al., 1998). É considerada uma CLDN impermeabilizante e, quando essa proteína se encontra expressa, ocorre o aumento de sua densidade entre células epiteliais, atuando como barreira epitelial. Sabe-se também que essa CLDN apresenta um papel muito importante durante o processo de formação da JC (Krause et al., 2008; Baker, 2016).

A CLDN-1 encontra-se expressa no epitélio, no néfron distal e na próstata. Nas glândulas salivares sua expressão ocorre nos ductos intercalares e estriados de glândulas salivares maiores e menores (Peppi; Ghabriel, 2004; Lourenço et al., 2007; Maria et al., 2008).

\subsubsection{Claudina 3}

A CLDN-3 apresenta a função de construção de junções endoteliais, podendo ser expressa no sistema respiratório, no sistema urinário, no sistema gastrointestinal, no fígado e no cérebro (Krause et al., 2008; Baker, 2016). Nas glândulas salivares a proteína está presente nos ácinos mucosos e serosos e nos ductos intercalados e estriados tanto de glândulas salivares maiores, quanto de glândulas salivares menores (Peppi; Ghabriel, 2004; Lourenço et al., 2007; Maria et al., 2008). A função da CLDN-3 na glândula salivar ainda não foi esclarecida, entretanto, acredita-se que ela esteja relacionada a secreção paracelular da água (Kawedia et al., 2007).

\subsubsection{Claudina 4}

A CLDN-4 realiza o controle da permeabilidade paracelular catiônica. Quando ocorre redução da expressão dessa proteína, observa-se que a JC perde a seletividade catiônica (Hou et al., 2006). Ela está expressa na vesícula biliar, no rim, 
no epitélio pulmonar, no intestino e nas células epidermoides (Krause et al., 2008; Baker, 2016). Nas glândulas salivares sua expressão ocorre nas células acinares e nas células ductais (Lourenço et al., 2007; Maria et al., 2008).

\subsubsection{Claudina 5}

A CLDN-5 detém a função de controle da permeabilidade paracelular de nutrientes e é expressa no endotélio, nos capilares cerebrais, no epitélio do ovário e no epitélio do colón (Krause et al., 2008; Baker, 2016). Em glândulas salivares sua expressão ocorre nas células endoteliais, em torno das células acinares e ductais (Peppi; Ghabriel, 2004; Lourenço et al., 2007; Maria et al., 2008). Acredita-se que a CLDN-5 esteja envolvida no controle do suprimento sanguíneo de nutrientes para a glândula salivar (Baker, 2016).

\subsubsection{Claudina 7}

A proteína CLDN-7 é expressa em células ductais de glândulas salivares menores desde os estágios iniciais do desenvolvimento até a fase adulta (Lourenço et al., 2007), e apresenta as funções de transporte de sódio e regulação do transporte de água nas glândulas salivares (Kawedia et al., 2007; Krause et al., 2008; Baker, 2016). Essa proteína também está presente no intestino e no epitélio do néfron. Em glândulas salivares sua expressão ocorre nas células ductais (Lourenço et al., 2007). 
2.7.6 Expressão das claudinas em neoplasias

Padrões específicos de expressão de diversas CLDNs tem sido relatada em neoplasias malignas (Baek et al., 2019; Danzinger et al., 2019; Yamamoto et al., 2019; Lourenço et al., 2010; Sobel et al., 2005). A ocorrência de maior expressão da CLDN-18.2 já foi descrita em casos de neoplasias malignas do trato gastrointestinal (Baek et al., 2019), já para casos de câncer cervical invasivo, o que foi observado foi a diminuição da expressão das CLDNs, mais especificamente das CLDNs -1 e -2 (Sobel et al., 2005); para câncer de mama observou-se associação entre a expressão da CLDN-3 e casos precoces da doença (Danzinger et al., 2019).

No carcinoma epidermoide da mucosa oral, já foi observado que ocorre uma diminuição da sua expressão em áreas de invasão tumoral e esta expressão é ausente em tumores pouco diferenciados (Lourenço et al., 2010), outro estudo notou que a presença intracelular da CLDN-1 está associada com metástase em linfonodos em carcinoma epidermoide de língua (Yamamoto et al., 2019).

No CME já foi observado que a alta expressão da proteína CLDN-1 está relacionada com tumores de baixo grau e que a alta expressão da proteína CLDN-3 se relaciona com tumores de grau intermediário e de alto grau (Aro et al., 2011).

Existem várias cascatas moleculares que podem afetar a expressão das proteínas CLDNS, como a cascata da proteína-quinase (MAPK), a cascata da proteína-fosfatase e a cascata da proteína-G; também estão relacionadas a regulação dessas proteínas fatores de crescimento epidérmico e cascatas moleculares relacionadas a microRNAs (Singh et al., 2007; Singh; Dhawan, 2015).

\subsection{Receptor de Fator de Crescimento Epidérmico - EGFR}

O receptor de fator de crescimento epidérmico (EGFR - epidermal growth factor receptor) é uma glicoproteína transmembrânica de $170 \mathrm{kDa}$ codificada pelo gene ErB1, na região 7 p12 do cromossomo 7. O EGFR possui uma região extracelular, uma porção transmembrânica e um domínio tirosina quinase 
citoplasmático (Jorissen et al., 2003), e é um receptor de tirosina quinase de superfície celular que pertence à família de receptores ErbB (Yano et al., 2003).

Os ligantes extracelulares específicos (EGF, TGF-ạ, anfirregulina, betacelulina, heparina ou epirregulina) se ligam ao domínio extracelular do EGFR e isso leva à sua ativação, o que culmina na auto-fosforilação do seu domínio tirosina quinase iniciando uma cascata de sinalização intracelular que leva a processos diversos como crescimento, proliferação, apoptose, adesão, migração e diferenciação (Capdevila et al., 2009; Linggi; Carpenter, 2006; Anderson et al., 2004; Artega, 2002).

O ligante extracelular EGF (fator de crescimento epidérmico ou epidermal growth factor), é uma proteína que age como um fator mitogênico muito importante no crescimento, proliferação e diferenciação celular (Lindsey; Langhans, 2015; Alberts et al., 2010).

O EGFR é expresso em tecidos de origem epidérmica, mesenquimal e neuronal, estando intrinsicamente associado ao crescimento, desenvolvimento e diferenciação desses tecidos (Yano et al., 2003). A ativação dele desencadeia uma cascata de reações que ativa, entre outras, a via RAS-RAF-MEK-MAPK que induz multiplicação celular; a ativação dessa via atua em eventos que podem levar a proliferação, adesão e invasão celular (da Cunha Santos et al., 2011; Yarden, 2001).

Drogas antagonistas do EGFR fazem parte de protocolos de tratamentos do carcinoma epidermoide de cabeça e pescoço (Ciardello; Tortora, 2008) e sua superexpressão está associada com um pior prognóstico em câncer de cabeça e pescoço (Kalyankrishna; Grandis, 2006); em CME de glândulas salivares a expressão do EGFR está, em geral, associada a tumores de alto grau (Gibbons et al., 2001; Shang et al., 2007; Lujan et al., 2010).

O EGFR representa um papel importante no desenvolvimento e crescimento de neoplasias malignas, por estar associado a proliferação de células malignas, angiogênese e metástase. Fatores como a desregulação na sinalização do EGFR e ativação imunológica podem facilitar a progressão do câncer (Singh et al., 2007; Dhawan et al., 2011). Apesar disso, existem outros mecanismos como os microRNAs que podem atuar em genes específicos do ciclo celular e podem estar associados aos processos de regulação de neoplasias (Mraz; Pospisilova, 2012; Wilmott et al., 2011). 


\section{9 microRNAs}

Os microRNAs (miRNAs) foram descobertos em 1993 e surgiram como uma nova classe de reguladores gênicos que modulam e controlam a atividade de muitos mRNAs (Lee et al., 1993). Eles representam uma grande família de pequenas sequências de RNAs constituídas por, aproximadamente, 19 a 25 nucleotídeos por cadeia que não são traduzidas em proteínas. Acredita-se que o genoma humano codifica mais de 2570 miRNAs e o número de genes codificadores de proteínas cuja regulação envolve os miRNAs tem aumentado conforme novos estudos são realizados (Bartel, 2009).

O princípio básico de regulação gênica ocorre da seguinte forma: O miRNA é transcrito a partir do DNA através de uma RNA polimerase II. O RNA constitui uma estrutura em formato de grampo (Pri-miRNA) que é processado por uma RNAse (Drosha) ainda no núcleo da célula formando o Pre-miRNA e este, então, é exportado para o citoplasma da célula onde sofre outra clivagem através da ação da enzima Dicer, que também é uma RNAse. A dupla fita de RNA formada é então carregada no complexo ribonucleoprotéico RISC (RNA-induced silencing complex ou complexo de silenciamento induzido por RNA), onde somente uma das fitas duplicadas permanecerá. A fita, então se liga a região $3^{\prime} U T R$ de um mRNA complementar a ela, bloqueando a tradução, o que conduz ao silenciamento gênico ou a inibição da tradução (Stroynowska-Czerwinska et al., 2014; Takahashi et al., 2014). A Figura 2.7 ilustra este processo.

Para que ocorra o pareamento do miRNA com a região 3', ele precisa se ligar a uma região denominada seed, essa região é importante para a associação com o mRNA alvo. O processo de formação do miRNA conta com variadas proteínas que atuam como suas reguladoras, essas proteínas podem ser específicas para determinadas famílias de miRNA ou atuarem de forma mais ampla e assim, afetar a expressão de muitos genes de variados miRNAs (Hammond, 2015; Krol et al., 2010).

Muitos miRNAs atuam na regulação da expressão de RNAs no interior das células onde são produzidos, mas alguns são exportados para células alvo no interior de exossomos que são vesículas medindo de 40 a $100 \mathrm{~nm}$ formadas a partir de endossomos de células secretoras (Chen at al., 2012; Vishnoi; Rani, 2017). 
Os miRNAs são moléculas importantes em vários processos celulares, como a diferenciação, a proliferação, a apoptose e a tumorigênese. Existem dois mecanismos pós-transcricionais pelos quais o complexo RISC pode regular a expressão gênica, são a degradação e a repressão da tradução do mRNA alvo (Zhang et al., 2007). Em humanos, a maioria dos mRNAs é processada pela repressão da tradução do mRNA sem que ocorra degradação de sua fita (Zhang et al., 2007; Engels; Hutvagner, 2006). Eles atuam interferindo em genes específicos do ciclo celular, ajudando na regulação de neoplasias (Mraz; Pospisilova, 2012; Wilmott et al., 2011).

Sabe-se que existe associação entre a expressão desregulada de miRNAs e o surgimento de câncer, isso foi primeiramente demonstrado na leucemia, onde ocorreu a perda de expressão do grupo miR-16/miR-16, e em câncer de pulmão, com a perda de expressão do let-7 (Calin et al., 2002; Takamizawa et al., 2004). A perda de expressão de um miRNA pode levar a diminuição da tradução de um gene supressor tumoral, os miRNAs relacionados com esse processo recebem a denominação de oncomiRs (Esquela-Kerscher; Slack, 2006). Um grupo de oncomiRs associados a características tumorais de agressividade é o miR-17-92, participa desse grupo o miRNA-18a (Swierniak et al., 2013).

\subsection{1 microRNA-18a}

O grupo miRNA-17-92 apresenta sete membros sendo estes o miRNA-17-5p, o miRNA-17-3p, o miRNA-19a, o miRNA-19b, o miRNA-20a, o miRNA-92a e o miRNA-18a. São miRNAs que possuem um papel importante na função de oncogenes ou na função de supressores em diferentes neoplasias (Mogilyansky; Rigoutsos, 2013; Xiang; Wu, 2010). Alterações na expressão desse grupo de miRNAs são notadas em uma ampla gama de neoplasias de característica mais agressiva, como em câncer de pulmão, em linfoma e em carcinoma anaplasico de tiroide (Hayashita et al., 2005; He et al., 2005; Volinia et al., 2006; Takakura et al., 2008).

Já se sabe que o grupo miRNA-17-92 atua na modulação da expressão de genes supressores de tumor como o PTEN, que age como supressor da via 
AKT/PI3K, esse grupo também atua na expressão do gene CDKN1A (p21), que possui um importante papel como bloqueador da progressão do ciclo celular e atua em outros genes associados ao processo de apoptose (Mendell, 2008), essas características deixam claras a importância e envolvimento desse grupo de miRNAs em processos de tumorigênese.

Figura 2.7 - Biogênese do miRNA

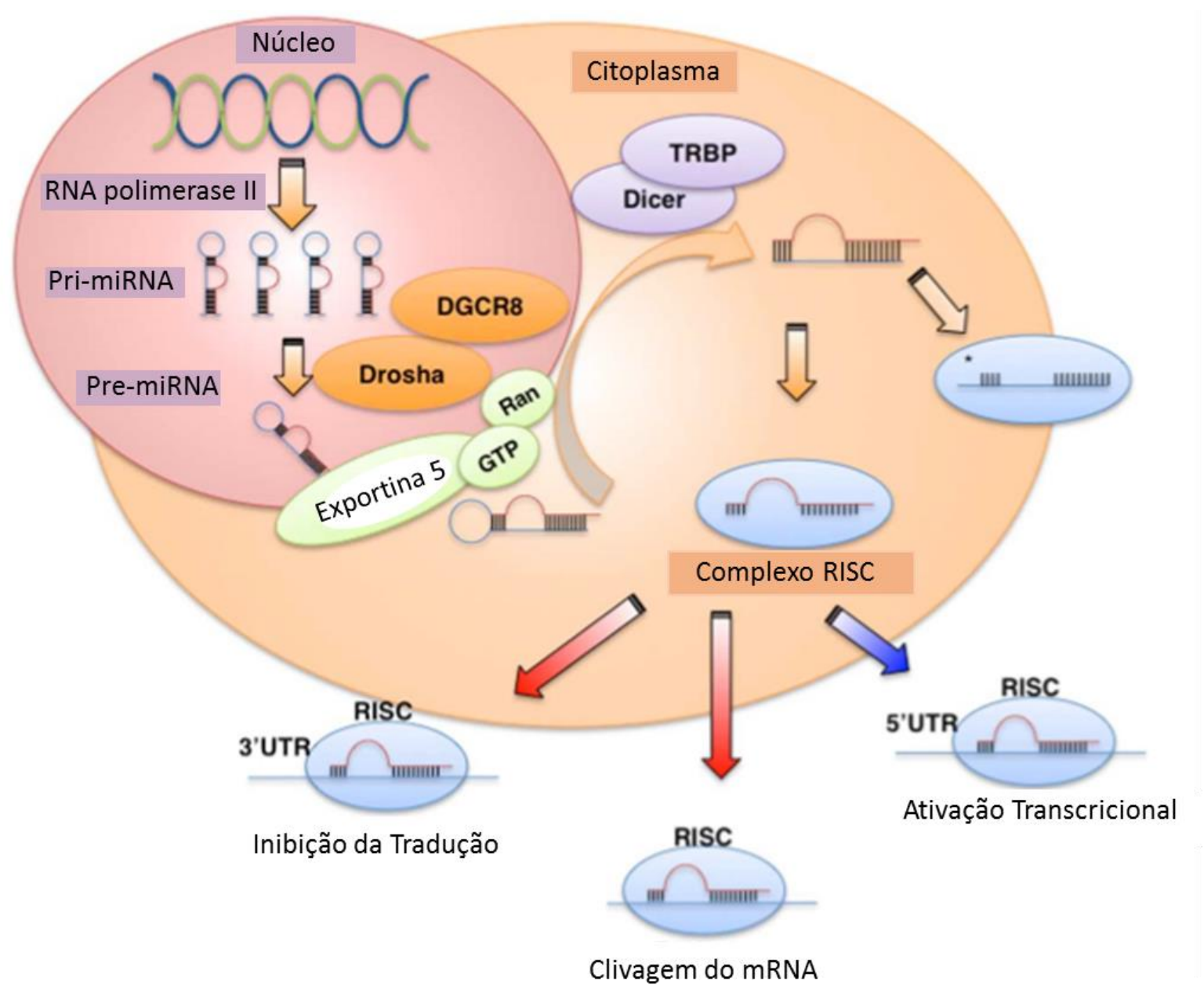

Fonte: Takahashi et al., Front Genet, 2014

O miRNA-18a é um dos miRNAs mais expressos do seu grupo, e é comumente encontrado em várias neoplasias malignas humanas, estando envolvido em processos patológicos que podem levar ao desenvolvimento do câncer como a ativação de vias de sinalização de proliferação celular, migração, invasão, apoptose 
e o fenômeno de TEM (Shen et al., 2019; Komatsu et al., 2014; Morimura et al., 2011, Hirajima et al., 2013).

A progressão do câncer de pulmão sofre influência direta do miRNA-18a (Liang et al., 2017; Savitsky et al., 2010), no câncer de pulmão foi observado que a superexpressão do miRNA-18a se associa positivamente com o EGFR levando a um processo de autofagia (Savitsky et al., 2010), em contrapartida o miRNA-18a promove a inibição da progressão do câncer colorretal e do câncer de mama (Humphreys et al., 2014; Zhang et al., 2019). A verificação desses achados mostrou que o miRNA-18a pode apresentar um papel duplo no processo de tumorigênese, em alguns casos ativando oncogenes e em outros inibindo oncogenes nas diferentes neoplasias (Shen et al., 2019).

Outra importante verificação sobre o miRNA-18a é a possibilidade de utiliza-lo como biomarcador, esse potencial já foi elucidado para alguns tipos de câncer como o câncer de pulmão e o câncer gástrico (Ullivi et al., 2013; Tsujiura et al., 2015).

Apesar de ser notável a importância da regulação genica exercida pelo miRNA-18a no processo de tumorigênese nas mais diversas neoplasias (Shen et al., 2019; Komatsu et al., 2014; Morimura et al., 2011, Hirajima et al., 2013), sua expressão no CME derivado das glândulas salivares ainda não foi determinada. 



\section{PROPOSIÇÃO}

Para testar a hipótese de influência das claudinas no comportamento do carcinoma mucoepidemoide das glândulas salivares, essa pesquisa pretendeu responder se a junção compacta está relacionada ao processo de desenvolvimento do carcinoma mucoepidermoide e se fatores de crescimento podem interferir na expressão das proteínas da junção compacta e do microRNA-18a nesta neoplasia.

\subsection{Objetivos gerais}

O objetivo deste trabalho foi avaliar a expressão das proteínas claudinas e do microRNA-18a e sua relação com o EGFR em carcinoma mucoepidermoide oral.

\subsection{Objetivos específicos}

1. Analisar o padrão da expressão das proteínas claudinas $-1,-3,-4,-5$ e -7 e do EGFR no carcinoma mucoepidermoide oral através da técnica de imunoistoquímica.

2. Analisar a influência do EGFR na regulação da expressão das proteínas claudinas in vitro.

3. Determinar se há expressão do microRNA-18a no carcinoma mucoepidermoide oral e a influência do EGFR na sua expressão in vitro. 



\section{MATERIAL E MÉTODOS}

\subsection{Organograma}

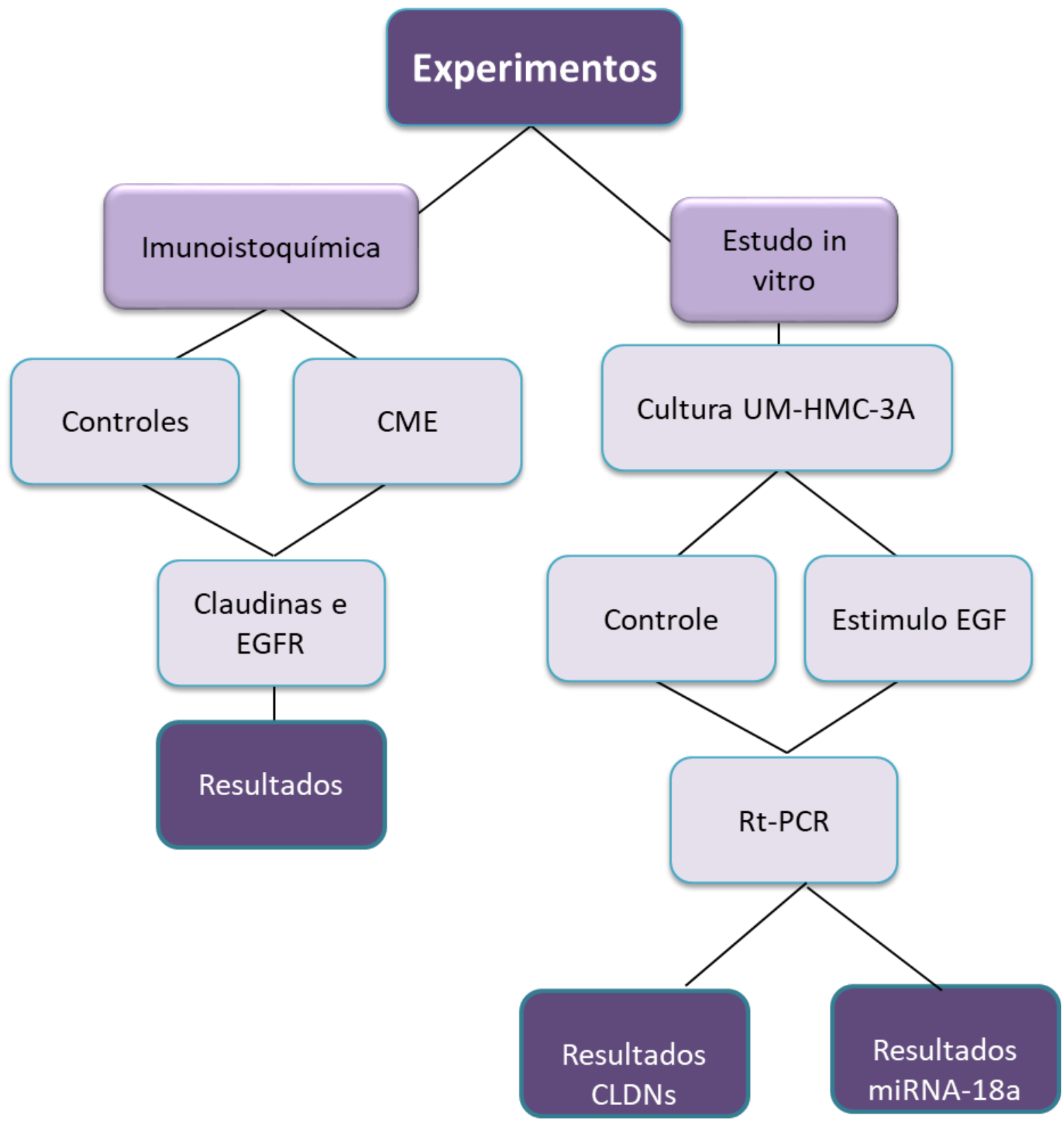




\subsection{Casuística}

Este trabalho foi aprovado pelo Comitê de Ética em Pesquisa da Faculdade de Odontologia da USP, sob parecer 1.774.954 e pelo Comitê de Ética em Pesquisa do A. C. Camargo Cancer Center, sob parecer 1.982.129

Os casos deste estudo foram selecionados a partir de uma amostra de 58 CME orais selecionados previamente pelo nosso grupo dos quais 36 apresentavam material suficiente para a realização da pesquisa. Todos os casos foram diagnosticados no Serviço de Patologia Cirúrgica do A. C. Camargo Cancer Center e as amostras teciduais encontravam-se fixadas em formol e emblocadas em parafina. Para a análise morfológica foram utilizadas lâminas histológicas coradas por hematoxilina e eosina que foram recuperadas dos arquivos do serviço, cujos blocos pertencem ao arquivo do Serviço de Patologia Cirúrgica do A. C. Camargo Cancer Center. Além disso, foram investigados os dados clínicos dos prontuários dos pacientes incluídos no estudo, tais como idade, sexo, cor da pele e hábitos, quando estes dados estavam presentes.

Critérios de inclusão: Foram considerados casos aceitos para este estudo todos aqueles que receberam como diagnóstico final 0 de carcinoma mucoepidermoide oral.

Critérios de exclusão: Foram excluídos deste estudo os casos cujos blocos de parafina apresentaram material insuficiente para realização dos ensaios propostos.

Para controle, foram selecionados 5 cortes histológicos que apresentavam parênquima glandular sem alteração.

\subsection{Análise morfológica}

Para a realização da graduação histológica, foram utilizados cortes de $5 \mu \mathrm{m}$ corados pelo método da hematoxilina e eosina (lâminas do arquivo do Serviço) que foram examinados ao microscópio de luz. Em cortes não homogêneos, a área selecionada para graduação foi aquela com maior número de alterações. As lesões 
foram classificadas em CME de baixo grau, de grau intermediário e de alto grau conforme proposto pela Organização Mundial da Saúde (El-Naggar et al., 2017).

A seguir, uma descrição da classificação segundo a Organização Mundial da Saúde, 2017

- CME de baixo grau: presença de componente mucoso proeminente, ninhos tumorais bem circunscritos e abundantes, espaços císticos frequentes, baixa atividade mitótica e pouca atipia citológica;

- CME de grau intermediário: menor frequência de células mucosas e de cistos, população proeminente de células intermediárias, ninhos celulares mais irregulares, atipia celular mais pronunciada;

- CME de alto grau: mais sólidos, maior quantidade de células epidermoides, presença de anaplasia celular, necrose e alta contagem mitótica.

\subsection{Imunoistoquímica}

Os blocos de parafina contendo as lesões que foram selecionadas foram recuperados dos arquivos do Serviço e novos cortes histológicos, com a espessura de $3 \mu \mathrm{m}$, foram obtidos utilizando-se um micrótomo e estendidos em lâminas tratadas pelo organosilano (3-aminopropyltriethoxysilane, DAKO).

A seguir, os cortes foram submetidos à técnica imunoistoquímica para pesquisa tecidual das proteínas CLDNs - $-1,-3,-4,-5$ e -7. A Tabela 4.1 apresenta as especificações dos soros primários utilizados nessa etapa do estudo.

Para a realização da técnica de imunoistoquímica, os cortes passaram por um processo de desparafinização, que consistiu em um banho de xilol por 30 minutos, seguido por um segundo banho de xilol por 30 minutos, e mais um banho de xilol por 15 minutos, todos em temperatura ambiente. $O$ processo seguinte foi a reidratação em cadeia descendente de etanóis (absoluto, 95\%, 90\%, 85\%, 80\%) em banhos de 5 minutos cada e um banho em hidróxido de amônio $10 \%$ em solução de etanol 95 은 para remoção do pigmento formólico por 10 minutos. As lâminas foram lavadas em água destilada por 5 minutos e foi realizado o tratamento de recuperação antigênica, utilizando-se o protocolo sumarizado na Tabela 4.1, em banho úmido aquecido a $95^{\circ} \mathrm{C}$, durante 20 minutos. Após nova lavagem das lâminas em água destilada por 
10 minutos, foi realizado o bloqueio da peroxidase endógena tecidual em solução de peróxido de hidrogênio a 10\% em 2 banhos de 10 minutos cada e solução de peróxido de hidrogênio a $20 \%$ em 2 banhos de 5 minutos cada. Após lavagem em água destilada por mais 5 minutos, as lâminas passaram por 3 banhos de 5 minutos com a solução tampão da reação TRIS (TRIS 50mM, NaCl 150mM), pH7,6.

\begin{tabular}{|c|c|c|c|c|}
\hline $\begin{array}{c}\text { Soro } \\
\text { primário }\end{array}$ & Clone & Diluição & Marca & $\begin{array}{c}\text { Recuperação } \\
\text { antigênica }\end{array}$ \\
\hline CLDN-1 & $\begin{array}{c}\text { Monoclonal } \\
\text { (EPRP18871) }\end{array}$ & $1: 250$ & Abcam, UK & EDTA, pH 7,0 \\
\hline CLDN-3 & Polyclonal & $1: 500$ & Neomarkers, USA & Citrato, $\mathrm{pH} 6,0$ \\
\hline CLDN-4 & Polyclonal & $1: 200$ & Neomarkers, USA & Citrato, $\mathrm{pH} 6,0$ \\
\hline CLDN-5 & Polyclonal & $1: 500$ & Neomarkers, USA & Citrato, $\mathrm{pH} 6,0$ \\
\hline CLDN-7 & Polyclonal & $1: 300$ & Zymed, USA & Citrato, $\mathrm{pH} 6,0$ \\
\hline EGFR & $\begin{array}{l}\text { Monoclonal } \\
\text { (EP38Y) }\end{array}$ & $1: 100$ & Abcam, UK & EDTA, pH7,0 \\
\hline
\end{tabular}

A seguir os cortes passaram pela incubação com os anticorpos primários, que foram diluídos em solução de TRIS (TRIS $50 \mathrm{mM}, \mathrm{NaCl} 150 \mathrm{mM}$ ), pH7,6, acrescido de albumina bovina a 1\% na proporção de 1:500. Os anticorpos foram incubados por 18 horas a $4^{\circ} \mathrm{C}$.

Após essa etapa, foi realizada a incubação do anticorpo de ligação biotinilado e do complexo terciário por meio do uso do sistema LSAB plus (DAKO, Carpinteria, CA, USA). Ambos foram incubados por 30 minutos a temperatura ambiente. Entre as etapas, os cortes foram lavados na solução tampão em três banhos de 5 minutos cada.

A diaminobenzidina (Liquid DAB plus, DAKO) foi o cromógeno da reação e foi incubado por 3 minutos e, após nova lavagem em solução tampão, os cortes foram contracorados com hematoxilina de Carazzi, desidratados em cadeia ascendentes de etanol, diafanizados em xilol e as lâminas foram montadas em resina Permount 
(Fischer Scientific, Waltham, MA, EUA) e protegidas por lamínulas para observação ao microscópio de luz.

Para o EGFR foram consideradas positivas as células que exibiram coloração acastanhada em núcleo ou membrana.

Para as CLDNs foi realizada uma análise semiquantitativa dos resultados. Toda a área da lamina histológica que continha a lesão foi avaliada e esta área recebeu a seguinte pontuação: Score 0 para os casos que apresentaram marcação imunoistoquímica < 1\%; 1 em casos de células com marcação positiva $\leq 30 \%$; 2 quando as células apresentavam marcação positiva $>30 \%$, o método de classificação por score para estas proteínas foi proposto e publicado previamente por Lourenco et al. (2010).

\subsection{Análise estatística da imunoistoquímica}

Para a análise estatística da associação entre os dados demográficos, dados clínicos e características patológicas dos pacientes e a expressão das proteínas CLDNs foram utilizados os testes chi-quadrado e exato de Fisher. O tempo de sobrevida livre de doença foi estimado pelo método de Kaplan-Meier e as curvas de Kaplan-Meier foram comparadas pelo teste de log-rank.

O nível de significância adotado foi $\mathrm{p} \leq 0,05$ para todas as análises estatísticas. Os testes estatísticos foram realizados com o auxílio software SPSS 25.0 (SPSS, Chicago, IL).

\subsection{Cultura de células}

Para a cultura de células, foi utilizada a linhagem de células de CME de glândulas salivares UM-HMC-3A gentilmente cedida pelo Dr Jacques E. Nör (Warner et al., 2013). As células foram cultivadas em garrafas de $75 \mathrm{~cm}^{2}$, em meio Dulbecco's Modified Eagle Medium - high glucose (DMEM; Gibco, Grand Island, NY, USA), suplementado com $10 \%$ de soro fetal bovino (FBS; Eurobio, Les Ulis, 
France), $1 \%$ de L-glutamina (Invitrogen), 1\% de estreptomicina (Invitrogen), 10ng/ml de EGF (EGF; Sigma-Aldrich, St. Louis, MO, USA), $50 \mathrm{ng} / \mathrm{ml}$ de hidrocortisona (Sigma-Aldrich) e $10 \mathrm{ng} / \mathrm{ml}$ de insulina (Sigma-Aldrich) e mantidas em estufa a $37^{\circ} \mathrm{C}$ e atmosfera de $5 \%$ de $\mathrm{CO}_{2}$.

As trocas de meio foram realizadas a cada $48 \mathrm{~h}$ e o crescimento celular foi avaliado a cada $24 \mathrm{~h}$. Foram realizadas passagens quando as células chegavam na confluência de $80 \%$ até o momento em que se obteve o número de células adequado para a realização do experimento. A determinação do número de células foi realizada por meio de contagem de células em câmara de Neubauer.

As células foram plaqueadas em placas de 6 poços (Techno Plastic Products AG-TPP, Zollstrasse, Trasadingen, Switzwerland) na concentração de 1,0 $\times 10^{4}$ células $/ \mathrm{cm}^{2}$. As células foram cultivadas no mesmo meio de cultura já citado e quando elas atingiram a confluência de $80 \%$, metade dos poços foi suplementado com $25 \mathrm{ng} / \mathrm{ml}$, $50 \mathrm{ng} / \mathrm{ml}$ e $100 \mathrm{ng} / \mathrm{ml}$ de EGF (EGF; Sigma-Aldrich, St. Louis, MO, USA) por $24 \mathrm{~h}$, a outra metade não recebeu a suplementação. Os experimentos foram realizados em triplicata.

\subsection{Extração do RNA}

O RNA foi extraído das amostras de cultura de células pelo método de Trizol (Invitrogen), por meio da técnica descrita a seguir: a monocamada de células foi colocada em tubo contendo $500 \mu \mathrm{l}$ da solução Trizol e incubada por 10 minutos à temperatura ambiente. Foi realizada a centrifugação do material com velocidade de $12000 \mathrm{~g}$, com temperatura de $4^{\circ} \mathrm{C}$, por $3 \mathrm{~min}$ e o sobrenadante foi transferido para outro tubo contendo $100 \mu \mathrm{l}$ de clorofórmio. Foi realizada outra centrifugação com velocidade de $12000 \mathrm{~g}$, com temperatura $4^{\circ} \mathrm{C}$, por $15 \mathrm{~min}$ e $\mathrm{o}$ sobrenadante transferido para outro tubo contendo $250 \mu$ l de isopropanol (volume/volume) e incubado por mais $10 \mathrm{~min}$ e em seguida centrifugado com velocidade de $12000 \mathrm{~g}$, com temperatura $4^{\circ} \mathrm{C}$, por $10 \mathrm{~min}$. Após centrifugação, o pellet foi lavado com etanol $75 \%$ e ressuspendido em $30 \mu \mathrm{l}$ de água tratada com dietilpirocarbonato (DEPC). A 
avaliação da qualidade dessas amostras foi feita no equipamento Nanodrop ND1000 (Nanodrop Technologies, Wilmington, DE).

\subsection{Tratamento com DNAse}

O RNA extraído das amostras de cultura de células, foi submetido ao tratamento com DNAse por meio da utilização do kit Deoxyribonuclease I, Amplification Grade (Invitrogen) para garantir uma maior pureza das amostras utilizadas; a técnica é descrita a seguir: Para cada $1 \mu \mathrm{l}$ de RNA foram utilizados $1 \mu \mathrm{l}$ de 10x DNAse I reaction buffer, $1 \mu$ l de DNAse I $(1 \mathrm{U} / \mu \mathrm{l})$ e água tratada com dietilpirocarbonato (DEPC) na quantidade necessária para se obter o volume final de $10 \mu \mathrm{l}$, para isso, foram adicionados ao tubo contendo o RNA a água, o buffer e a enzima. Elas foram incubadas por $15 \mathrm{~min}$ a temperatura ambiente, em seguida foi adicionado EDTA e incubado em termociclador (AppliedBiosystems) por 10min a $65^{\circ} \mathrm{C}$. Após isso, foram adicionados $25 \mu \mathrm{l}$ de etanol absoluto e $1 \mu \mathrm{l}$ de acetato de sódio e incubados por $18 \mathrm{~h} \mathrm{a}-20^{\circ} \mathrm{C}$. Após isso, as amostras foram centrifugadas com velocidade de $10000 \mathrm{rpm}$, com temperatura de $4^{\circ} \mathrm{C}$, por $15 \mathrm{~min}$, o sobrenadante foi descartado e o pellet foi lavado com $150 \mu$ l de etanol $75 \%$ e o RNA ressuspendido em $20 \mu \mathrm{l}$ de água tratada com dietilpirocarbonato (DEPC). A avaliação da qualidade dessas amostras foi feita no equipamento Nanodrop ND-1000 (Nanodrop Technologies, Wilmington, DE).

\subsection{Síntese do cDNA}

A reação de síntese do cDNA foi realizada conforme os procedimentos recomendados no manual dos "kits" High-Capacity cDNA Reverse Transcription (AppliedBiosystems) para as claudinas e TaqMan MicroRNA RT Reverse Transcription (AppliedBiosystems) para o miRNA, a seguir, descreveremos a técnica: 
Para as claudinas a reação foi feita em um volume final de $15,0 \mu$ l contendo 10ng de RNA total, $1,5 \mu \mathrm{l}$ de RT Buffer, $0,15 \mu \mathrm{l}$ de DNTP Mix (100 mM), 3,0 $\mu \mathrm{l}$ de Randon Primer, 1,0 $\mu \mathrm{l}$ da enzima MultiScribe Reverse Transcriptase, $0,19 \mu \mathrm{l}$ de inibidor de RNAse. A reação foi incubada a $16^{\circ} \mathrm{C}$ por 30 minutos, $42^{\circ} \mathrm{C}$ por 30 minutos e $85^{\circ} \mathrm{C}$ por 5 minutos em termociclador (AppliedBiosystems). A Beta-actin (ACTB) foi utilizada como gene de referência.

Para o miRNA a reação foi feita em um volume final de $15,0 \mu$ l contendo $10 \mathrm{ng}$

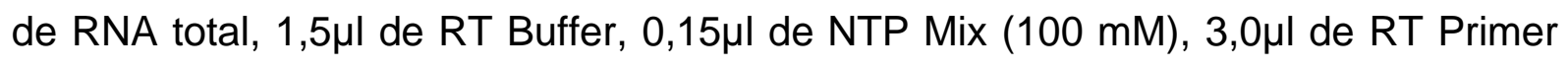
(stem-loop primer, específico para miRNA-18a e RNU48-miRNA endógeno), 1,0 $\mu$ la enzima MultiScribe Reverse Transcriptase, $0,19 \mu \mathrm{l}$ de inibidor de RNAse. A reação foi incubada a $16^{\circ} \mathrm{C}$ por 30 minutos, $42^{\circ} \mathrm{C}$ por 30 minutos e $85^{\circ} \mathrm{C}$ por 5 minutos em um termociclador (AppliedBiosystems).

Para as claudinas, foi sintetizado apenas o cDNA das amostras tratadas com $100 \mathrm{ng}$ de EGF e seus controles. Para o miRNA foi sintetizado o cDNA para todas as amostras e seus controles (tratados com 25ng/ml, 50ng/ml e 100ng/ml de EGF).

\subsection{PCR em tempo real}

A análise da expressão dos genes das CLDN-1, -3, -4, -5 e -7 foi realizada com auxílio do Taqman Gene Expression Assays no aparelho 7900HT Fast RealTime PCR System (AppliedBiosystems). A amplificação foi feita em 40 ciclos de $95^{\circ} \mathrm{C}$ por 15 segundos e $60^{\circ} \mathrm{C}$ por 1 minuto, precedidos por um período de $50^{\circ} \mathrm{C}$ por 2 minutos e $95^{\circ} \mathrm{C}$ por 10 minutos. Os resultados foram analisados utilizando-se $\mathrm{o}$ software RQ Manager 1.2 (AppliedBiosystems). A ACTB foi usada como gene de referência. $A$ análise da expressão genica foi realizada com auxílio do método $\Delta \Delta \mathrm{Ct}$ (Livak et al., 2001) e os dados foram analisados usando o software RQ Manager 1.2 (AppliedBiosystems). As reações foram feitas em duplicata.

A análise do miRNA foi feita com auxílio do Taqman Human microRNA Assay no aparelho 7900HT Fast Real-Time PCR System (AppliedBiosystems). A amplificação foi feita em 40 ciclos de $95^{\circ} \mathrm{C}$ por 15 segundos e $60^{\circ} \mathrm{C}$ por 1 minuto, precedidos por um período de $50^{\circ} \mathrm{C}$ por 2 minutos e $95^{\circ} \mathrm{C}$ por 10 minutos. Os

resultados foram analisados utilizando-se 0 software $R Q$ Manager 1.2 
(AppliedBiosystems). O nível de expressão do miRNA foi quantificado relativamente à expressão de um microRNA controle (RNU48) e também foi normalizado de acordo com um miRNA calibrador. O resultado final ( $\mathrm{n}$ miRNA) foi expresso como um aumento ou diminuição da expressão de um miRNA em n-vezes quando comparado ao controle e ao calibrador, da seguinte forma: $n$ miRNA $=2-(\Delta C t$ amostra $-\Delta C t$ calibrador), onde $\Delta \mathrm{Ct}$ da amostra e do calibrador são determinados subtraindo-se o valor médio de $\mathrm{Ct}$ do miRNA estudado do valor médio de Ct do miRNA usado como controle. As reações foram feitas em duplicata.

\subsection{Análise estatística da PCR em tempo real}

Para a análise estatística do efeito do EGF na expressão das CLDNs e do miRNA-18a na linhagem celular UM-HMC-3A foi utilizado o teste de Wilcoxon, considerando o nível de significância de 0,05 para todas as análises estatísticas. O teste estatístico foi realizado com o auxílio software SPSS 25.0 (SPSS, Chicago, IL) e os gráficos desses resultados foram obtidos com auxílio do software $R$. 



\subsection{Casuística}

Para este trabalho foram utilizados 36 casos de lesões diagnosticadas como CME oral que foram diagnosticados pelo Serviço de Anatomia Patológica do A. C. Camargo Cancer Center. Foi realizada a graduação histológica das 36 lesões utilizando-se o sistema da OMS (El-Naggar et al., 2017). Dos casos estudados, 6 (16,7\%) foram considerados como CME de baixo grau, 14 (38,9\%) como CME de grau intermediário e $16(44,4 \%)$ como CME de alto grau, segundo o sistema da OMS (El-Naggar et al., 2017). O Gráfico 5.1 e a Tabela 5.1 nos apresenta um panorama desses achados.

Gráfico 5.1 - Graduação histológica da amostra segundo o sistema da OMS (EI-Naggar et al., 2017)

\section{Graduação histológica}

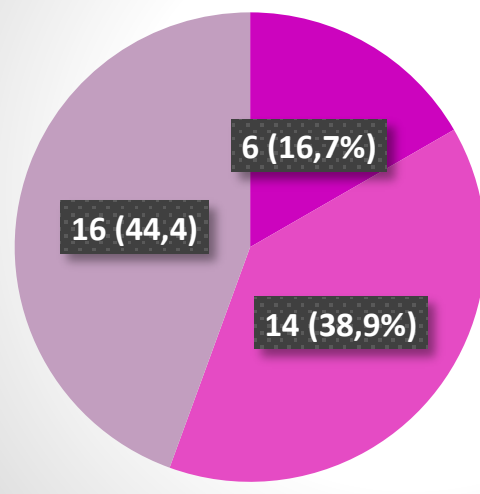

- Baixo grau

- Grau intermediário

$\square$ Alto grau

\subsection{Dados clínicos dos pacientes}

As informações clinicas dos 36 pacientes que foram inclusos nesse estudo foram levantadas, entretanto, alguns prontuários não se apresentavam preenchidos 
de forma satisfatória, o que resultou na perda de algumas informações de alguns pacientes. Das características avaliadas observou-se que mais da metade dos pacientes estudados tinha mais de 40 anos de idade (19 casos ou $52,8 \%$ dos casos), também foi notado que a maioria dos pacientes estudados era do sexo feminino (20 casos ou $55,6 \%$ dos casos) e se declaravam brancos (31 casos ou $86,1 \%$ dos casos). As localizações mais comuns foram a glândula parótida e as glândulas salivares menores, as duas juntas somaram 32 casos ( $88,9 \%$ dos casos), houve recorrência em 6 casos (16,7\% dos casos) e metástases em linfonodos em 12 casos (33,3\%). O número de pacientes que foi a óbito em decorrência de complicações do câncer foi de 10 casos ( $27,8 \%$ dos casos). A Tabela 5.1 apresenta esses dados.

Tabela 5.1 - Caracterização da amostra de cortes histológicos contendo CME

\begin{tabular}{|c|c|c|}
\hline Características & Categoria & No. de pacientes \\
\hline \multirow[t]{3}{*}{ Graduação histológica } & Baixo grau & $6(16,7 \%)$ \\
\hline & Grau intermediário & $14(38,9 \%)$ \\
\hline & Alto grau & $16(44,4 \%)$ \\
\hline \multirow[t]{3}{*}{ Idade } & $\leq 40$ & $16(44,4 \%)$ \\
\hline & $>40$ & $19(52,8 \%)$ \\
\hline & $\mathrm{NI}$ & $1(2,8 \%)$ \\
\hline \multirow[t]{2}{*}{ Sexo } & Masculino & $16(44,4 \%)$ \\
\hline & Feminino & $20(55,6 \%)$ \\
\hline \multirow[t]{3}{*}{ Cor da pele } & Branco & $31(86,1 \%)$ \\
\hline & Não branco & $3(8,3 \%)$ \\
\hline & $\mathrm{NI}$ & $2(5,6 \%)$ \\
\hline \multirow[t]{2}{*}{ Localização do tumor } & Parótida & $16(44,4 \%)$ \\
\hline & Outras glândulas & $20(55,6 \%)$ \\
\hline \multirow[t]{3}{*}{ Recorrência } & Não & $16(44,4 \%)$ \\
\hline & Sim & $6(16,7 \%)$ \\
\hline & $\mathrm{NI}$ & $14(38,9 \%)$ \\
\hline \multirow[t]{3}{*}{ Metástase em linfonodo } & Não & $11(30,6 \%)$ \\
\hline & Sim & $12(33,3 \%)$ \\
\hline & $\mathrm{NI}$ & $13(36,1 \%)$ \\
\hline \multirow[t]{4}{*}{ Situação do paciente } & Vivo sem doença & $14(38,9 \%)$ \\
\hline & Morto pelo câncer & $10(27,8 \%)$ \\
\hline & Morto outras causas & $4(11,1 \%)$ \\
\hline & $\mathrm{NI}^{*}$ & $8(22,2 \%)$ \\
\hline
\end{tabular}

${ }^{*} \mathrm{NI}$ indica os casos em que não foi possível recuperar os dados 


\subsection{Imunoistoquímica}

Para a análise tecidual da expressão das CLDNs $-1,-3,-4,-5$ e -7 , os 36 casos selecionados para esta pesquisa foram submetidos à técnica imunoistoquímica (Tabela 4.1). Todas as CLDNs pesquisadas estavam presentes nos espécimes analisados e nos controles.

Nas glândulas salivares sem alterações, utilizadas como controles, as proteínas foram observadas contornado a membrana celular das células que formam o ducto salivar de glândulas salivares sem alteração. A CLDN-1 apresentou marcação difusa na membrana celular das células do ducto salivar; a CLDN-3 também apresentou positividade para as células ductais; a CLDN-4 se encontrava expressa na membrana celular das células ductais; na CLDN-5 a expressão foi positiva no citoplasma e na membrana celular das células ductais; e para a CLDN-7 foi observada positividade em áreas focais com expressão fraca nas células ductais. Esses achados podem ser observados na Figura 5.1.

No caso do CME, as CLDNs também se mostraram positivas para todos os 36 casos incluídos nesse estudo, elas foram observadas na membrana celular e/ou no citoplasma das células da neoplasia, a imunomarcação foi observada quase que exclusivamente em células epidermoides e células intermediarias, a marcação em células mucosas foi muito pequena.

A CLDN-1 apresentou marcação forte e com distribuição difusa ao redor da membrana celular das células epidermoides e células intermediarias; a CLDN-3 foi intensamente positiva na membrana celular das ilhas de células epidermoides da lesão e nas células intermediarias; a CLDN-4 apresentou uma distribuição difusa tanto no citoplasma quanto na membrana celular de células epidermoides e células intermediárias; a CLDN-5 apresentou distribuição difusa no citoplasma e na membrana celular das ilhas de células epidermoides; a CLDN-7 apresentou marcação positiva na membrana celular das células que compõem o tumor, inclusive para células mucosas no caso do CME de baixo grau. Os resultados podem ser observados na Figura 5.1. 
Figura 5.1 - Marcação imunoistoquímica: A - CLDN1 em CME de grau intermediário: distribuição ampla em torno da membrana celular de células epidermoides e intermediárias (Magnificação original 200x); B - CLDN1 em glândula salivar: ampla distribuição na membrana celular das células ductais (Magnificação original 400x); C - CLDN3 em CME de alto grau: marcação na membrana celular das células epidermoides e intermediárias das ilhas tumorais (Magnificação original 400x): D - CLDN3 em glândula salivar: células ductais marcadas (Magnificação original 400x); E1 - CLDN4 em CME de alto grau: ampla distribuição em citoplasma e membrana celular das células epidermoides e intermediárias (Magnificação original 400x); E2 - CLDN4 em CME de baixo grau: ampla distribuição em citoplasma e membrana celular das células epidermoides e intermediárias (Magnificação original 400x); F - CLDN4 em glândulas salivares: células ductais apresentando marcação em membrana (Magnificação original 400x); G1 CLDN5 no CME de alto grau: ampla distribuição no citoplasma e membrana celular das células epidermoides das ilhas tumorais (Magnificação original 400x); G2 - CLDN5 em CME de baixo grau: ampla distribuição nas células intermediárias (Magnificação original 400x); H - CLDN5 em glândula salivar: marcação no citoplasma e membrana celular das células ductais (Magnificação original 400x); I1 - CLDN7 em CME: marcação positiva em membrana celular das células tumorais, incluindo células mucosas (Magnificação original 400x); I2 - CLDN7 em CME: marcação em membrana celular das células intermediárias (Magnificação original 400x); J - CLDN7 na glândula salivar: áreas focais de marcação fraca nas células ductais (Magnificação original 400x) 

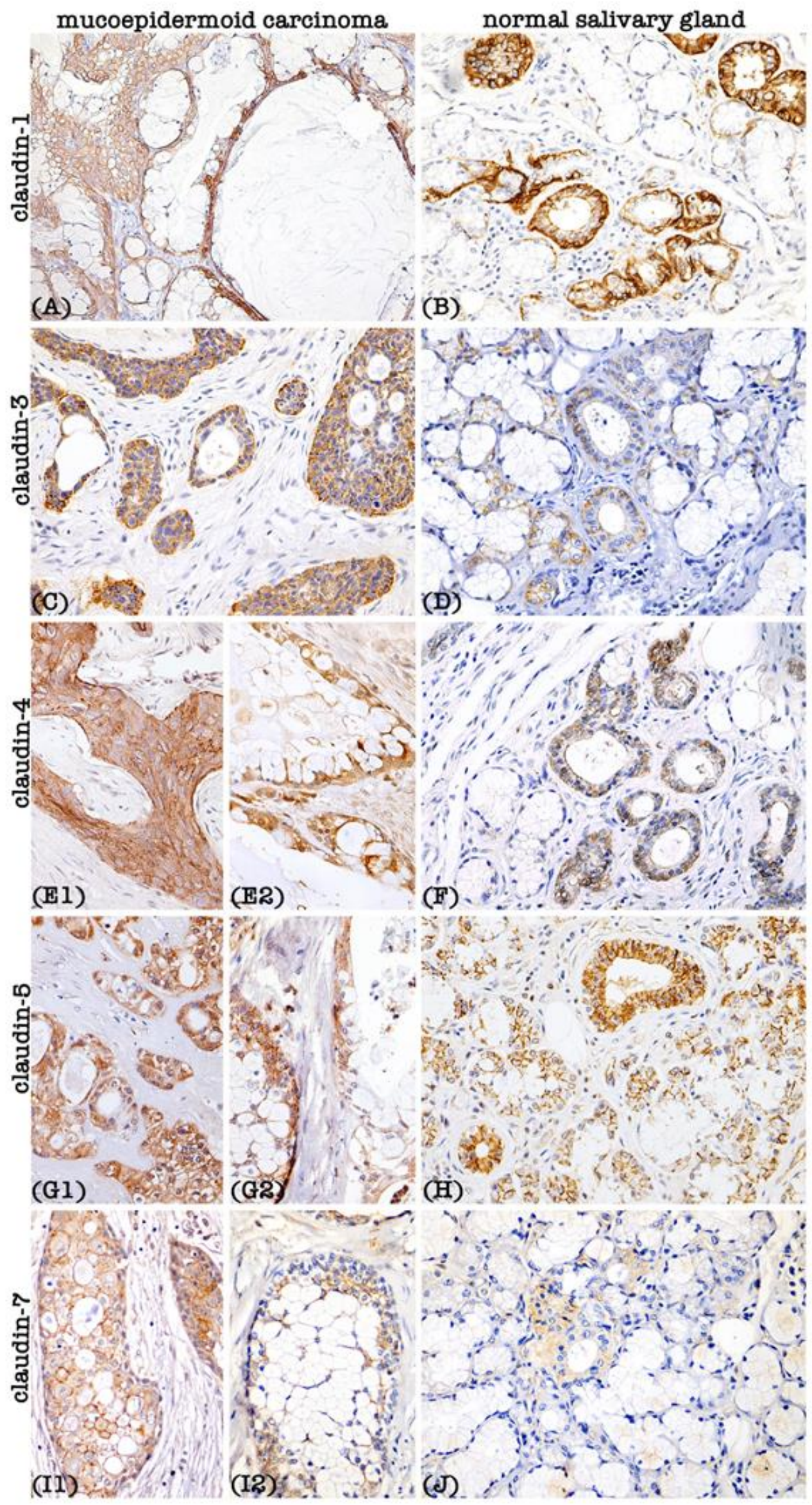
Para a pesquisa da expressão tecidual do receptor de EGF (EGFR), os 36 casos estudados apresentaram marcação positiva sem que houvesse distinção relacionada ao grau histológico da lesão. A marcação ocorreu principalmente na membrana das células epidermoides do CME. Também ocorreu marcação ductal, tanto dos ductos presentes na lesão, como daqueles presentes em glândulas salivares sem alteração adjacentes à lesão. Não houve marcação positiva para as células mucosas. A Figura 5.2 exemplifica esses resultados.

Figura 5.2 - Marcação imunoistoquímica para o anticorpo anti-EGFR em CME: A - marcação positiva da membrana das células epidermoides (Magnificação original 100x); B - marcação positiva das células intermediárias e negativa das células mucosas (Magnificação original 400x)
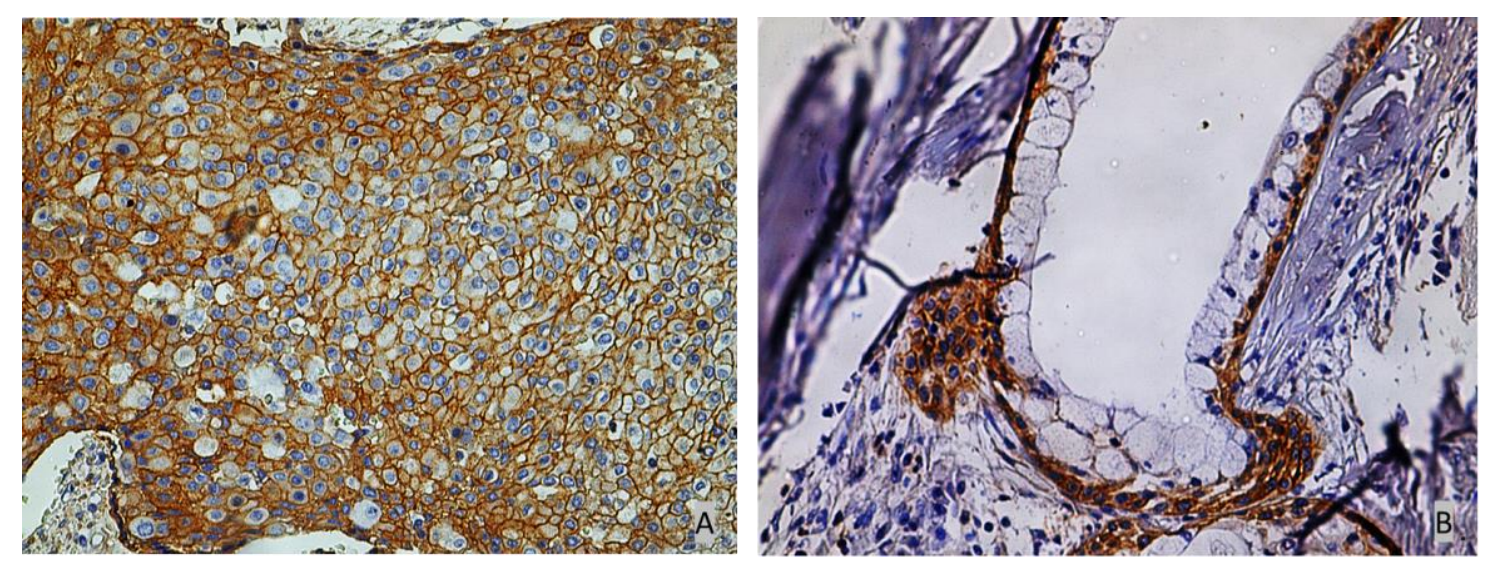

Não houve diferença estatisticamente significante na presença do EGFR entre os graus histológicos da lesão pois o que foi avaliado no caso desse anticorpo foi se ele apresentaria ou não marcação positiva nas células do tumor; e ele se encontrou expresso em todos os casos estudados.

Foi realizada a análise semiquantitativa como proposto em Lourenço et al. (2010), e observou-se que a grande maioria dos casos recebeu score 2 para todas as CLDNs estudadas. Para a CLDN-1, 5,6\% dos casos receberam score $0,25 \%$ dos casos receberam score 1 e $69,4 \%$ dos casos receberam score 2; para a CLDN-3, $25 \%$ dos casos receberam score 1 e $75 \%$ dos casos receberam score 2; para a CLDN-4, 2,8\% dos casos receberam score 1 e 97,2\% dos casos receberam score 2; para a CLDN-5, 19,4\% dos casos receberam score 1 e $80,6 \%$ dos casos receberam score 2; para a CLDN-7, 2,8\% dos casos receberam score $0,25 \%$ dos casos 
receberam score 1 e $72,2 \%$ dos casos receberam score 2 . Os dados são apresentados na Tabela 5.2.

Tabela 5.2 - Analise semiquantitativa da expressão das CLDNs no CME das glândulas salivares

\begin{tabular}{cccc}
\hline Proteína & $\begin{array}{c}\text { Marcação < 1\%: } \\
\text { score 0, } \mathbf{n}(\%)\end{array}$ & $\begin{array}{c}\text { Marcação } \leq \\
\mathbf{3 0 \%} \text { : score 1, n } \\
(\%)\end{array}$ & $\begin{array}{c}\text { Marcação > 30\%: } \\
\text { score 2, n (\%) }\end{array}$ \\
\hline CLDN-1 & $2(5,6)$ & $9(25,0)$ & $25(69,4)$ \\
CLDN-3 & $0(0,0)$ & $9(25,0)$ & $27(75,0)$ \\
CLDN-4 & $0(0,0)$ & $1(2,8)$ & $35(97,2)$ \\
CLDN-5 & $0(0,0)$ & $7(19,4)$ & $29(80,6)$ \\
CLDN-7 & $1(2,8)$ & $9(25,0)$ & $26(72,2)$ \\
\hline
\end{tabular}

\subsection{Relação entre a expressão das claudinas e os dados clínicos e histopatológicos}

A expressão das CLDNs foi associada com as características patológicas, clinicas e demográficas da população estudada. Apesar da maior parte dos casos estudados terem recebido graduação histológica de alto grau, esta não apresentou associação estatisticamente significante com a expressão das CLDNs, o valor de $p$ pode ser observado na Tabela 5.3.

O sexo dos pacientes que foram inclusos nesse estudo também não pode ser associado com a expressão das CLDNs, já a associação da idade dos pacientes com a expressão dessas proteínas foi estatisticamente significante para a alta expressão (score 2) de CLDN-1, ela está associada a pacientes com mais de 40 anos $(p=0,050)$. A alta expressão da CLDN-1 também pode ser associada com pacientes de pele branca $(p=0,024)$. Os dados podem ser observados na Tabela 5.3. 

Tabela 5.3 - Associação entre a expressão das CLDNs e as características demográficas, clinicas e patológicas dos pacientes com CME das glândulas salivares

\begin{tabular}{|c|c|c|c|c|c|c|c|c|c|c|c|c|c|}
\hline Característic. & Categoria & $\begin{array}{l}\text { Pacient. } \\
\text { (n) }\end{array}$ & Imuno Score & $\begin{array}{l}\text { Claudina } 1, \\
\text { no. de casos }\end{array}$ & $\begin{array}{l}\text { Valor de } \\
\mathbf{p}\end{array}$ & $\begin{array}{l}\text { Claudina } \\
3, \text { no. de } \\
\text { casos }\end{array}$ & $\begin{array}{l}\text { Valor de } \\
\mathbf{p}\end{array}$ & $\begin{array}{l}\text { Claudina } \\
4, \text { no. de } \\
\text { casos }\end{array}$ & $\begin{array}{l}\text { Valor de } \\
\mathbf{p}\end{array}$ & $\begin{array}{l}\text { Claudina } \\
5, \text { no. de } \\
\text { casos }\end{array}$ & $\begin{array}{l}p \text { valor de } \\
p\end{array}$ & $\begin{array}{l}\text { Claudina } \\
7 \text {, no. de } \\
\text { casos }\end{array}$ & $\begin{array}{l}\text { Valor de } \\
\mathbf{p}\end{array}$ \\
\hline \multirow[t]{9}{*}{$\begin{array}{l}\text { Graduação } \\
\text { histológica }\end{array}$} & Baixo & 6 & 0 & 0 & & 0 & & 0 & & 0 & & 1 & \\
\hline & & & 1 & 2 & & 0 & & 0 & & 0 & & 2 & \\
\hline & & & 2 & 4 & & 6 & & 6 & & 6 & & 3 & \\
\hline & Intermed. & 14 & 0 & 1 & $p=0,519$ & 0 & $p=0,453$ & 0 & $p=0,556$ & 0 & $p=0,557$ & 0 & $p=0,187$ \\
\hline & & & 1 & 5 & & 4 & & 1 & & 3 & & 2 & \\
\hline & & & 2 & 8 & & 10 & & 13 & & 11 & & 12 & \\
\hline & Alto & 16 & 0 & 1 & & 0 & & 0 & & 0 & & 0 & \\
\hline & & & 1 & 2 & & 5 & & 0 & & 4 & & 5 & \\
\hline & & & 2 & 13 & & 11 & & 16 & & 12 & & 11 & \\
\hline \multirow[t]{6}{*}{ Sexo } & Masculino & 16 & 0 & 1 & & 0 & & 0 & & 0 & & 0 & \\
\hline & & & 1 & 3 & & 6 & & 0 & & 5 & & 4 & \\
\hline & & & 2 & 12 & $p=0,846$ & 10 & $p=0,146$ & 16 & $\mathrm{p}>0,999$ & 11 & $p=0,204$ & 12 & $p>0,999$ \\
\hline & Feminino & 20 & 0 & 1 & & 0 & & 0 & & 0 & & 1 & \\
\hline & & & 1 & 6 & & 3 & & 1 & & 2 & & 5 & \\
\hline & & & 2 & 13 & & 17 & & 19 & & 18 & & 14 & \\
\hline \multirow[t]{6}{*}{ Idade } & $\leq 40$ & 16 & 0 & 1 & & 0 & & 0 & & 0 & & 0 & \\
\hline & & & 1 & 7 & & 6 & & 1 & & 4 & & 4 & \\
\hline & & & 2 & 8 & $p=0,050$ & 10 & $p=0,245$ & 15 & $p=0,457$ & 12 & $p=0,677$ & 12 & $p>0,999$ \\
\hline & $>40$ & 19 & 0 & 1 & & 0 & & 0 & & 0 & & 1 & \\
\hline & & & 1 & 2 & & 3 & & 0 & & 3 & & 5 & \\
\hline & & & 2 & 16 & & 16 & & 19 & & 16 & & 13 & \\
\hline
\end{tabular}




\begin{tabular}{|c|c|c|c|c|c|c|c|c|c|c|c|c|c|}
\hline Característic. & Categoria & Pacient. (n) & $\begin{array}{l}\text { Imuno } \\
\text { Score }\end{array}$ & $\begin{array}{l}\text { Claudina } \\
1 \text {, no. de } \\
\text { casos }\end{array}$ & $\begin{array}{l}\text { Valor de } \\
\text { p }\end{array}$ & $\begin{array}{l}\text { Claudina } \\
3 \text {, no. de } \\
\text { casos }\end{array}$ & $\begin{array}{l}\text { Valor de } \\
\text { p }\end{array}$ & $\begin{array}{l}\text { Claudina } \\
4 \text {, no. de } \\
\text { casos }\end{array}$ & $\begin{array}{l}\text { Valor de } \\
\text { p }\end{array}$ & $\begin{array}{l}\text { Claudina } \\
5 \text {, no. de } \\
\text { casos }\end{array}$ & $\begin{array}{l}\text { Valor de } \\
\text { p }\end{array}$ & $\begin{array}{l}\text { Claudin } \\
\text { a } 7, \text { no. } \\
\text { de } \\
\text { casos }\end{array}$ & $\begin{array}{l}\text { Valor de } \\
\text { p }\end{array}$ \\
\hline \multirow[t]{6}{*}{ Cor da pele } & Branco & 31 & 0 & 1 & & 0 & & 0 & & 0 & & 0 & \\
\hline & & & 1 & 6 & & 7 & & 1 & & 6 & & 7 & \\
\hline & & & 2 & 24 & $p=0,024$ & 24 & $p>0,999$ & 30 & $p>0,999$ & 25 & $p=0,511$ & 24 & $p>0,999$ \\
\hline & Não-branco & 3 & 0 & 1 & & 0 & & 0 & & 0 & & 0 & \\
\hline & & & 1 & 2 & & 1 & & 0 & & 1 & & 1 & \\
\hline & & & 2 & 0 & & 2 & & 3 & & 2 & & 2 & \\
\hline \multirow[t]{6}{*}{$\begin{array}{l}\text { Localização } \\
\text { do tumor }\end{array}$} & Parótida & 16 & 0 & 0 & & 0 & & 0 & & 0 & & 0 & \\
\hline & & & 1 & 5 & & 4 & & 0 & & 2 & & 4 & \\
\hline & & & 2 & 11 & $p=0,403$ & 12 & $p=0,513$ & 16 & $p>0,999$ & 14 & $p=0,617$ & 12 & $p>0,999$ \\
\hline & $\begin{array}{l}\text { Outras } \\
\text { glândulas }\end{array}$ & 20 & 0 & 2 & & 0 & & 0 & & 0 & & 1 & \\
\hline & & & 1 & 4 & & 5 & & 1 & & 5 & & 5 & \\
\hline & & & 2 & 14 & & 15 & & 19 & & 15 & & 14 & \\
\hline \multirow[t]{6}{*}{ Metástases } & Não & 11 & 0 & 2 & & 0 & & 0 & & 0 & & 0 & \\
\hline & & & 1 & 2 & & 4 & & 0 & & 3 & & 3 & \\
\hline & & & 2 & 7 & $p=0,545$ & 7 & $p=0,371$ & 11 & $p>0,999$ & 8 & $p=0,640$ & 8 & $p>0,999$ \\
\hline & Sim & 12 & 0 & 0 & & 0 & & 0 & & 0 & & 0 & \\
\hline & & & 1 & 3 & & 2 & & 1 & & 2 & & 4 & \\
\hline & & & 2 & 9 & & 10 & & 11 & & 10 & & 8 & \\
\hline \multirow[t]{6}{*}{ Recorrência } & Não & 16 & 0 & 2 & & 0 & & 0 & & 0 & & 0 & \\
\hline & & & 1 & 4 & & 5 & & 1 & & 4 & & 5 & \\
\hline & & & 2 & 10 & $p=0,307$ & 11 & $p=0,634$ & 15 & $p>0,999$ & 12 & $p>0,999$ & 11 & $\mathrm{p}=0,634$ \\
\hline & Sim & 6 & 0 & 0 & & 0 & & 0 & & 0 & & 0 & \\
\hline & & & 1 & 0 & & 1 & & 0 & & 1 & & 1 & \\
\hline & & & 2 & 6 & & 5 & & 6 & & 5 & & 5 & \\
\hline
\end{tabular}


Não houve qualquer outra associação entre a expressão das CLDNs e qualquer outro parâmetro patológico, clinico ou demográfico que fosse estatisticamente significante nesse estudo. Os resultados estatísticos completos são apresentados na Tabela 5.3. Entretanto, quando as CLDNs foram comparadas entre elas, houve associação entre a alta expressão da CLDN-3 e a alta expressão da CLDN-5 ( $p=0,050)$. Os dados podem ser observados na Tabela 5.4.

Tabela 5.4 - Comparação da expressão das proteínas CLDNs entre si

\begin{tabular}{cc}
\hline Comparação & Valor de $\mathbf{p}$ \\
\hline CLDN1 * CLDN3 & 0,419 \\
CLDN1 * CLDN4 & 0,306 \\
CLDN1 * CLDN5 & 0,338 \\
CLDN1 * CLDN7 & 0,374 \\
CLDN3 * CLDN4 & 1,000 \\
CLDN3 * CLDN5 & 0,050 \\
CLDN3 * CLDN7 & 0,748 \\
CLDN4 * CLDN5 & 1,000 \\
CLDN4 * CLDN7 & 0,278 \\
CLDN5 * CLDN7 & 0,716 \\
\hline
\end{tabular}

As taxas de sobrevida em cinco anos tenderam a ser menores em pacientes que apresentaram alta expressão de CLDN-3 (score 2), em comparação com aqueles que apresentaram baixa expressão da CLDN-3 (score 1). No entanto, os resultados não foram estatisticamente significantes $(p=0.245)$. A média da taxa global de sobrevida em cinco anos foi de $83,3 \%$ para pacientes com baixa expressão de CLDN-3 e de 53,6\% para pacientes com alta expressão de CLDN-3. Não foi observada a associação com a taxa de sobrevida e a expressão de nenhuma outra proteína estudada. 


\subsection{PCR em tempo real}

\subsubsection{Expressão gênica das claudinas}

A expressão gênica das cinco CLDNs estudadas nesse experimento foi observada para a linhagem celular UM-HMC-3A de CME de glândulas salivares; a expressão estava presente tanto nas células tratadas como nas não tratadas (controles) com o EGF. Foi observado um ligeiro aumento na expressão genica das CLDNs nas células tratadas com o EGF. Entretanto, não foi observada significância estatística quanto a expressão gênica das CLDNs em células tratadas e células não tratadas. A CLDN-1 apresentou $p=0,515$ em células tratadas e não tratadas; a CLDN-3 apresentou $p=0,110$; para a CLDN-4 o valor de $p$ para a média da expressão em células tratadas e não tratadas foi de 0,441 ; para CLDN-5 obteve-se $p$ $=0,441$; para CLDN-7, $p=0,515$. A Figura 5.3 nos apresenta esses resultados.

\subsubsection{Expressão do microRNA-18a}

A expressão do miRNA-18a foi observada para a linhagem celular UM-HMC3A de CME de glândulas salivares; a expressão estava presente tanto nas células tratadas como nas não tratadas (controles) com o EGF. Foi observado, na maior parte dos casos, um ligeiro aumento na expressão do miRNA-18a nas células tratadas com o EGF em, praticamente, todas as concentrações observadas. Para as concentrações de $25 \mathrm{ng} / \mathrm{ml}$ foi observada significância estatística $(p=0,015)$, assim como para a concentração de $100 \mathrm{ng} / \mathrm{ml}(p=0,024)$. A Figura 5.4 nos apresenta esses resultados e os valores de $p$. 
Figura 5.3 - Expressão dos mRNAs das CLDNs estudadas na linhagem celular HM-UMC-3A de $\mathrm{CME}$, a expressão foi medida nas células tratadas e nas células não tratadas pelo EGF $(100 \mathrm{ng} / \mathrm{ml})$. A expressão relativa foi medida por qPCR considerando um pool de mucosa oral não neoplásica como calibrador e os resultados foram normalizados pela expressão do gene ACTB. Legenda cld1 - claudina 1; cld 3 - claudina 3; cld 4 - claudina 4; cld 5 claudina 5 ; cld 7 - claudina 7
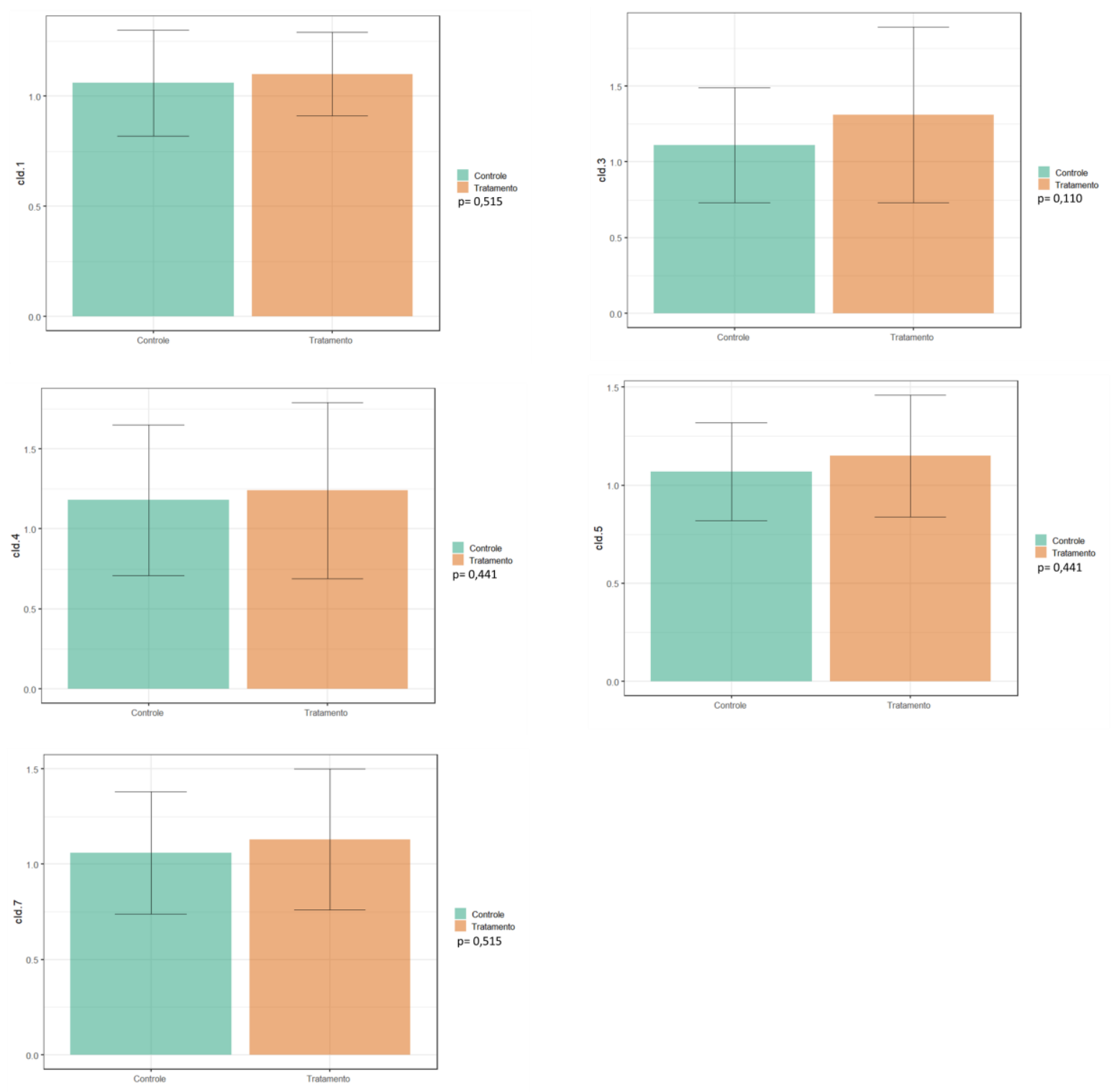
Figura 5.4 - Expressão do mRNA do miRNA-18a estudado na linhagem celular HM-UMC-3A de CME, a expressão foi medida nas células tratadas e nas células não tratadas pelo EGF nas três diferentes concentrações $(25 \mathrm{ng} / \mathrm{ml}, 50 \mathrm{ng} / \mathrm{ml}$ e $100 \mathrm{ng} / \mathrm{ml})$. A expressão relativa foi medida por qPCR considerando um pool de mucosa oral não neoplásica como calibrador e os resultados foram normalizados pela expressão do micro-RNA endógeno RNU48
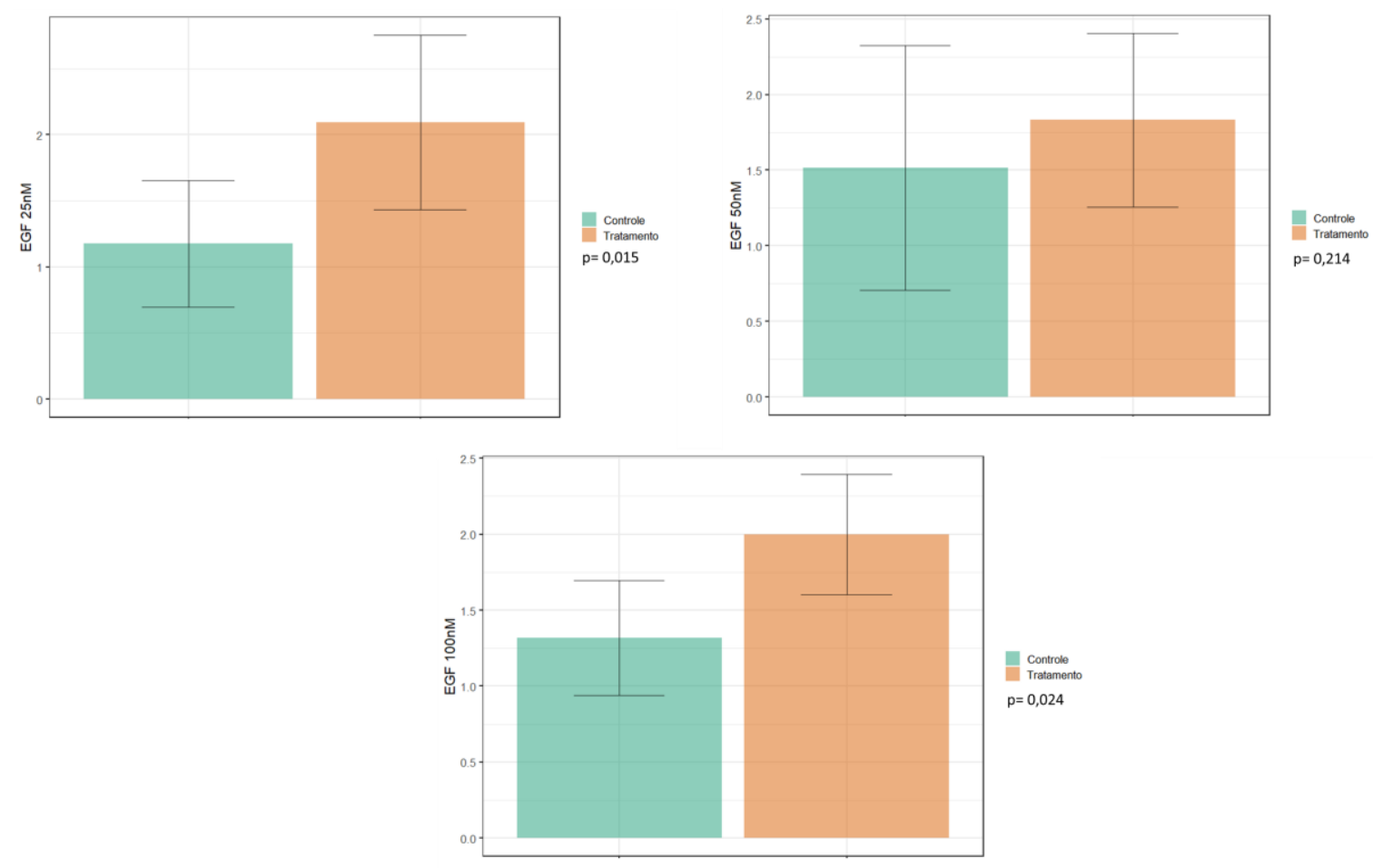


\section{DISCUSSÃO}

O CME é considerado por muitos pesquisadores como sendo a neoplasia maligna mais comum das glândulas salivares, por se tratar de um tumor com grande heterogeneidade em sua composição celular, a lesão pode apresentar comportamento clinico variado (Adams et al., 2013; Coca-Pelaz et al., 2015; Galdirs et al., 2019; Reinheimer et al., 2019). As informações clinicas dos 36 casos inclusos em nosso estudo nos mostraram que a maioria dos nossos pacientes tinha idade superior a 40 anos; esse achado está de acordo com o que se observa na literatura que nos diz que a idade média ao diagnóstico é de 45 anos (Coca-Pelaz et al., 2015; Hellquist; Skalova, 2014). Outro achado consonante com a literatura é a discreta predileção pelo sexo feminino (Coca-Pelaz et al., 2015; Hellquist; Skalova, 2014), Reinheimer et al (2019) observaram a presença de maioria de casos de neoplasias malignas de glândulas salivares em pacientes do sexo feminino em uma população de brasileiros. Em nosso trabalho pacientes do sexo feminino somaram $55,6 \%$ dos casos estudados (20 casos).

Quando avaliamos a localização do CME nos casos estudados observamos a glândula parótida como sendo a localização mais comum (16 casos), as glândulas salivares menores também somaram 16 casos em nossa casuística, entretanto, por estarem dispersas por, virtualmente, toda a cavidade bucal, as localizações foram muito variadas. Na literatura a localização mais comum para o CME é a glândula parótida (Guntinas-Lichius et al., 2004; Adams et al., 2013; Coca-Pelaz et al., 2015; Reinheimer et al., 2019) portanto, nossos achados também são condizentes ao que já se sabe sobre a localização da lesão.

As informações sobre recorrência foram recuperadas em apenas 22 dos 36 casos estudados, entretanto, a recorrência esteve presente em $27,3 \%$ desses casos (6 casos), as informações sobre metástase foram recuperadas para 23 dos casos estudados e foram observadas em $52,2 \%$ desses casos (12 casos), já a morte provocada pelo CME ocorreu em $35,7 \%$ dos casos (10 casos), sendo que essa informação foi recuperada em 28 dos 36 casos. A literatura tem nos mostrado que a presença de recorrência em casos de CME é possível mesmo em tumores de baixo grau histológico, assim como a ocorrência de metástases e esta é muito associada com um pior prognóstico para neoplasias de glândulas salivares; o CME se 
apresenta entre as neoplasias malignas das glândulas salivares como uma lesão com grande incidência de metástases e de mortes relacionadas a ele (Israel et al., 2019a; Israel et al., 2019b; Liu et al., 2014; Nance et al., 2008).

Sabe-se que os CMEs são tumores que apresentam uma grande diversidade de células em sua composição, tendo como células principais dessa composição as células mucosas, células intermediárias e células epidermoides (Adams et al., 2013; Stewart et al., 1945; Coca-Pelaz et al., 2015); os casos de CME incluídos em nosso estudo foram principalmente tumores de alto grau (44,4\% dos casos) e de grau intermediário, juntos eles corresponderam a $83,3 \%$ dos tumores estudados (30 casos de 36). É uma característica importante dos tumores de alto e médio graus a presença de maior proporção de células epidermoides e células intermediárias (Luna et al. 2006; El-Naggar et al. 2017), justamente essas células foram as que mais se mostraram positivas para as CLDNs em nossa análise, nesse contexto, nossa discussão considerará aspectos da expressão das CLDNs nos diferentes tipos de células que constituem as neoplasias analisadas.

A expressão das CLDN-1, -3, -4, -5 e -7 em CME da glândula salivar foi caracterizada como alta e generalizada para todas as 5 proteínas estudadas, principalmente ao redor da membrana celular das células intermediárias e epidermoides, independentemente do grau histológico do tumor.

As células epidermoides e células intermediárias geralmente apresentam pleomorfismos, tanto celular quanto nuclear, e mitoses atípicas. A alta expressão de CLDNs em células pleomórficas neoplásicas também foi observada por Soini (2005), que descreveu uma grande positividade das CLDN-1, -2, -3, -4, -5 e -7 em muitos tipos de carcinomas. Outros autores observaram alta expressão de CLDNs em outros tipos de tumores epiteliais (Dos Reis et al. 2008; Chao et al. 2009).

Células neoplásicas menos diferenciadas, como células intermediárias e células epidermoides de CMEs, ainda podem se assemelhar biologicamente a células primitivas da glândula salivar. Essa possibilidade pode ser sustentada pelos achados publicados por Lourenço et al. (2007) que descreveram uma presença intensa de CLDNs durante o desenvolvimento da glândula salivar em fetos humanos.

Em nosso estudo as CLDNs foram observadas em células epidermoides e células intermediárias de todos os subtipos de CME, mas sua expressão não foi associada à classificação histológica da lesão. Entretanto, Aro et al. (2011) 
avaliaram a expressão das CLDN-1, $-3,-4$ e -7 no CME e observaram uma correlação da intensidade da coloração para as CLDN-1 e -3 quando comparadas ao grau histológico da lesão.

A classificação da expressão das CLDNs utilizada em nosso estudo foi realizada por meio de um método de score (Lourenço et al., 2010), Aro et al. (2011) se utiliza da classificação da expressão das CLDNs considerando a intensidade de sua marcação imunoistoquímica. Optamos por não classificar a intensidade da marcação, e ao invés disso utilizar a classificação por score por considerar que a classificação da intensidade da marcação é um parâmetro altamente subjetivo e não facilmente reprodutível.

Aro et al. (2011) sugeriram em seu estudo que a expressão das CLDN-1 e -3 pode ser usada como ferramenta auxiliar no diagnóstico e prognóstico do CME. Entretanto, diferente de nossa estratégia, esses autores avaliaram a intensidade da marcação imunoistoquímica obtida pelas proteínas, essa forma de análise pode ser difícil de aplicar na prática clínica de rotina visto que na avaliação da intensidade da marcação cada patologista pode interpretar as lâminas de uma forma, isso pode conduzir a avaliações demasiadamente subjetivas levando a diagnósticos diferentes para um mesmo tumor; o diagnóstico e o prognóstico do CME continuam sendo feitos baseados nos critérios morfológicos e genéticos da OMS (El-Naggar et al., 2017).

Em nosso estudo, o score de positividade foi determinado pela porcentagem de células coradas, conforme descrito por Lourenço et al. (2010). Verificamos que a alta expressão de CLND-1 estava associada à etnia branca e a idade > 40 anos. Já foi visto que a CLDN-1, que é considerada como o primeiro membro identificado da família das CLDNs (Furuse et al. 1998), atua como uma barreira epitelial e desempenha um importante papel no processo de formação da JC (Krause et al. 2008; Baker 2016). A CLDN-1 é expressa nos ductos intercalados e estriados das glândulas salivares maiores e menores. Essa proteína é descrita como mediadora da função de barreira nas glândulas salivares serosas (Lourenço et al. 2007; Maria et al. 2008; Baker 2016). Entretanto, os papéis biológicos adicionais da CLDN-1 e o motivo de sua maior expressão nas neoplasias apresentadas por pacientes de etnia branca e com idade $>40$ anos ainda precisam ser elucidados. Apesar das muitas questões em aberto sobre os papéis da CLDN-1 nas neoplasias epiteliais, já se observou que a alta expressão da CLDN-1 no carcinoma epidermoide oral está 
associada a um prognóstico desfavorável (Dos Reis et al., 2008); em nosso estudo, como a maioria dos casos foi classificada como tumor de alto grau, é esperado um prognóstico ruim, e a expressão intensa e generalizada da CLDN-1 corrobora com os indicativos de prognóstico desfavorável.

A CLDN-3 está presente nos ácinos mucosos, ácinos serosos, ductos intercalados e ductos estriados das glândulas salivares maiores e menores (Lourenço et al. 2007; Maria et al. 2008). Sua função na glândula salivar ainda não foi esclarecida, mas acredita-se que a CLDN-3 atua como facilitadora da passagem paracelular da água (Kawedia et al. 2007). Nosso estudo demonstrou alta expressão de CLDN-3 (escore 2), especialmente no CME de alto grau (a maioria dos casos incluídos na presente coorte), esse achado vai de encontro com o que já foi observado na literatura visto que outro estudo também relatou alta expressão de CLDN-3 em CMEs de alto grau (Aro et al., 2011). Um outro estudo recente observou que o aumento da expressão citoplasmática da CLDN-3 pode estar associado a um prognóstico desfavorável no câncer de mama (Jääskeläinen et al., 2018). Tomados em conjunto, esses estudos destacam um papel importante da CLDN-3 em processos neoplásicos agressivos.

A CLND-4 controla a permeabilidade paracelular catiônica; a redução de sua expressão resulta na perda de seletividade catiônica da JC (Hou et al., 2006). A expressão da CLDN-4 é induzida durante o reparo epitelial, e a alta expressão da CLND-4 no pulmão humano lesionado tem sido associada à função de barreira mantida (Rokkam et al. 2011). Nas glândulas salivares, a CLDN-4 é expressa em células acinares e células ductais. Existem indicações de que a CLDN-4 regula a função de barreira durante a secreção estimulada por agonista no epitélio salivar (Lourenço et al. 2007; Maria et al. 2008; Baker 2016).

Um estudo de Abd El-Ghani et al. (2013), observou que a CLDN-4 se encontrava expressa em apenas metade de sua amostra de CME com marcação imunoistoquímica fraca em tumores de alto grau, entretanto, o número de casos estudados foi de apenas 6 casos de CME; Aro et al. (2011) por sua vez, examinou 39 casos de CME de glândulas salivares e não conseguiu estabelecer relação entre os graus histológicos da lesão e a expressão da CLDN-4. Em nosso estudo, todos os 36 tumores apresentaram positividade para a CLDN-4, com alta expressão (escore 2) na maioria dos casos (35 casos). Esse padrão pode estar relacionado à 
capacidade de renovação das células tumorais, porque a alta expressão dessa proteína está relacionada ao reparo epitelial.

A CLDN-5 é expressa no endotélio ao redor das células acinares e ductais das glândulas salivares (Lourenço et al. 2007; Maria et al. 2008). Acredita-se que a CLDN-5 controle a entrada de nutrientes por meio do suprimento sanguíneo das glândulas salivares (Baker 2016). A alta expressão da CLDN-5 no CME sugere aumento da capacidade do tumor para se auto manter.

Acredita-se que a CLDN-7 desempenhe algum papel na regulação da adesão entre as células e na motilidade celular, devido à sua forte expressão nas membranas basolaterais de muitos tipos de células e sua interação com muitas moléculas de adesão (Heiler et al. 2015). A CLDN-7 é expressa em células ductais de glândulas salivares maiores e menores. A CLDN-7 é expressa nas glândulas salivares menores, desde os estágios iniciais do seu desenvolvimento até a idade adulta (Lourenço et al. 2007); essa proteína contribui para o transporte de sódio e a regulação do transporte de água nas glândulas salivares (Baker 2016; Krause et al. 2008; Kawedia et al. 2007). A alta expressão da CLDN-7 no CME pode destacar sua fundamental função na manutenção de bombas iônicas e de água para preservar a estrutura celular.

Alterações na expressão das CLDNs são vistas em muitos tipos de cânceres (Agarwal et al. 2005; Resnick et al. 2005), incluindo o carcinoma epidermoide oral (Bello et al. 2008; Lourenço et al. 2010) e o câncer de mama (Hoevel et al., 2002; Jääskeläinen et al., 2018), o que pode ser uma evidência de que sua expressão alterada possa trazer como consequência processos de carcinogênese.

Existem diversas evidencias de que a alteração da expressão das CLDNs pode estar relacionada com o prognóstico da lesão em diferentes tipos de neoplasias malignas como em câncer de mama, câncer de ovário e câncer colorretal (Jääskeläinen et al., 2018; Hoevel et al., 2002; Kim et al., 2008; Agarwal et al., 2005; Resnick et al., 2005; English; Santin, 2013). Para os tumores que ocorrem na cavidade oral, já foi observado que a diminuição da expressão da CLDN-7 em carcinoma epidermoide está associada com áreas de invasão tumoral, essa expressão é ausente em tumores pouco diferenciados (Bello et al., 2008; Lourenço et al., 2010).

Infelizmente a relação da expressão das CLDNs com o prognóstico do CME ainda não está completamente clara, mas os resultados encontrados nesse estudo 
imunoistoquímico somados ao que já se conhece na literatura, refletem a importância das CLDNs na JC, e sua importância na manutenção do trafego das substancias mesmo em processos neoplásicos, o que é provavelmente necessário para a manutenção da célula e manutenção do alto metabolismo celular nessas lesões.

Esses achados nos motivaram a realizar uma etapa in vitro desse experimento visto que nosso grupo já observou que a expressão dessas proteínas nas glândulas salivares se inicia desde o princípio do desenvolvimento dessas estruturas e se mantem nas glândulas salivares adultas (Lourenço et al., 2007); agora sabemos que ela é mantida mesmo após a transformação maligna das células.

Quando observamos a etapa in vitro do experimento, foi possível notar que a expressão gênica das CLDN-1, -3, -4, -5 e -7 ocorriam na linhagem celular UMHMC-3A de CME das glândulas salivares. Essa expressão se encontrava ligeiramente aumentada nas culturas celulares que receberam estimulação por EGF.

A superexpressão do EGFR já foi associada ao CME de alto grau e tumores que apresentam comportamento agressivo (Gibbons et al., 2001; Shang et al., 2007; Lujan et al., 2010), essa expressão elevada também está associada a tumores que apresentam prognóstico desfavorável (Ettl et al., 2008); sabe-se que a via do EGFR/ERK está ativada em CMEs de alto grau e que tratamentos com medicações inibidoras da vai do EGFR podem beneficiar esses pacientes (Lujan et al., 2010).

Além disso, a sinalização do EGF modula a expressão das CLDNs em diversos tipos celulares como em hepatócitos, nas células epiteliais alveolares, entre muitos outros tipos de células (Kojima et al., 2004; Chen et al., 2005; Singh; Harris, 2004; Ikari et al., 2009). Chen et al. (2005) investigaram a expressão das CLDN-1, $3,-4,-5$ e -7 em células epiteliais alveolares de ratos e observaram que, nessas células, o EGF pode levar ao aumento da expressão das CLDN-4 e -7 e pode induzir a diminuição na expressão das CLDN-3 e -5.

Portanto, pode-se notar que o EGF está associado com o processo de expressão gênica das CLDNs em diferentes tipos celulares, inclusive células epiteliais (Kojima et al., 2004; Chen et al., 2005; Singh; Harris, 2004; Ikari et al., 2009); o CME é um tumor que tem sua origem em células epiteliais, esse tumor ainda não apresenta bem compreendidos os mecanismos envolvidos no processo de regulação da expressão das CLDNs; todavia, pensando-se que se trata de um 
tumor de origem em células epiteliais, talvez o EGF possa estar envolvido nesses mecanismos; e realmente foi observado em nosso estudo um pequeno aumento na expressão gênica das CLDNs nas culturas celulares que foram estimuladas com o EGF. No entanto, não houve diferença estatisticamente significativa na expressão gênica entre as células que foram estimuladas e as células que não foram estimuladas pelo EGF. Apesar disso, não se pode descartar a possibilidade de que alguma via de sinalização celular envolvendo o EGFR possa estar relacionada a esse processo, visto que apenas o EGF foi investigado.

No caso do miRNA-18a, sabe-se que ele pertence a um grupo de miRNAs relacionados ao papel de oncogenes e genes supressores de tumor em várias neoplasias (Mogilyansky; Rigoutsos, 2013; Xiang; Wu, 2010); e apesar de se saber que o miRNA-18a é encontrado em diversas neoplasias malignas humanas (Komatsu et al., 2014; Morimura et al., 2011, Hirajima et al., 2013), ainda não se sabia se ele se encontrava ou não expresso no CME. Nós observamos a sua expressão in vitro para a linhagem celular UM-HMC-3A de CME de glândulas salivares.

O miRNA-18a está relacionado ao processo de tumorigênese no câncer de fígado (Sanchez-Mejias et al., 2019) e a eventos apoptóticos em osteossarcoma (Ding et al., 2018), talvez a sua presença no CME também possa de alguma forma se relacionar com eventos que facilitem a progressão da lesão.

Em casos de câncer de mama a alta expressão do miRNA-18a está relacionada com prognóstico favorável (Kim et al., 2017; Zhang et al., 2019). As glândulas mamárias, assim como as glândulas salivares, são órgãos exócrinos e guardam semelhanças entre si. Outro órgão que apresenta histologia semelhante à das glândulas salivares é o pulmão, que possui glândulas seromucosas; em casos de neoplasia de pulmão foi observado que o aumento de miRNA-18a no sangue de pacientes está relacionado com prognóstico desfavorável (Xu et al., 2018). Traçando-se uma comparação entre as glândulas mamárias, as glândulas seromucosas do pulmão e as glândulas salivares pode-se pensar que, talvez, a presença da expressão do miRNA-18a em CME de glândulas salivares possa apresentar alguma utilidade futura na avaliação do prognóstico para a lesão.

A expressão do miRNA-18a foi observada tanto para as culturas de células do CME de glândulas salivares que receberam tratamento com EGF quanto para as culturas de células que não receberam o tratamento. Já foi observado na literatura 
que a via do EGFR pode estar relacionada com a expressão de miRNAs em diferentes neoplasias malignas (Liang et al., 2017; Angius et al., 2019; Cao et al., 2019; Li; Wang, 2019), para o miRNA-18a, também já é conhecida a influência do EGFR em casos de câncer de pulmão, o EGFR pode levar a superexpressão desse miRNA nesse tumor (Savitsky et al., 2010).

Em nosso estudo foi observado um ligeiro aumento da expressão do miRNA18a nas células tratadas com o EGF em, praticamente, todas as concentrações estudadas e para as concentrações de $25 \mathrm{ng} / \mathrm{ml}$ e $100 \mathrm{ng} / \mathrm{ml}$ foram obtidos resultados estatisticamente significantes quanto a expressão do miRNA-18a em células tratadas e células não tratadas pelo EGF, o que sugere que nessa lesão a via do EGFR, pelo menos para o ligante EGF, pode estar relacionada com a expressão do miRNA-18a. 


\section{CONCLUSÕES}

Neste trabalho concluiu-se que:

- As proteínas CLDN-1, -3, $-4,-5$ e 7 apresentam expressão imunoistoquímica para o CME, assim como o EGFR, essa expressão não pode ser relacionada com a graduação histológica da lesão, apenas com a idade superior a 40 anos, com pacientes de etnia branca e quando se comparou a expressão das CLDN-3 e CLDN-5 entre si mas, mais estudos são necessários para demonstrar a importância desses achados;

- Não foi possível estabelecer relação entre o EGFR e a expressão gênica das CLDNs estudadas, o que se pode notar é um pequeno aumento na expressão desses genes em culturas que receberam tratamento com EGF;

- A presença da expressão do miRNA-18a no CME foi evidenciada nesse estudo e foi possível estabelecer relação entre a sua expressão e o EGFR.

Em conclusão, nosso estudo demonstrou que a expressão proteica das CLDNs é mantida no CME, especialmente nas células epidermoides e intermediárias, demonstrando que essas proteínas continuam sendo expressas em todas as etapas do desenvolvimento do tumor e a expressão gênica das CLDNs estudadas, não é influenciada pela estimulação do EGF; já no caso do miRNA-18a, o estimulo pelo EGF pode influenciar a sua expressão. No entanto, o papel das CLDNs e do miRNA-18a no processo de tumorigênese do CME ainda não está claro. Mais estudos são necessários para determinar com clareza os papéis específicos das CLDNs e do miRNA-18a em neoplasias malignas de glândulas salivares. 



\section{REFERÊNCIAS 1}

Abd El-Ghani SF, Kasem RF, Ghallab NA, Shaker OG. Detection of claudin-4 in salivary gland neoplasms (a study utilizing RT-PCR and immunohistochemistry). J Oral Pathol Med. 2013 Nov;42(10):781-7. doi: 10.1111/jop.12070. Epub 2013 Apr 25.

Adams A, Warner K, Nör JE. Salivary gland cancer stem cell. Oral Oncol. 2013 Sep;49(9):845-853. doi: 10.1016/j.oraloncology.2013.05.013. Epub 2013 Jun 28.

Agarwal R, D'Souza T, Morin PJ. Claudin-3 and claudin-4 expression in ovarian epithelial cells enhances invasion and is associated with increase matrix metalloproteinase-2 activity. Cancer Res. 2005 Aug 15;65(16):7378-85.

Alberts B, Johnson A, Lewis J, Raff M, Roberts K, Walter P. Biologia molecular da célula. 5를. São Paulo, SP: Artmed; 2010.

Amano O, Mizobe K, Bando Y, Sakiyama K. Anatomy and histology of rodent and human major salivary glands: -overview of the Japan salivary gland societysponsored workshop-. Acta Histochem Cytochem. 2012 Oct 31;45(5):241-50. doi: 10.1267/ahc.12013. Epub 2012 Sep 22.

Anderson U, Guo G, Bergebheim BMAT, Hedman TBH, Henriksson R. Epidermal growth factor receptor family (EGFR, ErbB2-4) in gliomas and meningiomas. Acta Neuropathol. 2004 Aug;108(2):135-42. Epub 2004 May 18.

Angelow S, Ahlstrom R, Yu AS. Biology of Claudins. Am J Physiol Renal Physiol. 2008 Oct;295(4):F867-76. doi: 10.1152/ajprenal.90264.2008. Epub 2008 May 14.

Angius A, Pira G, Scanu AM, Uva P, Sotgiu G, Saderi L, Manca A, Serra C, Uleri E, Piu C, Caocci M, Ibba G, Zinellu A, Cesaraccio MR, Sanges F, Muroni MR, Dolei A, Cossu-Rocca P, De Miglio MR. MicroRNA-425-5p Expression Affects BRAF/RAS/MAPK Pathways In Colorectal Cancers. Int J Med Sci. 2019 Oct 11;16(11):1480-1491. doi: 10.7150/ijms.35269. eCollection 2019.

Aro K, Rosa LE, Bello IO, Soini Y, Mäkitie AA, Salo T, Leivo I. Expression pattern of claudins 1 and 3 - an auxiliary tool in predicting behavior of mucoepidermoid carcinoma of salivary gland origin. Virchows Arch. 2011 Mar;458(3):341-8. doi: 10.1007/s00428-010-1026-1. Epub 2010 Dec 24.

${ }^{1}$ De acordo com Estilo Vancouver. 
Artega CL. Epidermal growth factor receptor dependence in human tumors: more than Just expression? Oncologist. 2002; 7 Suppl 4: 31-9.

Auclair PL, Goode RK, Ellis GL. Mucoepidermoid carcinoma of intraoral salivary glands. Evaluation and application of grading criteria in 143 cases. Cancer. $1992 \mathrm{Apr}$ 15; 69(8): 2021-30.

Azevedo RS, de Almeida OP, Kowalski LP, Pires FR. Comparative cytoketarin expression in the different cell types of salivary gland mucoepidermoid carcinoma. Head Neck Pathol. 2008 Dec;2(4):257-64. doi: 10.1007/s12105-008-0074-1. Epub 2008 Aug 8.

Baek JH, Park DJ, Kim GY, Cheon J, Kang BW, Cha HJ, Kim JG. Clinical Implications of Claudin18.2 Expression in Patients With Gastric Cancer. Anticancer Res. 2019 Dec;39(12):6973-6979. doi: 10.21873/anticanres.13919.

Baker OJ. Current trends in salivary gland tight juctions. Tissue Barriers. 2016 Mar 10;4(3):e1162348. doi: 10.1080/21688370.2016.1162348. eCollection 2016 Jul-Sep.

Barnes L, Eveson JW, Reichert P, Sidransk YD. World Health Organization classification of tumours. Pathology and genetivs of head and neck tumours. Lyon: IARC Press, 2005.

Bartel DP. MicroRNAs: target recognition and regulatory functions. Cell. 2009 Jan 23;136(2):215-33. doi: 10.1016/j.cell.2009.01.002.

Batsakis JG, Luna MA. Histopathologic grading of salivary gland neoplasms: I. Mucoepidermoid carcinoma. Ann OtolRhinolLaryngol. 1990 Oct; 99(10 Pt 1): 835-8.

Bello IO, Vilen ST, Niinimaa A, Kantola S, Soini Y, Salo T. Expression of claudins 1, 4, 5 and 7 and occludin, and relationship with prognosis in squamous cell carcinoma of the tongue. Hum Pathol. 2008 Aug;39(8):1212-20. doi: 10.1016/j.humpath.2007.12.015. Epub 2008 Jun 10.

Bradley PJ. Distant metastases from salivary glands cancer. ORL J Otorhinolaryngol Relat Spec. 2001 Jul-Aug; 63(4): 233-42. 
Byrd AS, Spector ME, Carey TE, Bradford CR, McHugh JB. Predictors of recurrence and survival for head and neck mucoepidermoid carcinoma. Otolaryngol Head Neck Surg. 2013 Sep;149(3):402-8. doi: 10.1177/0194599813489659. Epub 2013 May 21.

Calin GA, Dumitru CD, Shimizu M, Bichi R, Zupo S, Noch E, Aldler H, Rattan S, Keating M, Rai K, Rassenti L, Kipps T, Negrini M, Bullrich F, Croce CM. Frequent deletions and down-regulation of micro- RNA genes miR15 and miR16 at 13q14 in chronic lymphocytic leukemia. Proc Natl Acad Sci U S A. 2002 Nov 26; 99(24):15524-9. Epub 2002 Nov 14.

Cao Y, Shen T, Zhang C, Zhang QH, Zhang ZQ. MiR-125a-5p inhibits EMT of ovarian cancer cells by regulating TAZ/EGFR signaling pathway. Eur Rev Med Pharmacol Sci. 2019 Oct;23(19):8249-8256. doi: 10.26355/eurrev_201910_19134.

Capaldo CT, Farkas AE, Hilgarth RS, Krug SM, Wolf MF, Benedik JK, Fromm M, Koval M, Parkos C, Nusrat A. Proinflammatory cytokine-induced tight junction remodeling through dynamicself-assembly of claudins. Mol Biol Cell. 2014 Sep 15;25(18):2710-9. doi: 10.1091/mbc.E14-02-0773. Epub 2014 Jul 16.

Capaldo CT, Nusrat A. Claudin switching: Physiological plasticity of the Tight Junction. Semin Cell Dev Biol. 2015 Jun;42:22-9. doi: 10.1016/j.semcdb.2015.04.003. Epub 2015 May 7.

Capaldo CT, Nusrat A. Cytokine regulation of tight junctions. Biochim Biophys Acta. 2009 Apr;1788(4):864-71. doi: 10.1016/j.bbamem.2008.08.027. Epub 2008 Oct 8.

Capdevila J, Elez E, Macarulla T, Ramos FJ, Ruiz-Echarri M, Tabernero J. Antiepidermal growth factor receptor monoclonal antibodies in cancer treatment. Cancer Treat Rev. 2009 Jun;35(4):354-63. doi: 10.1016/j.ctrv.2009.02.001. Epub 2009 Mar 6.

Chao YC, Pan SH, Yang SC, Yu SL, Che TF, Lin CW, Tsai MS, Chang GC, Wu CH, Wu YY, Lee YC, Hong TM, Yang PC. Claudin-1 is a metastasis suppressor and correlates with clinical outcome in lung adenocarcinoma. Am J Respir Crit Care Med. 2009 Jan 15; 179(2): 123-33. doi: 10.1164/rccm.200803-456OC. Epub 2008 Sep 11.

Chen AM, Garcia J, Lee NY, Bucci MK, Eisele DW. Patterns of nodal relapse after surgery and postoperative radiation therapy for carcinomas of the major and minor salivary glands: what is the role of elective neck irradiation? Int J Radiat Oncol Biol Phys. 2007 Mar 15;67(4):988-94. Epub 2007 Jan 17. 
Chen AM, Granchi PJ, Garcia J, Bucci MK, Fu KK, Eisele DW. Local-regional recurrence after surgery without postoperative irradiation for carcinomas of the major salivary glands: implications for adjuvant therapy. Int J Radiat Oncol Biol Phys. 2007 Mar 15;67(4):982-7. Epub 2007 Jan 22.

Chen SP, Zhou B, Willis BC, Sandoval AJ, Liebler JM, Kim KJ, Ann DK, Crandall ED, Borok Z. Effects of transdifferentiation and EGF on claudin isoform expression in alveolar epithelial cells. J Appl Physiol (1985). 2005 Jan;98(1):322-8. Epub 2004 Sep 10.

Chen X, Liang $\mathrm{H}$, Zhang J, Zen K, Zhang CY. Secreted microRNAs: a new form of intercellular communication. Trends Cell Biol. 2012 Mar;22(3):125-32. doi: 10.1016/j.tcb.2011.12.001. Epub 2012 Jan 17.

Chiba H, Osanai M, Murata M, Kojima T, Sawada N. Transmembrane proteins of tight junction. Biochim Biophys Acta. 2008 Mar;1778(3):588-600. Epub 2007 Sep 4.

Chiu GA, Woodwards RT, Benatar B, Hall R. Mandibular central mucoepidermoid carcinoma with distant metastasis. Int J Oral Maxillofac Surg. 2012 Mar;41(3):361-3. doi: 10.1016/j.ijom.2011.10.005. Epub 2011 Nov 6.

Ciardello F, Tortora G. EGFR antagonists in cancer treatment. N Engl J Med. 2008 Mar 13;358(11):1160-74. doi: 10.1056/NEJMra0707704.

Cipriani NA, Lusardi JJ, McElherme J, Pearson AT, Olivas AD, Fitzpatrick C, Lingen MW, Blair EA. Mucoepidermoid Carcinoma: A Comparison of Histologic Grading Systems and Relationship to MAML2 Rearrangement and Prognosis. Am J Surg Pathol. 2019 Jul;43(7):885-897. doi: 10.1097/PAS.0000000000001252.

Claude P, Goodenough DA. Fracture faces of zonulae occludentes from "tight" and "leaky" epithelia. J Cell Biol. 1973 Aug; 58(2): 390-400.

Coca-Pelaz A, Rodrigo JP, Triantafyllou A, Hunt JL, Rinaldo A, Strojan P, Haigentz M Jr, Mendenhall WM, Takes RP, Vander Poorten V, Ferlito A. Salivary mucoepidermoid carcinoma revisited. Eur Arch Otorhinolaryngol. 2015 Apr;272(4):799-819. doi: 10.1007/s00405-014-3053-z. Epub 2014 Apr 26.

Cohen-Kerem R, Campisi P, Ngan BY, lera D, Sándor GK, Forte V. Central mucoepidermoid carcinoma of the mandible in a child. Int J Pediatr Otorhinolaryngol. 2004 Sep; 68(9): 1203-7. 
da Cunha Santos G, Shepherd FA, Tsao MS. EGFR mutations and lung cancer. Annu Rev Pathol. 2011;6:49-69. doi: 10.1146/annurev-pathol-011110-130206.

Danzinger S, Tan YY, Rudas M, Kastner MT, Weingartshofer S, Muhr D, Singer CF. Association of Cytokeratin 5 and Claudin 3 expression with BRCA1 and BRCA2 germline mutations in women with early breast cancer. BMC Cancer. 2019 Jul 15;19(1):695. doi: 10.1186/s12885-019-5908-6.

Dardick I. Color atlas/text of salivary gland pathology. New York: Igaku-Shoin Medical Publishers; c1996.

Daugherty BL, Ward C, Smith T, Ritzenthaler JD, Koval M. Regulation of heterotypic claudin compatibility. J Biol Chem. 2007 Oct 12;282(41):30005-13. Epub 2007 Aug 14.

Delporte C, Steinfeld S. Distribution and roles of aquaporins in salivary glands. Biochim Biophys Acta. 2006 Aug;1758(8):1061-70. Epub 2006 Feb 28.

Denker BM, Nigam SK. Molecular structure and assembly of tight junction. Am J Physiol. 1998 Jan;274(1):F1-9. doi: 10.1152/ajprenal.1998.274.1.F1.

Dhawan P, Ahmad R, Chaturvedi R, Smith JJ, Midha R, Mittal MK, Krishnan M, Chen X, Eschrich S, Yeatman TJ, Harris RC, Washington MK, Wilson KT, Beauchamp RD, Singh AB. Claudin-2 expression increases tumorigenicity of colon cancer cells: role of epidermal growth factor receptor activation. Oncogene. 2011 Jul 21;30(29):323447. doi: 10.1038/onc.2011.43. Epub 2011 Mar 7.

Ding J, Sha L, Shen P, Huang M, Cai Q, Li J. MicroRNA-18a inhibits cell growth and induces apoptosis in osteosarcoma by targeting MED27. Int J Oncol. 2018 Jul;53(1):329-338. doi: 10.3892/ijo.2018.4374. Epub 2018 Apr 16.

Dos Reis PP, Bharadwaj RR, Machado J, Macmillan C, Pintilie M, Sukhai MA, PerezOrdonez B, Gullane P, Irish J, Kamel-Reid S. Claudin 1 overexpression increases invasion and is associated with aggressive histological features in oral squamous cell carcinoma. Cancer. 2008 Dec 1; 113(11): 3169-80. doi: 10.1002/cncr.23934.

D'Souza T, Agarwal R, Morin P. Phosphorylation of claudin-3 at threonine 192 by cAMP-dependent protein kinase regulates tight junction barrier functionin ovarian cancer cells. J Biol Chem. 2005 Jul 15;280(28):26233-40. Epub 2005 May 19. 
Ellis GL, Auclair P. Tumors of salivary glands, in Armed Forces Institute of Pathology, Atlas of tumor pathology, 4rd series. Washington; 2008. p. 155-75.

El-Naggar AK, Chan JKC, Grandis JR, Takata T, Slootweg PJ. World Health Organization classification of tumours 4th ed. Lyon: IARC Press, 2017.

Engels BM, Hutvagner G. Principles and effects of microRNA-mediated posttranscriptional gene regulation. Oncogene. 2006 Oct 9;25(46):6163-9.

English DP, Santin AD. Claudins overexpression in ovarian cancer: potential targets for Clostridium Perfringens Enterotoxin (CPE) based diagnosis and therapy. Int J Mol Sci. 2013 May 17; 14(5): 10410-37. doi: 10.3390/ijms140510412.

Esquela-Kerscher A, Slack FJ. Oncomirs - microRNAs with a role in cancer. Nat Rev Cancer. 2006 Apr;6(4):259-69.

Ettl T, Schwarz S, Kleinsasser N, Hartmann A, Reichert TE, Driemel $O$. Overexpression of EGFR and absence of C-KIT expression correlate with poor prognosis in salivary gland carcinomas. Histopathology. 2008 Nov;53(5):567-77. doi: 10.1111/j.1365-2559.2008.03159.x.

Fanning AS, Jameson BJ, Jesaitis LA, Anderson JM. Tight junction protein ZO-1 estabilishes a link between the transmembrane protein occluding and the actin cytoskeleton. J Biol Chem. 1998 Nov 6; 273(45): 29745-53.

Farquhar MG, Palade GE. Junctional complexes in various epithelia. J Cell Biol. 1963 May; 17: 375-412.

Förster C. Tight junctions and the modulation of barrier function in disease. Histochem Cell Biol. 2008 Jul;130(1):55-70. doi: 10.1007/s00418-008-0424-9. Epub 2008 Apr 16.

Frixen UH, Behrens J, Sachs M, Eberle G, Voss B, Warda A, Löchner D, Birchmeier W. E-cadherin-mediated cell-cell adhesion prevents invasiveness of human carcinoma cells. J Cell Biol. 1991 Apr; 113(1): 173-85.

Furuse M, Fujita K, Hiiragi T, Fujimoto K, Tsukita S. Claudin-1 and 2: novel integral membrane proteins localizing at tight junctions with no sequence similarity to occluding. J Cell Biol. 1998 Jun 29; 141(7): 1539-50. 
Furuse M, Hirase T, Itoh M, Nagafuchi A, Yonemura S, Tsukita S, Tsukita S. Occludin: a novel integral membrane protein localizing at tight junctions. J Cell Biol. 1993 Dec; 123(6 Pt 2): 1777-88.

Galdirs TM, Kappler M, Reich W, Eckert AW. Current aspects of salivary gland tumors - a systematic review of the literature. GMS Interdiscip Plast Reconstr Surg DGPW. 2019 Aug 2;8:Doc12. doi: 10.3205/iprs000138. eCollection 2019.

Garden AS, el-Naggar AK, Morrison WH, Callender DL, Ang KK, Peters LJ. Postoperative radiotherapy for malignant tumors of the parotid gland. Int $\mathrm{J}$ RadiatOncolBiol Phys. 1997 Jan 1; 37(1): 79-85.

Gibbons MD, Manne U, Carroll WR, Peters GE, Weiss HI, Grizzle WE. Molecular differences in mucoepidermoid carcinoma and adenoid cystic carcinoma of the major salivar glands. Laryngoscope. 2001 Aug; 111(8): 1373-8.

Guntinas-Lichius O, Kick C, Klussmann JP, Jungehuelsing M, Stennert E. Pleomorphic adenoma of the parotid gland: a 13-year experience of consequent management by lateral or total paratidectomy. Eur Arch Otorhinolaryngol. 2004 Mar;261(3):143-6. Epub 2003 Jul 22.

Hammond SM. An overview of microRNAs. Adv Drug Deliv Rev. 2015 Jun 29;87:314. doi: 10.1016/j.addr.2015.05.001. Epub 2015 May 12.

Hayashita Y, Osada H, Tatematsu Y, Yamada H, Yanagisawa K, Tomida S, Yatabe Y, Kawahara K, Sekido Y, Takahashi T. A polycistronic microRNA cluster, miR-1792 , is overexpressed in human lung cancers and enhances cell proliferation. Cancer Res. 2005 Nov 1;65(21):9628-32.

He H, Jazdzewski K, Li W, Liyanarachchi S, Nagy R, Volinia S, Calin GA, Liu CG, Franssila K, Suster S, Kloos RT, Croce CM, de la Chapelle A. The role of microRNA genes in papillary thyroid carcinoma. Proc Natl Acad Sci U S A. 2005 Dec 27;102(52):19075-80. Epub 2005 Dec 19.

Healey WV, Perzin KH, Smith L. Mucoepidermoid carcinoma of salivary gland origin. Classification, clinical-pathologic correlation, and results of treatment. Cancer. 1970 Aug; 26(2): 368-88.

Heiler S, Mu W, Zoller M, Thuma F. The importance of claudin-7 palmitoylation on membrane subdomain localization and metastasis-promoting activities. Cell Commun Signal. 2015 Jun 9;13:29. doi: 10.1186/s12964-015-0105-y. 
Hellquist HB, Skalova A. Histopathology of the salivary glands. 1st ed. Berlim, Heidelberg: Springer-Verlag; 2014.

Hicks MJ, el-Naggar AK, Flaitz CM, Luna MA, Batsakis JG. Histocytologic grading of mucoepidermoid carcinoma of major salivary glands in prognosis and survival: a clinicopathologic and flow cytometric investigation. Head Neck. 1995 Mar-Apr; 17(2): 89-95.

Hirajima S, Komatsu S, Ichikawa D, Takeshita H, Konishi H, Shiozaki A, Morimura R, Tsujiura M, Nagata H, Kawaguchi T, Arita T, Kubota T, Fujiwara H, Okamoto K, Otsuji E. Clinical impact of circulating miR-18a in plasma of patients with oesophageal squamous cell carcinoma. Br J Cancer. 2013 May 14;108(9):1822-9. doi: 10.1038/bjc.2013.148. Epub 2013 Apr 11.

Hoevel T, Macek R, Mundigl O, Swisshelm K, Kubbies M. Expression and targeting of the tight junction protein CLDN1 in CLDN1- negative human breast tumor cells. $J$ Cell Physiol. 2002;191(1):60-8.

Holmberg KV, Hoffman MP. Anatomy, biogenesis and regeneration of salivary glands. Monogr Oral Sci. 2014;24:1-13. doi: 10.1159/000358776. Epub 2014 May 23.

Hosokawa Y, Shirato H, Kagei K, Hashimoto S, Nishioka T, Tei K, Ono M, Ohmori K, Kaneko M, Miyasaka K, Nakamura M. Role of radiotherapy for mucoepidermoid carcinoma of salivary gland. Oral Oncol. 1999 Jan; 35(1): 105-11.

Hou J, Gomes AS, Paul DL, Goodenough DA. Study of claudin function by RNA interference. J Biol Chem. 2006 Nov 24;281(47):36117-23. Epub 2006 Oct 3.

Humphrey SP, Williamson RT. A review of saliva: normal composition, flow, and function. J Prosthet Dent. 2001 Feb;85(2):162-9.

Humphreys KJ, McKinnon RA, Michael MZ. miR-18a inhibits CDC42 and plays a tumour suppressor role in colorectal cancer cells. PLoS One. 2014 Nov 7;9(11):e112288. doi: 10.1371/journal.pone.0112288. eCollection 2014.

Ikari A, Atomi K, Takiguchi A, Yamazaki Y, Miwa M, Sugatani J. Epidermal growth factor increases claudin-4 expression mediated by Sp1 elevation in MDCK cells. Biochem Biophys Res Commun. 2009 Jul 3;384(3):306-10. doi: 10.1016/j.bbrc.2009.04.120. Epub 2009 May 3. 
Israel Y, Rachmiel A, Gourevich K, Nagler R. Kaplan-Meier analysis of salivary gland tumors: prognosis and long-term survival. J Cancer Res Clin Oncol. 2019 Aug;145(8):2123-2130. doi: 10.1007/s00432-019-02953-9. Epub 2019 Jun 11.

Israel Y, Rachmiel A, Gourevich K, Nagler R. Salivary malignancies- medical, demographic and diagnostic analysis. J Craniomaxillofac Surg. 2019 Mar;47(3):500504. doi: 10.1016/j.jcms.2019.01.006. Epub 2019 Jan 11.

Ivanov Al. Actin motors that drive formation and disassembly of epithelialapical junctions. Front Biosci. 2008 May 1;13:6662-81.

Jääskeläinen A, Soini Y, Jukkola-Vuorinen A, Auvinen P, Haapasaari KM, Kirihtala P. High-level cytoplasmic claudin 3 expression is an independent predictor of poor survival in triple-negative breast cancer. BMC Cancer. 2018 Feb 27;18(1):223. doi: 10.1186/s12885-018-4141-z.

Jakobsson PA, Blanck C, Eneroth CM. Mucoepidermoid carcinoma of the parotid gland. Cancer. 1968 Jul; 22(1): 111-24.

Jorissen RN, Walker F, Pouliot N, Garrett TP, Ward CW, Burgess AW. Epidermal growth factor receptor: mechanisms of activation and signalling. Exp Cell Res. 2003 Mar 10; 284(1): 31-53.

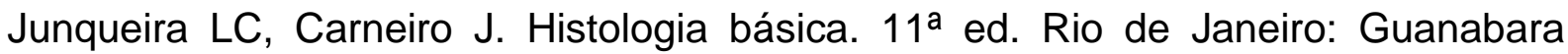
Koogan; 2008.

Kalyankrishna S1, Grandis JR. Epidermal growth factor receptor biology in head and neck cancer. J Clin Oncol. 2006 Jun 10;24(17):2666-72.

Katchburian E, Arana V. Histologia e embriologia oral: texto-atlas-correlações clinicas. 2 ed. Buenos Aires-Rio de Janeiro: Panamericana-Guanabara Koogan; 2004.

Kawedia JD, Nieman ML, Boivin GP, Melvin JE, Kikuchi K, Hand AR, Lorenz JN, Menon AG. Interaction between transcellular and paracellular water transport pathways through Aquaporin 5 and the tight junction complex. Proc Natl Acad Sci U S A. 2007 Feb 27;104(9):3621-6. Epub 2007 Feb 21. 
Kim SY, Kawaguchi T, Yan L, Young J, Qi Q, Takabe K. Clinical Relevance of microRNA Expressions in Breast Cancer Validated Using the Cancer Genome Atlas (TCGA). Ann Surg Oncol. 2017 Oct;24(10):2943-2949. doi: 10.1245/s10434-0175984-2. Epub 2017 Aug 1.

Kim TH, Huh JH, Lee S, Kang H, Kim GI, An HJ. Down-regulation of claudin-2 in breast carcinomas is associated with advanced disease. Histopathology. 2008 Jul; 53(1): 48-55. doi: 10.1111/j.1365-2559.2008.03052.x. Epub 2008 May 12.

Kimura $\mathrm{Y}$, Shiozaki H, Hirao M, Maeno $\mathrm{Y}$, Doki $\mathrm{Y}$, Inoue $\mathrm{M}$, Monden $\mathrm{T}$, AndoAkatsuka Y, Furuse M, Tsukita S, Monden M. Expression of occludin, tight junction associated protein, in human digestive tract. Am J Pathol. 1997 Jul; 151(1): 45-54.

Kojima T, Yamamoto T, Lan M, Murata M, Takano K, Go M, Ichimiya S, Chiba H, Sawada N. Inhibition of MAP kinase activity moderates changes in expression and function of $\mathrm{C} \times 32$ but not claudin-1 during DNA synthesis in primary cultures of rat hepatocytes. Med Electron Microsc. 2004 Jun;37(2):101-13.

Komatsu S, Ichikawa D, Takeshita $H$, Morimura $R$, Hirajima S, Tsujiura $M$, Kawaguchi T, Miyamae M, Nagata $H$, Konishi $H$, Shioaki A, Otsuji E. Circulating miR18a: a sensitive cancer screening biomarker in human cancer. In vivo. 2014 MayJun; 28(3): 293-7.

Komiya T, Park Y, Modi S, Coxon AB, Oh H, Kaye FJ. Sustained expression of Mect1-Maml2 is essential for tumor cell growth in salivary gland cancers carrying the $\mathrm{t}(11 ; 19)$ translocation. Oncogene. 2006 Oct 5; 25(45): 6128-32. Epub 2006 May 1.

Krause G, Winkler L, Muller SL, Haseloff RF, Piontek J, Blasig IE. Structure and function of claudins. Biochim Biophys Acta. 2008 Mar;1778(3):631-45. Epub 2007 Oct 25.

Krol J, Loedige I, Filipowicz W. The widespread regulation of microRNA biogenesis, function and decay. Nat Rev Genet. 2010 Sep;11(9):597-610. doi: 10.1038/nrg2843. Epub 2010 Jul 27.

Krug SM, Schulzke JD, Fromm M. Tight junction, selective permeability, and related diseases. Semin Cell Dev Biol. 2014 Dec;36:166-76. doi: 10.1016/j.semcdb.2014.09.002. Epub 2014 Sep 16. 
Kupferman ME, de la Garza GO, Santillan AA, Williams MD, Varghese BT, Huh W, Roberts D, Weber RS. Outcomes of pediatric patients with malignancies of the major salivary glands. Ann Surg Oncol. 2010 Dec;17(12):3301-7. doi: 10.1245/s10434-0101165-2. Epub 2010 Jun 29.

Lal-Nag M, Morin P. The claudins. Genome Biol. 2009;10(8):235. doi: 10.1186/gb2009-10-8-235. Epub 2009 Aug 26.

Lee RC, Feinbaum RL, Ambros V. The C. elegans heterochronic gene lin-4 encodes small RNAs with antisense complementarity to lin-14. Cell. 1993 Dec 3; 75(5): 84354.

Li L, Wang D. MicroRNA-128-b regulates epidermal growth factor receptor expression in non-small cell lung cancer. Mol Med Rep. 2019 Dec;20(6):4803-4810. doi: 10.3892/mmr.2019.10731. Epub 2019 Oct 8.

Liang C, Zhang X, Wang HM, Liu XM, Zhang XJ, Zheng B, Qian GR, Ma ZL. MicroRNA-18a-5p functions as an oncogene by directly targeting IRF2 in lung cancer. Cell Death Dis. 2017 May 4;8(5):e2764. doi: 10.1038/cddis.2017.145.

Lindsey S, Langhans SA. Epidermal growth factor signaling in transformed cells. Int Rev Cell Mol Biol. 2015;314:1-41. doi: 10.1016/bs.ircmb.2014.10.001. Epub 2014 Nov 18.

Lingaraju A, Long TM, Wang Y, Austin II JR, Turner JR. Conceptual barriers to understanding physical barriers. Semin Cell Dev Biol. 2015 Jun;42:13-21. doi: 10.1016/j.semcdb.2015.04.008. Epub 2015 May 21.

Linggi B, Carpenter G. ErbB receptors: new insights on mechanisms and biology. Trends Cell Biol. 2006 Dec;16(12):649-56. Epub 2006 Nov 7.

Liu S, Ruan M, Li S, Wang L, Yang W. Increased expression of muc1 predicts poor survival in salivary gland mucoepidermoid carcinoma. J Craniomaxillofac Surg. 2014 Dec;42(8):1891-6. doi: 10.1016/j.jcms.2014.07.008. Epub 2014 Aug 6.

Livak KJ, Schmittgen TD. Analysis of relative gene expression data using real-time quantitative PCR and the 2(-Delta Delta C(T)) Method. Methods. 2001;25(4):402-8. 
Lourenço SV, Coutinho-Camilo CM, Buim ME, Pereira CM, Carvalho AL, Kousalski LP, Soares EA. Oral squamous cell carcinoma: status of tight junction claudins in the different histopathological patters and relationship with clinical parameters. A tissuemicroarray-based study of 136 cases. J Clin Pathol. 2010 Jul;63(7):609-14. doi: 10.1136/jcp.2009.070409.

Lourenço SV, Coutinho-Camillo CM, Buim ME, Uyekita SH, Soares FA. Human salivary gland branching morphogenesis: morphological localization of claudins and its parallel relation with developmental stages revealed by expression of cytoskeleton and secretion markers. Histochem Cell Biol. 2007 Oct;128(4):361-9. Epub 2007 Aug 9.

Loyola AM, de Sousa SO, Araújo NS, Araújo VC. Study of minor salivary gland mucoepidermoid carcinoma differentiation based on immunohistochemical expression of cytokeratins, vimentin and muscle-specific actin. Oral Oncol. 1998 Mar;34(2):112-8.

Lujan B, Hakim S, Moyano S, Nadal A, Caballero M, Diaz A, Valera A, Cerrara M, Cardesa A, Alos L. Activation of the EGFR/ERK pathway in high-grade mucoepidermoid carcinomas of the salivar glands. $\mathrm{Br} J$ Cancer. 2010 Aug 10;103(4):510-6. doi: 10.1038/sj.bjc.6605788. Epub 2010 Jul 27.

Luna MA. Salivary mucoepidermoid carcinoma: revisited. Adv Anat Pathol. 2006 Nov; 13(6): 293-307.

Maria OM, Kim JW, Gerstenhaber JA, Baum BJ, Tran SD. Distribution of tight junction proteins in adult human salivary glands. J Histochem Cytochem. 2008 Dec;56(12):1093-8. doi: 10.1369/jhc.2008.951780. Epub 2008 Sep 2.

Martin TA, Jiang WG. Loss of tight junction barrier function and its role in cancer metastasis. Biochim Biophys Acta. 2009 Apr;1788(4):872-91. doi: 10.1016/j.bbamem.2008.11.005. Epub 2008 Nov 14.

Martins C, Cavaco B, Tonon G, Kaye FJ, Soares J, Fonseca I. A study of MECT1MAML2 in mucoepidermoid carcinoma and Warthin's tumor of salivary glands. J Mol Diagn. 2004 Aug; 6(3): 205-10.

Matter K, Aijaz S, Tsapara A, Balda MS. Mammalian tight junction in the regulation of epithelial differentiation and proliferation. Curr. Opin. Cell Biol. 2005 Oct; 17(5): 453458. 
Mendell JT. miRiad roles for the miR-17-92 cluster in development and disease. Cell. 2008 Apr 18;133(2):217-22. doi: 10.1016/j.cell.2008.04.001.

Mineta K, Yamamoto Y, Yamazaki Y, Tanaka H, Tada Y, Saito K, Tamura A, Igarashi $\mathrm{M}$, Endo T, Takeuchi K, Tsukita S. Predicted expansion of the claudin multigene family. FEBS Lett. 2011 Feb 18;585(4):606-12. doi: 10.1016/j.febslet.2011.01.028. Epub 2011 Jan 26.

Mitic LL, Van Itallie CM, Anderson JM. Molecular physiology and pathophysiology of tight junctions I. Tight junction structure and function: lessons from mutant animals and proteins. Am J Physiol Gastrointest Liver Physiol. 2000 Aug;279(2):G250-4.

Mogilyansky E, Rigoutsos I. The miR-17/92 cluster: a comprehensive update on its genomics, genetics, functions and increasingly important and numerous roles in health and disease. Cell Death Differ. 2013 Dec;20(12):1603-14. doi: 10.1038/cdd.2013.125.

Morimura R, Komatsu S, Ichikawa D, Takeshita $H$, Tsujiura M, Nagata $H$, Konishi $H$, Shiozaki A, Ikoma H, Okamoto K, Ochiai T, Tanigushi H, Otsuji E. Novel diagnostic value of circulating miR-18a in plasma of patients with pancreatic cancer. $\mathrm{Br} \mathrm{J}$ Cancer. 2011 Nov 22;105(11):1733-40. doi: 10.1038/bjc.2011.453. Epub 2011 Nov 1.

Morse E, Fujiwara RJT, Husain Z, Judson B, Mehra S. Pediatric salivary cancer: Epidemiology, treatment trends, and association of treatment modality with survival. Otolaryngol Head Neck Surg. 2018 Sep;159(3):553-563. doi: 10.1177/0194599818771926. Epub 2018 Apr 24.

Mraz M, Pospisilova S. MicroRNAs in chronic lymphocytic leukemia: from casuality to associations and back. Expert Rev Hematol. 2012 Dec;5(6):579-81. doi: 10.1586/ehm.12.54.

Nagano CP, Coutinho-Camillo CM, Pinto CA, Soares FA, Santos F, Fonseca I, Lourenço SV. Cytokeratin immunoprofile of primary and metastatic adenoid cystic carcinoma of salivary glands: a report of two cases. Autops Case Rep. 2016 Dec 30;6(4):57-63. doi: 10.4322/acr.2016.056. eCollection 2016 Oct-Dec.

Nance MA, Seethala RR, Wang Y, Chiosea SI, Myers EN, Johnson JT, Lai SY. Treatment and survival outcomes based on histologic grading in patients with head and neck mucoepidermoid carcinoma. Cancer. 2008 Oct 15;113(8):2082-9. doi: 10.1002/cncr.23825. 
Neville BW, Damm DD, Allen CM, Bouquot JE. Oral and maxillofacial pathology. 2nd ed. New York, NY: Saunders; 2008.

Niessen CM, Gottardi CJ. Molecular components of the adherens junction. Biochim Biophys Acta. 2008 Mar;1778(3):562-71. doi: 10.1016/j.bbamem.2007.12.015. Epub 2008 Jan 14.

Nordkvist A, Gustafsson H, Juberg-Ode M, Stenman G. Recurrent rearrangements of 11q14-22 in mucoepidermoid carcinoma. Cancer Genet Cytogenet. 1994 Jun; 74(2): 77-83.

Okabe M, Inagaki H, Murase T, Inoue M, Nagai N, Eimoto T. Prognostic significance of p27 and ki-67 expression in mucoepidermoid carcinoma of the intraoral minor salivary gland. Mod Pathol. 2001 Oct; 14(10): 1008-14.

Patel VN, Hoffman MP. Salivary gland development: a template for regeneration. Semin Cell Dev Biol. 2014 Jan-Feb;25-26:52-60. doi: 10.1016/j.semcdb.2013.12.001. Epub 2013 Dec 11.

Peppi M, Ghabriel MN. Tissue-specific expression of the tight junction proteins claudins and occludin in the rat salivary glands. J Anat. 2004 Oct; 205(4): 257-66.

Pérez-de-Oliveira ME, Wagner VP, Araújo ALD, Martins MD, Santos-Silva AR, Bingle L, Vargas PA. Prognostic value of CRTC1-MAML2 translocation in salivary mucoepidermoid carcinoma: Systematic review and meta-analysis. J Oral Pathol Med. 2019 Oct 29. doi: 10.1111/jop.12970. [Epub ahead of print]

Pinkston JA, Cole P. Incidence rates of salivary gland tumors: results from a population based study. Otolaryngol Head Neck Surg.1999 Jun; 120(6): 834-40.

Pires FR, Azevedo RS, Ficarra G, Cardoso AS, Carlos R, Kowalski LP, de Almeida OP. Metastatic renal cell carcinoma to the oral cavity and clear cell mucoepidermoid carcinoma: comparative clinicopathologic and immunohistochemical study. Oral Surg Oral Med Oral Pathol Oral Radiol Endod. 2010 Apr;109(4):e22-7. doi: 10.1016/j.tripleo.2009.12.006.

Reinheimer A, Vieira DS, Cordeiro MM, Rivero ER. Retrospective study of 124 cases of salivary gland tumors and literature review. J Clin Exp Dent. 2019 Nov 1;11(11):e1025-e1032. doi: 10.4317/jced.55685. eCollection 2019 Nov. 
Resnick MB, Konkin T, Routhier J, Sabo E, Pricolo VE. Claudin -1 is a strong prognostic indicator in stage II colonic cancer: a tissue microarray study. Mod Pathol 2005; 18:511-8.

Rokkam D, Lafemina MJ, Lee JW, Matthay MA, Frank JA. Claudin-4 levels are associated with intact alveolar fluid clearance in human lungs. Am J Pathol. 2011 Sep;179(3):1081-7. doi: 10.1016/j.ajpath.2011.05.017. Epub 2011 Jul 8.

Sanchez-Mejias A1, Kwon J1, Chew XH1, Siemens A1, Sohn HS1, Jing G1, Zhang $\mathrm{B} 1$, Yang $\mathrm{H} 1$, Tay $\mathrm{Y} 1,2$. A novel SOCS5/miR-18/miR-25 axis promotes tumorigenesis in liver cancer. Int J Cancer. 2019 Jan 15;144(2):311-321. doi: 10.1002/ijc.31857. Epub 2018 Nov 9.

Savitsky D1, Tamura T, Yanai H, Taniguchi T. Regulation of immunity and oncogenesis by the IRF transcription factor family. Cancer Immunol Immunother. 2010 Apr;59(4):489-510. doi: 10.1007/s00262-009-0804-6. Epub 2010 Jan 5.

Seifert G, Brocheriou C, Cardesa A, Eveson JW. WHO international histological classification of tumours. Tentative histological classification of salivary gland tumours. Pathol Res Pract. 1990 Oct; 186(5): 555-81.

Shang J, Shui Y, Sheng I, Wang K, HGu Q, Wei Q. Epidermal growth factor receptor and human epidermal growth receptor 2 expression in parotid mucoepidermoid carcinoma: possible implications for targeted therapy. Oncol Rep. 2007 Feb; 19(2): 435-40.

Shen K, Cao Z, Zhu R, You L, Zhang T. The dual functional role of MicroRNA-18a (miR-18a) in cancer development. Clin Transl Med. 2019 Dec 23;8(1):32. doi: 10.1186/s40169-019-0250-9.

Shen L, Weber CR, Turner JR. The tight junction protein complex undergoes rapid and continuous molecular remodeling at steady state. J Cell Biol. 2008 May 19;181(4):683-95. doi: 10.1083/jcb.200711165. Epub 2008 May 12.

Singh $A B$, Dhawan $P$. Claudins and cancer: Fall of the soldiers entrusted to protect the gate and keep the barrier intact. Semin Cell Dev Biol. 2015 Jun;42:58-65. doi: 10.1016/j.semcdb.2015.05.001. Epub 2015 May 27.

Singh AB1, Harris RC. Epidermal growth factor receptor activation differentially regulates claudin expression and enhances transepithelial resistance in Madin-Darby canine kidney cells. J Biol Chem. 2004 Jan 30;279(5):3543-52. Epub 2003 Oct 30. 
Singh $A B$, Sharma A, Dhawan P. Claudin family of proteins and cancer: an overview. J Oncol. 2010;2010:541957. doi: 10.1155/2010/541957. Epub 2010 Jul 8.

Singh $A B$, Sugimoto $K$, Dhawan $P$, Harris $R C$. Juxtacrine activation of EGFR regulatesclaudin expression and increases transepithelial resistance. Am J Physiol Cell Physiol. 2007 Nov;293(5):C1660-8. Epub 2007 Sep 13.

Sobel G, Páska C, Szabó I, Kiss A, Kádár A, Schaff Z. Increased expression of claudins in cervical squamous intraepithelial neoplasia and invasive carcinoma. Hum Pathol. 2005 Feb; 36(2):162-9.

Soini $Y$. Expression of claudins 1, 2, 3, 4, 5 and 7 in various types of tumours. Histopathology. 2005 May; 46(5): 551-60.

Stelwagen K, Singh $\mathrm{K}$. The role of tight junction in mammary gland function. J Mammary Gland Biol Neoplasia. 2014 Mar;19(1):131-8. doi: 10.1007/s10911-0139309-1. Epub 2013 Nov 19.

Stevenson BR, Keon BH. The tight junction: morphology to molecules. Annu Rev Cell Dev Biol. 1998; 14: 89-109.

Stewart FW, Foote FW, Becker WF. Muco-epidermoid tumors of salivary glands. Ann Sureg. 1945 Nov; 122(5): 820-44.

Stroynowska-Czerwinska A, Fiszer A, Krzyzosiak WJ. The panorama of miRNAmediated mechanisms in mammalian cells. Cell Mol Life Sci. 2014 Jun;71(12):225370. doi: 10.1007/s00018-013-1551-6. Epub 2014 Jan 29.

Swierniak M, Wojcicka A, Czetwertynska M, Stachlewska E, Maciag M, Wiechno W, Gornicka B, Bogdanska M, Koperski L, de la Chapelle A, Jazdzewski K. In-depth characterization of the microRNA transcriptome in normal thyroid and papillary thyroid carcinoma. J Clin Endocrinol Metab. 2013 Aug;98(8):E1401-9. doi: 10.1210/jc.2013-1214. Epub 2013 Jun 19.

Takahashi RU, Miyazaki H, Ochiya T. The role of microRNAs in the regulation of cancer stem cells. Front Genet. 2014 Jan 3;4:295. doi: 10.3389/fgene.2013.00295. 
Takakura S, Mitsutake N, Nakashima M, Namba H, Saenko VA, Rogounovitch TI, Nakazawa Y, Hayashi T, Ohtsuru A, Yamashita S. Oncogenic role of miR-17-92 cluster in anaplastic thyroid cancer cells. Cancer Sci. 2008 Jun;99(6):1147-54. doi: 10.1111/j.1349-7006.2008.00800.x. Epub 2008 Apr 21.

Takamizawa J, Konishi H, Yanagisawa K, Tomida S, Osada H, Endoh H, Harano T, Yatabe Y, Nagino M, Nimura Y, Mitsudomi T, Takahashi T. Reduced expression of the let-7 microRNAs in human lung cancers in association with shortened postoperative survival. Cancer Res. 2004 Jun 1;64(11):3753-6.

Thompson EW, Newgreen DF, Tarin D. Carcinoma invasion and matastasis: a role epithelial-mesenchymal transition. Cancer Res. 2005 Jul 15;65(14):5991-5; discussion 5995.

Tirado Y, Williams MD, Hanna EY, Kaye FJ, Batsakis JG, El-Naggar AK. CRTC1MAML2 fusion transcript in high grade mucoepidermoid carcinomas of salivary and thyroid glands and Warthin's tumors: Implications for histogenesis and biologic behaviour. Genes Chromosomes Cancer. 2007 Jul; 46(7):708-15.

Tonon G, Modi S, Wu L, Kubo A, Coxon AB, Komiya T, O’Neil K, Stover K, El-Naggar A, Griffin JD, Kirsch IR, Kaye FJ. T(11;19)(q21;p13) translocation in mucoepidermoid carcinoma creates a novel fusion product that disrupts a Notch signaling pathway. Nat Genet. 2003 Feb;33(2):208-13. Epub 2003 Jan 21.

Tsujiura M, Komatsu S, Ichikawa D, Shiozaki A, Konishi $H$, Takeshita $H$, Moriumura $R$, Nagata $H$, Kawaguchi T, Hirajima S, Arita T, Fujiwara H, Okamoto K, Otsuji E. Circulating miR-18a in plasma contributes to cancer detection and monitoring in patients with gastric cancer. Gastric Cancer. 2015 Apr;18(2):271-9. doi: 10.1007/s10120-014-0363-1. Epub 2014 Mar 14.

Tsukita S, Furuse M, Itoh M. Multifunctional strands in tight junctions. Nat Rev Mol Cell Biol. 2001 Apr; 2(4): 285-93.

Tsukita S, Furuse M. The structure and function of claudins, cell adhesionmolecules at tight junctions. Ann N Y Acad Sci. 2000; 915: 129-35.

Turksen K, Troy TC. Barriers built on claudins. J Cell Sci. 2004 May 15; 117 (Pt 12): 2435-47. 
Vander Poorten V, Hunt J, Bradley PJ, Haigentz M Jr, Rinaldo A, Mendenhall WM, Suarez C, Silver C, Takes RP, Ferlito A. Recent trends in the management of minor salivary gland carcinoma. Head Neck. 2014 Mar;36(3):444-55. doi: 10.1002/hed.23249. Epub 2013 Apr 4.

Van Itallie CM, Anderson JM. Claudins and epithelial paracelular transport. Annu Rev Physiol 2006; 68: 403-29.

Van Itallie CM, Colegio OR, Anderson JM. The cytoplasmic tails of claudins can influence tight junction barrier properties through effects on protein stability. J Membr Biol. 2004 May 1; 199(1):29-38.

Van Itallie CM, Holmes J, Bridges A, Gookin JL, Coccaro MR, Proctor W, Colegio $\mathrm{OR}$, Anderson JM. The density of small tight junction pores varies among cell types and is increasedby expression of claudin-2. J Cell Sci. 2008 Feb 1;121(Pt 3):298305. doi: 10.1242/jcs.021485. Epub 2008 Jan 15.

Vargas PA, Gerhard R, Araujo Filho VJ, Castro IV. Salivary gland tumors in a Brazilian population: a retrospective study of 124 cases. Rev Hosp Clin Fac Med Sao Paulo. 2002 Nov-Dec;57(6):271-6. Epub 2003 Feb 17.

Vishnoi A, Rani S. MiRNA Biogenesis and Regulation of Diseases: An Overview. Methods Mol Biol. 2017;1509:1-10.

Volinia S, Calin GA, Liu CG, Ambs S, Cimmino A, Petrocca F, Visone R, lorio M, Roldo C, Ferracin M, Prueitt RL, Yanaihara N, Lanza G, Scarpa A, Vecchione A, Negrini M, Harris CC, Croce CM. A microRNA expression signature of human solid tumors defines cancer gene targets. Proc Natl Acad Sci U S A. 2006 Feb 14;103(7):2257-61. Epub 2006 Feb 3.

Warner KA, Adams A, Bernardi L, Nor C, Finkel KA, Zhang Z, McLean SA, Helman J, Wolf GT, Divi V, Queimado L, Kaye FJ, Castilho RM, Nör JE. Characterization of tumorigenic cell lines from the recurrence and lymph node metastasis of a human salivary mucoepidermoid carcinoma. Oral Oncol. 2013 Nov;49(11):1059-66. doi: 10.1016/j.oraloncology.2013.08.004. Epub 2013 Sep 12.

Weinreb I, Seethala RR, Perez-Ordoñez B, Chetty R, Hoschar AP, Hunt JL. Oncocytic mucoepidermoid carcinoma: clinicopathologic description in a series of 12 cases. Am J Surg Pathol. 2009 Mar;33(3):409-16. doi: 10.1097/PAS.0b013e318184b36d. 
Wilmott JS, Zhang XD, Hersey $P$, Scolyer RA. The emerging important role of microRNAs in the pathogenesis, diagnosis and treatment of human cancers. Pathology. 2011 Oct;43(6):657-71. doi: 10.1097/PAT.0b013e32834a7358.

Woolgar JA, Triantafyllou A. Pitfalls and procedures in the histopathological diagnosis of oral and oropharyngeal squamous cell carcinoma and a review of the role of pathology in prognosis. Oral Oncol. 2009 Apr-May;45(4-5):361-85. doi: 10.1016/j.oraloncology.2008.07.016. Epub 2008 Oct 11.

Woolgar JA, Triantafyllou A, Thompson LD, Hunt JL, Lewis JS Jr, Williams MD, Cardesa A, Rinaldo A, Barnes L, Slootweg PJ, Devaney KO, Gnepp DR, Westra WH, Ferlito A. Double reporting and second opinion in head and neck pathology. Eur Arch Otorhinolaryngol. 2014 May;271(5):847-54. doi: 10.1007/s00405-014-2879-8. Epub 2014 Jan 17.

Xiang J, Wu J. Feud or Friend? The Role of the miR-17-92 Cluster in Tumorigenesis. Curr Genomics. 2010 Apr;11(2):129-35. doi: 10.2174/138920210790886853.

Xu X, Zhu S, Tao Z, Ye S. High circulating miR-18a, miR-20a, and miR-92a expression correlates with poor prognosis in patients with non-small cell lung cancer. Cancer Med. 2018 Jan;7(1):21-31. doi: 10.1002/cam4.1238. Epub 2017 Dec 21.

Yamamoto D, Kayamori K, Sakamoto K, Tsuchiya M, Ikeda T, Harada H, Yoda T, Watabe T, Hara-Yokoyama M. Intracellular claudin-1 at the invasive front of tongue squamous cell carcinoma is associated with lymph node metastasis. Cancer Sci. 2019 Nov 26. doi: 10.1111/cas.14249. [Epub ahead of print].

Yano S, Kondo K, Yamaguchi M, Richmond G, Hutchison M, Wakeling A, Averbuch $S$, Wadsworth P. Distribution and function of EGFR in human tissue and the effect of EGFR tyrosine kinase inhibition. Anticancer Res. 2003 Sep-Oct; 23(5A): 3639-50.

Yang S, Chen X. Calcification in clear cell mucoepidermoid carcinoma. Oral Surg Oral Med Oral Pathol Oral Radiol Endod. 2010 Feb;109(2):274-5. doi: 10.1016/j.tripleo.2009.08.012. Epub 2009 Oct 31.

Yarden Y. The EGFR family and its ligands in human cancer signalling mechanisms and therapeutic opportunities. Eur J Cancer. 2001 Sep; 37 Suppl 4: 53-8. 
Zhang N, Zhang H, Liu Y, Su P, Zhang J, Wang X, Sun M, Chen B, Zhao W, Wang L, Wang $H$, Moran MS, Haffty BG, Yang Q. SREBP1, targeted by miR-18a-5p, modulates epithelial-mesenchymal transition in breast cancer via forming a corepressor complex with Snail and HDAC1/2. Cell Death Differ. 2019 May;26(5):843859. doi: 10.1038/s41418-018-0158-8. Epub 2018 Jul 9.

Zhang W, Dhalberg JE, Tam W. MicroRNAs in tumorigenesis: a primer. Am J Pathol. 2007 Sep;171(3):728-38. 
ANEXO A - Parecer do Comitê de Ética em Pesquisa da FOUSP

FACULDADE DE
ODONTOLOGIA DA
UNIVERSIDADE DE SÃO $\quad$ Ploboforma

\section{PARECER CONSUBSTANCIADO DO CEP}

\section{DADOS DO PRONETO DE PESQUISA}

Titulo da Pocquiles: Avalaç5o da aç5o do EGF e do m/RNA-18a na regulaçbo da expresabo das proteinas claudinas no carcinoma mucoepldermolde das glandulas salvares

Pocqulcador: aikla Vaneasa Lourenço

Ares Tomatios:

Vercso: 2

CAAE: 59415116.7 .0000 .0075

Inctitulǫso Proponente: Unlverzidade de Bao Paulo

Patroolnador Prinolpal: Financlamento Proprio

DADOS DO PARECER

Numero do Parecer: 1.774 .954

Aprocentagso do Projoto:

Nesta pesquasa serbo estudados cortes histologlcos de 50 casos dlagnoaticados como carcinoma mucoepidermoide e 15 casos que apresentam partnquima glandular saudivel, que serfo os controles Estes casos zer\$o submetidos a tecnica de imunolstooulmica para os anticorpos ant-proteina claudina 1, 3,4,5 e 7 e ant-proteina EGFR, no intulto de determinar se ha relaçbo entre a expresabo dessas proteinas e caurgimento do carcinoma mucoepldermolde.

Objettvo da Pocquica:

Avaliar a expressfo das proteinas claudnas e aGFR no carcinoma mucoepidermolde oral, bem como analisar o padrbo da expressto das proteinas claudinas 1, 3, 4, 5 e 7 e do EGFR no carcinoma mucoepidermolde oral por melo da tecnica da imunolatoquimica.

\section{Avallagso doc Ricooc o Benefloloc:}

A pesquisa n5o apresenta nenhum risco visto que o material utlileado para imunolatoquimica te procedente de biopslas ja realizadas e que foram envisdas ao serviço para a obtençlo de dlagnostico histopatologico e a outra parte do estudo sers realzada com aurillo de celula.

Os benélicios trazidos para este estudo eat5o llgados ao eaciarecimento de parte dos mecaniamce

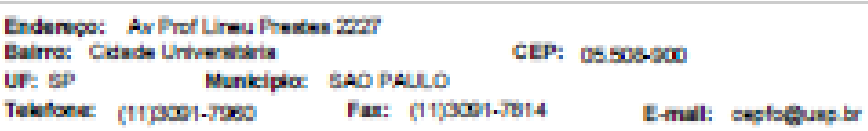




\section{FACULDADE DE ODONTOLOGIA DA UNIVERSIDADE DE SÃO}

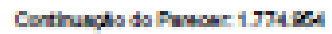

envolvidos no desenvolvimento do carcinoma mucoepldermolide.

Comentarioc o Conclderapoec cobre a Pecqulca:

A pesqulas pretende responder se a junç5o compacta esta relacionada ao processo de desenvolvimento do carcinoma mucoepidermolde e se fatores de crescimento ou cascatas moleculares podem interierir na expressbo das proteinas compacta no carcinoma mucoepldermolde. Berbo utllzados 50 casos que receberam o dlagnostico histopatologico de carcinoma mucoepldermolde e 15 casos que apresentam paranqula glandular em les5o para a realzaç5o da imunolatoquimica das proteinas clavelnas e do EGFR e tambem sers realizada cuhura celuar de celula acinar de glandula submandbular.

Conclderagobec cobre oc Termoc de aprecentap̧so obrigatorla:

Os termos de apresentaçlo obrigatorio eatso de acordo com as exigenclas do CEPFO.

Reoomendapoec:

As pendenclas foram atendidas, Incluiram os documentos ECACC General Cell Collection: NCl+H292 e A253

Concluebec ou Pendb́nolsc o Lleta de Inadequagbec:

sem pendencias

Conclderagoec Finale a orttorio do CEP:

Ecte parecer fol elaborado becesdo noc documentoc abalro relaolonadoc:

\begin{tabular}{|c|c|c|c|c|}
\hline Tipo Documento & Arqulvo & Postspem & Autor & Stousfio \\
\hline $\begin{array}{l}\text { Informagzdes Basicas } \\
\text { do Proleto }\end{array}$ & $\begin{array}{l}\text { PB_INFORMAÇCEB_BABICA3_DO_F } \\
\text { ROUETO_777229.pdf }\end{array}$ & $\begin{array}{c}28 / 03 / 2016 \\
15: 1755\end{array}$ & & Acelto \\
\hline $\begin{array}{l}\text { Deciaraç\$o de } \\
\text { Manuseio Material } \\
\text { Bloiogico f } \\
\text { Blorepositorio f } \\
\text { Blobanco }\end{array}$ & ECACC.pdf & $\begin{array}{c}28,08 \sqrt{2016} \\
15: 1700\end{array}$ & $\begin{array}{l}\text { Clavd a Fablana Joca } \\
\text { de Amuda }\end{array}$ & Acelto \\
\hline $\begin{array}{l}\text { Deciaraç\$o de } \\
\text { Manuseio Material } \\
\text { Bloiogico f } \\
\text { Blorepositorio f } \\
\text { Blobanco }\end{array}$ & BCRN.pdf & $\begin{array}{c}29 \sqrt{08 \sqrt{2016}} \\
15: 16: 42\end{array}$ & $\begin{array}{l}\text { Clavd a Fablana Joca } \\
\text { de Amuda }\end{array}$ & Acelto \\
\hline
\end{tabular}

Endence: Av Prot Ureu Presen Z20:

Balrra: Cedade Untrensievis

CEP: 0 SSOS-200

UT: BP Munkipio: BAO PAUE

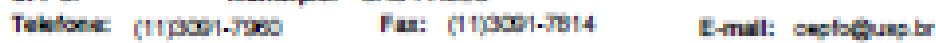




\section{FACULDADE DE ODONTOLOGIA DA UNIVERSIDADE DE SÃO}

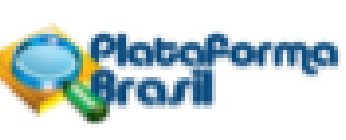

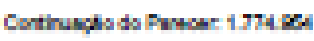

\begin{tabular}{|c|c|c|c|c|}
\hline $\begin{array}{l}\text { Proleto Deta'nado l } \\
\text { Brochura } \\
\text { Inveztogador }\end{array}$ & proleto.docx & $\begin{array}{c}29 / 09 / 2016 \\
15: 15: 26\end{array}$ & $\begin{array}{l}\text { Clavdia Fablana Joca } \\
\text { de Amuda }\end{array}$ & Aceito \\
\hline Folna de Rosto & Folha.pdf & $\begin{array}{c}29 / 03 / 2016 \\
14: 33: 17\end{array}$ & $\begin{array}{l}\text { Ollvia Vanessa } \\
\text { Lourenge }\end{array}$ & Aceito \\
\hline $\begin{array}{l}\text { Deciaraç\$o de } \\
\text { Manuseio Material } \\
\text { Blologico f } \\
\text { Blorepositorio f } \\
\text { Blobanco }\end{array}$ & Declaracao pdf & $\begin{array}{c}17 / 08 / 2016 \\
22: 2301\end{array}$ & $\begin{array}{l}\text { Elvia Vanessa } \\
\text { Lourenço }\end{array}$ & Acelto \\
\hline Cronograma & CRONOGRAMA DOCX & $\begin{array}{c}17 / 08 / 2016 \\
22 \cdot 20: 49 \\
\end{array}$ & $\begin{array}{l}\text { Elvia Vanessa } \\
\text { Lourenco }\end{array}$ & Acelto \\
\hline
\end{tabular}

artusgso do Parooer:

\section{Aprovado}

Nooeccita Apreolsgso da CONEP:

NSo

BAO PAULO, 14 de Outubro de 2016

Acclnado por:

Marla Gabriela Hayo Blazevio

(Coordenador) 

ANEXO B - Parecer do Comitê de Ética em Pesquisa do AC Camargo Cancer Center

A.C.Camargo

Cancer Center
HOSPITAL A.C. CAMARGO CANCER CENTER

\section{PARECER CONSUBSTANCIADO DO CEP}

Elaborado pela inctitulģso Copartiolpanto

\section{DADOS DO PRONETO DE PESQUISA}

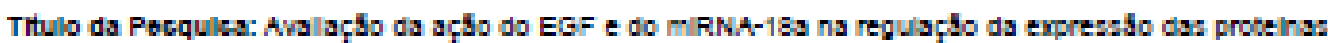
claudinas no carcinoma mucoepldermolde das glandulas salvares

Pocqulcador: alwla Vaneasa Lourenço

Area Tematioa:

Vercso: 1

CAAE: 59415116.7 .3001 .5432

Inetitulọso Proponente: Faculdade de Odontologla da Univeraldade de sso Paulo

Patroolnador Prinolpal: Financlamento Proprio

DADOS DO PARECER

Numero do Parecer: 1.982.129

Aprocentagso do Projoto:

A introduçdo do projeto descreve aspectos importantes sobre o tema de estudo, mas poderia ser mala abrangente. Os marcadores que serbio avalados no projeto, tanto as Clsudinas, quanto EGF e mIRNA $18 \mathrm{a}$ eatio pouco conectados entre al. Principalmente os topicos sobre EGF e miR.18a eatio multo pobremente apresentados. Todas as qguras eatio embaralinadas (1, 2 e Organograma), n 50 fol possivel avallar nenhuma delas.

Objettvo da Pocquica:

Os objetivos, assim como a Introduçbo, tem uma pobre conexdo entre sl. Especiaimente a avallaçlo do miRNA1Ba, que parece ser bem eapeculativa.

Avallagso doc Riceoc o Benefloloc:

A pesqulsadora deve assumir o risco minimo de perda de conflidenclalidade doa pacientes, mesmo se tratando de eatudo retrospectivoa.

Comentarioc o Conclderapoec cobre a Pecquica:

A Inveatigaçlo da expreasto das Claudinas em carcinoma mucoepidermolde oral t Justencada e resuladoa reievantes podem ser gerados no projeto. No entanto, nito ha em momento algum uma Justifcativa para o

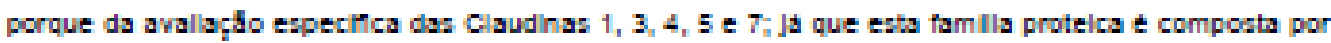
mals de 20 Clavdinas.

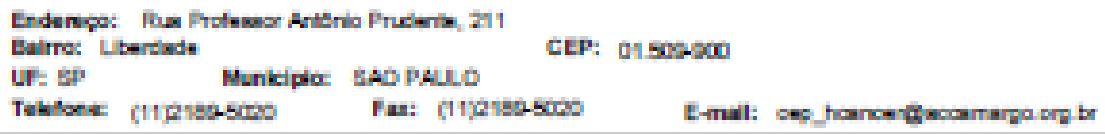




\section{A.c.Camargo
Cancer Center
CANCERTAL A.C. CAMARGO
CANCENTER}

Continumgas do Pwacer 1 se2 128

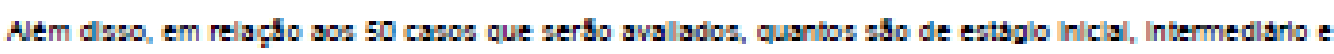
avançado? Dependendo do número de casos por grupo estes podem ser estrasficados de tal forma que difculte a comparaçso entre eies.

A parte de Material e Metodos esta absolutamente Incompleta. Como e o planejamento para oa

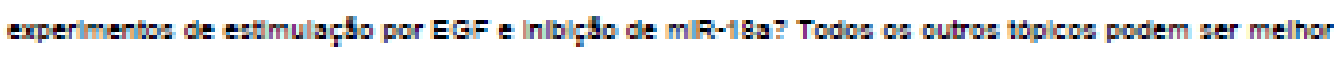
detahadoa e deacritoa.

Conelderapbec cobre oc Termoc de aprecentagso obrigatorla:

Foram adequadamente apresentadsa.

Reoomendapoec:

Recomends-se que a pesquisadora e sluna revejam todo o projeto e busque meinors-lo diante doa questionamentos levantados.

Conoluebec ou Pendénolsc o Lieta do Insdequsyoec:

Nfo ha pendencisa, mas sugerimos fortemente que o projeto seja resdequado.

Conelderagbec Finalc a ortterio do CEP:

Conalderaçbes da Comlasto de Pesquias:

-Inciur intormş̧bes nSo apresentadas no projeso, eg. Resultadoa eaperodos.

-Os dols pontos apresentados na Juatficativa s\$o multo amplos para serem respondidos com o projeto propoato. Readequar.

-Refazer o fluxograma utlizando um padrdo nivel doutorado.

-Resdequar CeJETINOs inciundo os outros procedimentos que serfo avallados no estudo e que foram menclonsdos em MATERIAv E MÉTOOOS, e.g. utllzaçlo de linhagem celular comerclal para avalar EGF e miR-18s

- Informar se esses pacientes que serßo utllzados no estudo retrospectivo receberam qualquer tpo de tratamento e se ha Informaçs̆o sobre mutaçbes ldentifcadas nesses genes.

- Se o número de 50 pacientes ja tol definibo, informar no projeto, em forma de tabela, as caracteriaticas clinicas dos pacientes, principaimente squelas que serdo abordsdas no estudo (Informar se fol felta genotipsgem para HPV). E importante deixar claro no projeto se sera congiderado um nümero minimo de pacientes em cada grupo para cada comparaç̧o estatiatica. Alem diseo, Informar se oa pacientes aval|sdoa serdo seiecionsdos de acordo com estadiamento e se esas caracteriettes serd conalderads.

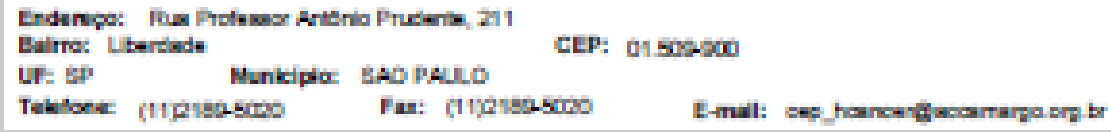


A.C.Camargo

Cancer Center

HOSPITAL A.C. CAMARGO

CANCER CENTER

Corthungs do Pavecer 1 see, 128

Nota: Informaçbes a respelto do andamento do referido projeto deverdo ser encaminhadas ao CEP dentro de 05 meses a partir desta data em relaterio (modelo Cef).

Ecte pareoer fol olaborado baceado noc dooumentoc abalwo relsolonadoc:

\begin{tabular}{|c|c|c|c|c|}
\hline Tipo Documento & Arquivo & Footspem & Autor & Shusgado \\
\hline $\begin{array}{l}\text { Informaz̧des Basicas } \\
\text { do Proisto }\end{array}$ & $\begin{array}{l}\text { PB_INFORMAÇCEB_BASICA3_DO_F } \\
\text { RQIETO } 777229 \text { odf }\end{array}$ & $\begin{array}{c}2909 / 2016 \\
15: 17: 55 \\
\end{array}$ & & Acelto \\
\hline $\begin{array}{l}\text { Deciaraç50 de } \\
\text { Manuseio Material } \\
\text { Bloiogico f } \\
\text { Blorepositoriof } \\
\text { Blobanco }\end{array}$ & ECACC.pdf & $\begin{array}{c}29 / 09 / 2016 \\
15: 17: 00\end{array}$ & $\begin{array}{l}\text { Cleveda Fablana Joca } \\
\text { de Arruda }\end{array}$ & Acelto \\
\hline $\begin{array}{l}\text { Declaraç\$̆ de } \\
\text { Manuseio Material } \\
\text { Bloiogico f } \\
\text { Blorepositorio f } \\
\text { Blobanco }\end{array}$ & BCRJ.pdf & $\begin{array}{c}29 / 09 / 2016 \\
15: 16: 42\end{array}$ & $\begin{array}{l}\text { Clevela Fablana Joca } \\
\text { de Arruda }\end{array}$ & Acel to \\
\hline $\begin{array}{l}\text { Projeto Deta'nado / } \\
\text { Brochura } \\
\text { Inveztspador }\end{array}$ & pro/eto.docx & $\begin{array}{c}29 / 09 / 2016 \\
15: 15: 25\end{array}$ & $\begin{array}{l}\text { Clavela Fablana Joca } \\
\text { de Amuda }\end{array}$ & Acelto \\
\hline $\begin{array}{l}\text { Informaz̧des Basicas } \\
\text { do Proleto }\end{array}$ & $\begin{array}{l}\text { PB_INFORMAÇCEB_BABICA3_DO_P } \\
\text { ROUETO_777229.pdf }\end{array}$ & $\begin{array}{c}29 / 08 / 2016 \\
14: 41: 40 \\
\end{array}$ & & Acelto \\
\hline Folna de Rosto & Folna.pd? & $\begin{array}{c}29 / 08 / 2016 \\
14: 33: 17 \\
\end{array}$ & $\begin{array}{l}\text { Olvia Vaneasa } \\
\text { Leurence } \\
\end{array}$ & Acelto \\
\hline $\begin{array}{l}\text { Proleto Detahado / } \\
\text { Brochura } \\
\text { Inveatspador }\end{array}$ & pro/eto.doc & $\begin{array}{c}17 / 08 / 2016 \\
22: 24: 11\end{array}$ & $\begin{array}{l}\text { Ollvia Vaneasa } \\
\text { Lourenço }\end{array}$ & Acelto \\
\hline 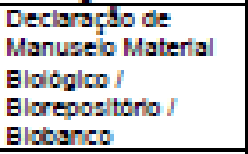 & Declaracas pdf & $\begin{array}{c}17 / 08 / 2016 \\
22: 23: 01\end{array}$ & $\begin{array}{l}\text { Ollvia Vaneasa } \\
\text { Lourenço }\end{array}$ & Acel to \\
\hline Cronograma & CRONOGRAUA DOCX & $\begin{array}{c}17 / 08 / 2016 \\
22: 20: 49 \\
\end{array}$ & $\begin{array}{l}\text { Ollvia Vaneasa } \\
\text { Leurence }\end{array}$ & Acelto \\
\hline
\end{tabular}

situsgso do Parsoor:

Aprovado

Neoecclta Apreolsgso da CONEP:

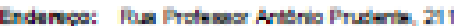

Ealre: iterta

CEP: ansosese

UT: BP Munkipio BAO PAUC

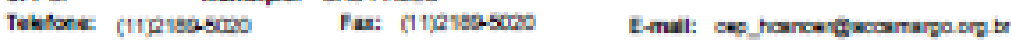




\section{A.C.Camargo
Cancer Center
CANPITAL A.C. CAMARGO CENTER}

Conthumbs do Pracor 1 see 128

NSo

SAO PAULO, 24 de MarçO de 2017

Acelnado por:

Jefterton Lulz Groce

(Coordenador)

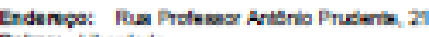

Ealmo: Ltertiede

CEP: ansoaso:

UF: Bp Munkipio SAO paud

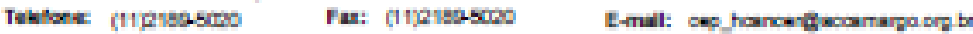

